University of Tennessee Health Science Center

UTHSC Digital Commons

\title{
$5-2011$
}

\section{Systemic AAV-Mediated Gene Therapy Using Epo-R76E to Protect Retinal Ganglion Cells from Optic Nerve Injury and Disease}

Timothy A. Sullivan

University of Tennessee Health Science Center

Follow this and additional works at: https://dc.uthsc.edu/dissertations

Part of the Medical Pharmacology Commons

\section{Recommended Citation}

Sullivan, Timothy A. , "Systemic AAV-Mediated Gene Therapy Using Epo-R76E to Protect Retinal Ganglion Cells from Optic Nerve Injury and Disease" (2011). Theses and Dissertations (ETD). Paper 353.

http://dx.doi.org/10.21007/etd.cghs.2011.0389. 


\title{
Systemic AAV-Mediated Gene Therapy Using Epo-R76E to Protect Retinal Ganglion Cells from Optic Nerve Injury and Disease
}

\begin{abstract}
Neuroprotection is a strategy to prevent or reduce neuronal cell death regardless of the underlying cause. Erythropoietin (EPO) exhibits neuroprotective effects in a variety of in vitro and in vivo models of neuronal cell death although its classical function is the regulation of red blood cell production. EPO crosses the blood brain barrier and therefore can be delivered systemically. However, long term treatment with exogenous EPO causes over stimulation of the erythropoietic pathway which can be lethal. The erythropoietic and neuroprotective pathways are regulated by different receptors; further, it is possible to modify EPO to primarily, if not solely, activate the receptor responsible for neuroprotection. An example of this is a novel form of EPO that we developed by altering a single amino acid, arginine to glutamate, at position 76 (EPO-R76E). The present study uses recombinant adeno-associated virus (rAAV) gene therapy and systemic delivery of EPO-R76E to assess treatment potential for degenerating neurons in an induced model of neurodegeneration and a spontaneous model of glaucoma.

Optic nerve crush is a model of retinal ganglion cell (RGC) death. Crushing the optic nerve causes the axons to undergo Wallerian degeneration and apoptotic loss of retinal ganglion cells over time. This pattern of cell death is very similar to that observed in glaucoma. The BALB/cByJ mouse strain is highly susceptible to optic nerve crush and therefore was selected to examine the potential effects of EPO-R76E as a neuroprotectant. Mice received a single intramuscular injection of rAAV carrying either Epo or EpoR76E. Upon reaching peak gene expression (30 days), mice were subjected to optic nerve crush. Neuronal cell death was examined in both the ganglion cell layer and the optic nerve. Treatment with either Epo vector resulted in a significantly greater amount of cells at the ganglion cell layer compared to crushed controls but had no effect on axon number. The observed protection occurred in a dose dependent manner. Furthermore, EPO-R76E did not stimulate erythropoiesis to the same extent as wild type EPO.
\end{abstract}

The neuroprotective effects of EPO-R76E following optic nerve crush prompted its investigation as a treatment for glaucoma. The DBA/2J mouse strain develops a naturally occurring pigmentary glaucoma as a result of increased intraocular pressure (IOP). At 1 month of age DBA/2J mice received a single intramuscular injection of rAAV carrying either Epo or EpoR76E. The mice were aged to 10 months and IOP was used as a marker for glaucoma. Treatment with either Epo vector prevented death of the RGC somata and their axons within the optic nerve. Furthermore this morphological rescue was accompanied by preservation of visual function as demonstrated by flash visual evoked potentials. The protection provided by EPO-R76E was independent of IOP and did not cause a significant increase in hematocrit. This is the first example of a neuroprotective agent for glaucoma that protects the RGC soma as well as the axon while maintaining function.

\section{Document Type}

Dissertation

Degree Name

Doctor of Philosophy (PhD)

Program

Biomedical Sciences 
Research Advisor

Tonia S. Rex, Ph.D.

\section{Keywords}

Adeno-associated virus, DBA/2J mouse, Erythropoietin, Gene therapy, Glaucoma, Optic nerve crush

\section{Subject Categories}

Medical Pharmacology | Medicine and Health Sciences 
Systemic AAV-Mediated Gene Therapy Using Epo-R76E to Protect Retinal Ganglion Cells from Optic Nerve Injury and Disease

\author{
A Dissertation \\ Presented for \\ The Graduate Studies Council \\ The University of Tennessee \\ HealthScienceCenter \\ In Partial Fulfillment \\ Of the Requirements for the Degree \\ Doctor of Philosophy \\ From The University of Tennessee
}

By

Timothy A. Sullivan

May 2011 
Copyright (C) 2011 by Timothy Allen Sullivan. All rights reserved. 
This dissertation is dedicated to my parents Christa K. Sullivan and Bob E. Sullivan. Thank you for the inspiration to complete such a monumental endeavor. 


\begin{abstract}
Neuroprotection is a strategy to prevent or reduce neuronal cell death regardless of the underlying cause. Erythropoietin (EPO) exhibits neuroprotective effects in a variety of in vitro and in vivo models of neuronal cell death although its classical function is the regulation of red blood cell production. EPO crosses the blood brain barrier and therefore can be delivered systemically. However, long term treatment with exogenous EPO causes over stimulation of the erythropoietic pathway which can be lethal. The erythropoietic and neuroprotective pathways are regulated by different receptors; further, it is possible to modify EPO to primarily, if not solely, activate the receptor responsible for neuroprotection. An example of this is a novel form of EPO that we developed by altering a single amino acid, arginine to glutamate, at position 76 (EPO-R76E). The present study uses recombinant adeno-associated virus (rAAV) gene therapy and systemic delivery of EPO-R76E to assess treatment potential for degenerating neurons in an induced model of neurodegeneration and a spontaneous model of glaucoma.

Optic nerve crush is a model of retinal ganglion cell (RGC) death. Crushing the optic nerve causes the axons to undergo Wallerian degeneration and apoptotic loss of retinal ganglion cells over time. This pattern of cell death is very similar to that observed in glaucoma. The BALB/cByJ mouse strain is highly susceptible to optic nerve crush and therefore was selected to examine the potential effects of EPO-R76E as a neuroprotectant. Mice received a single intramuscular injection of rAAV carrying either Epo or EpoR76E. Upon reaching peak gene expression (30 days), mice were subjected to optic nerve crush. Neuronal cell death was examined in both the ganglion cell layer and the optic nerve. Treatment with either Epo vector resulted in a significantly greater amount of cells at the ganglion cell layer compared to crushed controls but had no effect on axon number. The observed protection occurred in a dose dependent manner.

Furthermore, EPO-R76E did not stimulate erythropoiesis to the same extent as wild type EPO.
\end{abstract}

The neuroprotective effects of EPO-R76E following optic nerve crush prompted its investigation as a treatment for glaucoma. The DBA/2J mouse strain develops a naturally occurring pigmentary glaucoma as a result of increased intraocular pressure (IOP). At 1 month of age DBA/2J mice received a single intramuscular injection of rAAV carrying either Epo or EpoR76E. The mice were aged to 10 months and IOP was used as a marker for glaucoma. Treatment with either Epo vector prevented death of the RGC somata and their axons within the optic nerve. Furthermore this morphological rescue was accompanied by preservation of visual function as demonstrated by flash visual evoked potentials. The protection provided by EPO-R76E was independent of IOP and did not cause a significant increase in hematocrit. This is the first example of a neuroprotective agent for glaucoma that protects the RGC soma as well as the axon while maintaining function. 


\section{TABLE OF CONTENTS}

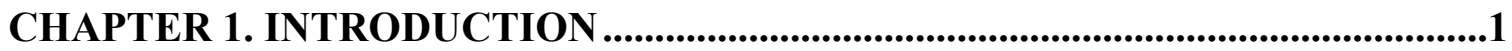

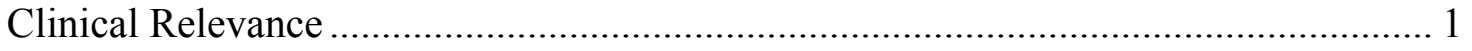

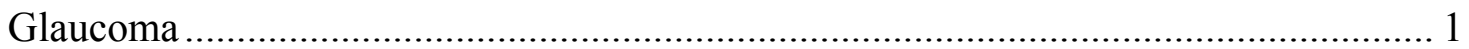

Mouse Models for RGC Death and Glaucoma....................................................... 2

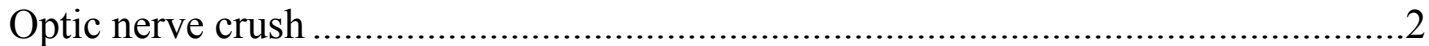

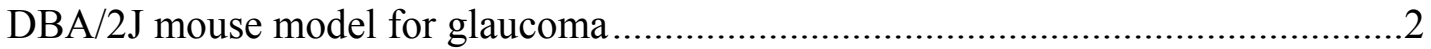

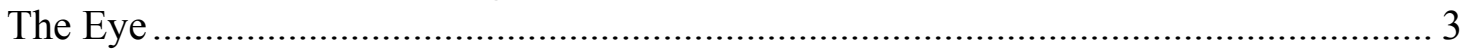

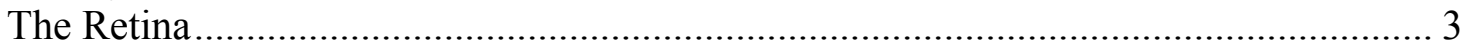

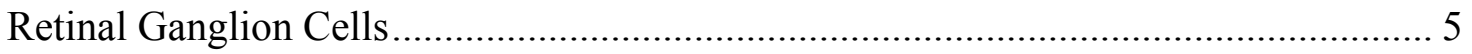

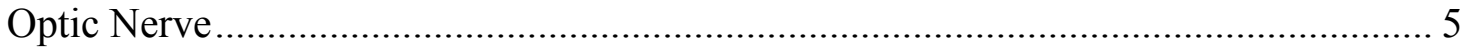

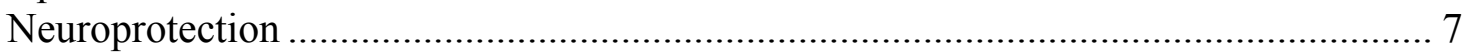

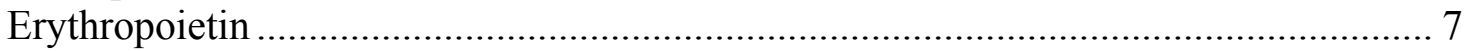

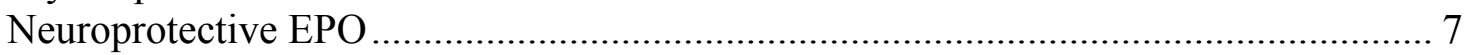

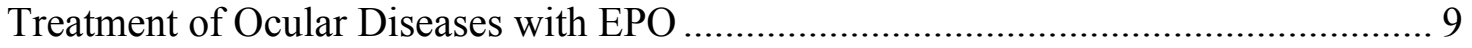

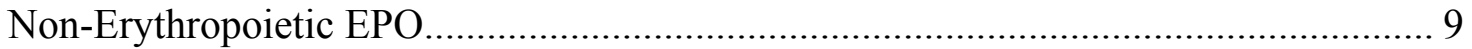

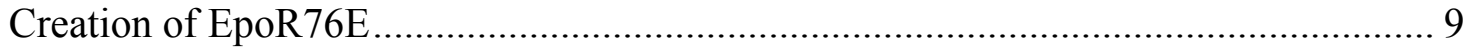

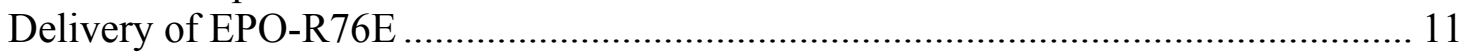

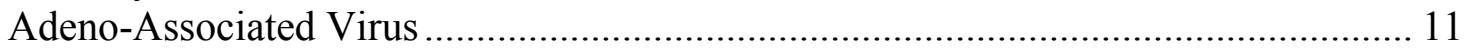

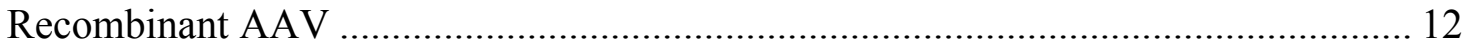

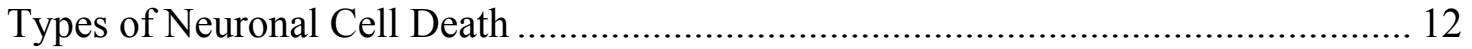

RGC Death Following Optic Nerve Injury and Disease............................................ 13

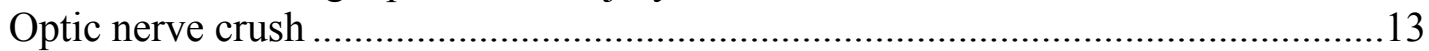

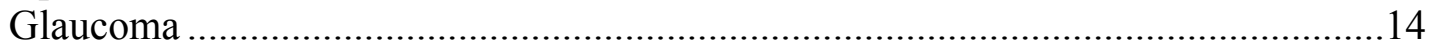

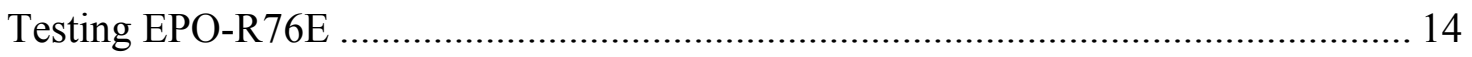

\section{CHAPTER 2. SYSTEMIC AAV-MEDIATED GENE THERAPY PROTECTS NeuN POSITIVE CELLS IN BALB/cByJ MICE AGAINST OPTIC NERVE}

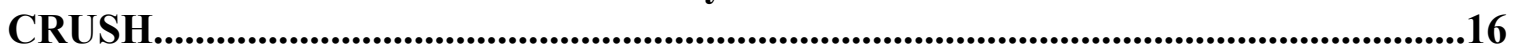

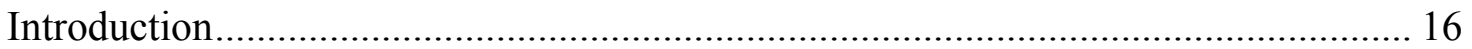

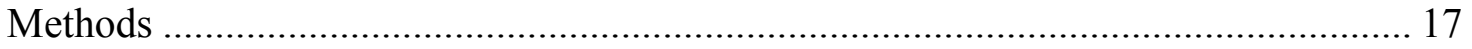

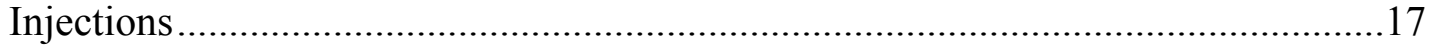

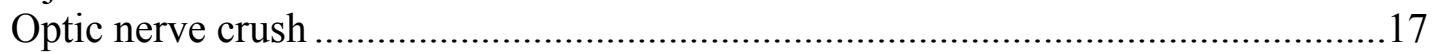

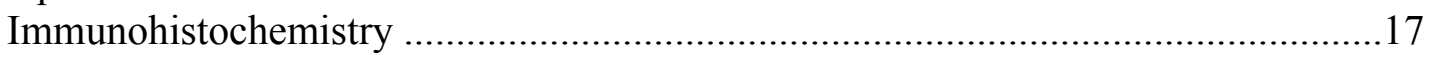

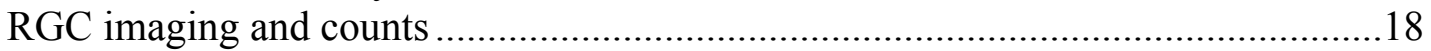

EPO enzyme-linked immuno-sorbant analysis (ELISA) and hematocrit ...................18

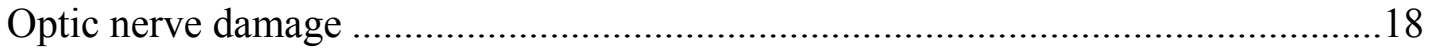

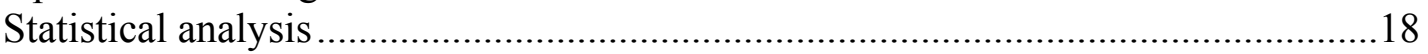

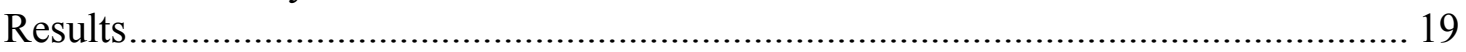

Systemic treatment of EPO or EPO-R76E provides a moderate level of protection to NeuN positive cells at the ganglion cell layer against optic nerve

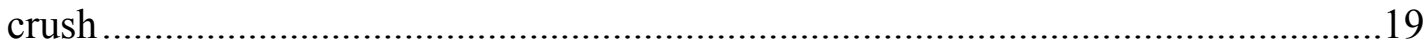

EPO and EPO-R76E are unable to protect axons against optic nerve crush .............19 
Effects of systemically expressed EPO and EPO-R76E on hematocrit and serum

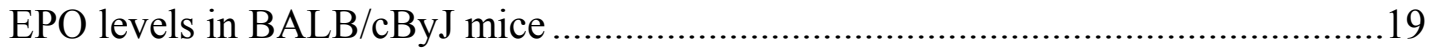

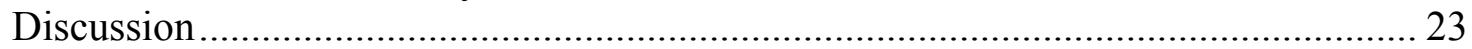

\section{CHAPTER 3. SYSTEMIC AAV-MEDIATED GENE THERAPY PRESERVES RETINAL GANGLION CELLS AND VISUAL FUNCTION IN DBA/2J

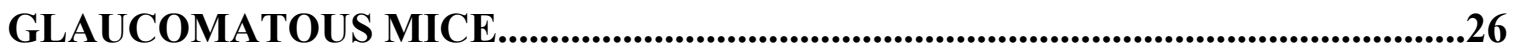

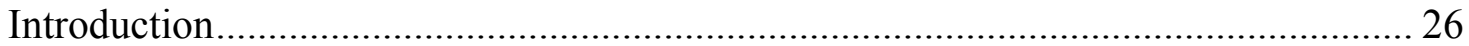

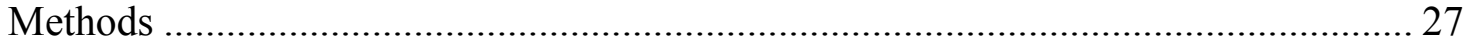

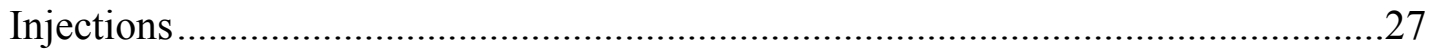

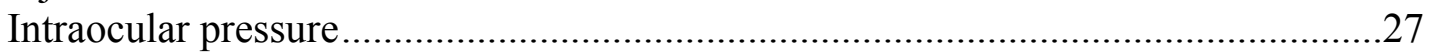

Retinal flatmounts and NeuN counts ..................................................................2

Optic nerve cross sections and total axon counts..................................................2

EPO enzyme-linked immuno-sorbant analysis (ELISA) and hematocrit ..................27

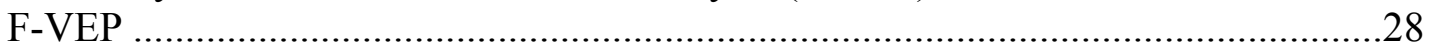

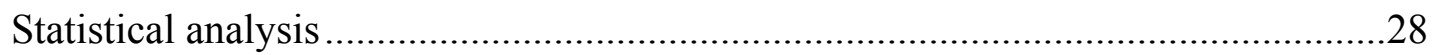

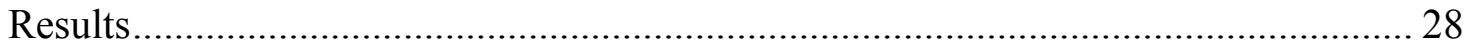

IOP as marker for glaucoma in DBA/2J mice .....................................................28

Both rAAV2/5.CMV.Epo and rAAV2/5.CMV.EpoR76E protect RGC axons .........28

Treatment with rAAV2/5.CMV.Epo or rAAV2/5.CMV.EpoR76E protects NeuN

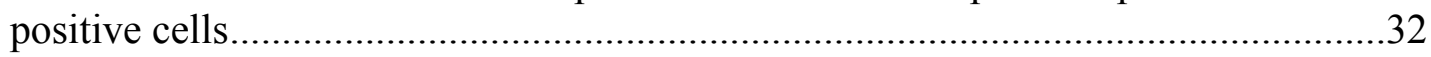

Functional preservation of the visual pathway in DBA/2J mice treated with rAAV2/5.CMV.Epo and rAAV2/5.CMV.EpoR76E .............................................32

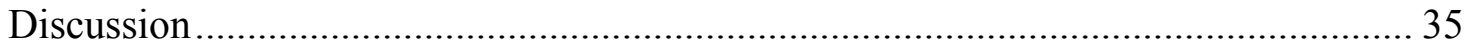

CHAPTER 4. DISCUSSION ..........................................................................................41

EPO-R76E Protects RGC Somata and Axons Independently ...................................... 41

Potential Mechanism of Neuroprotection .............................................................. 41

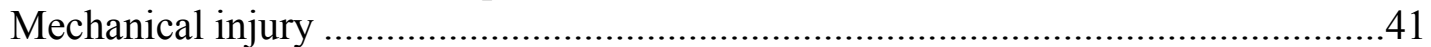

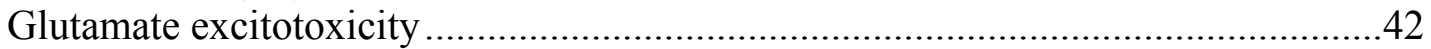

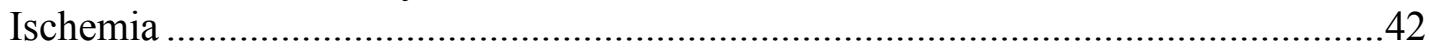

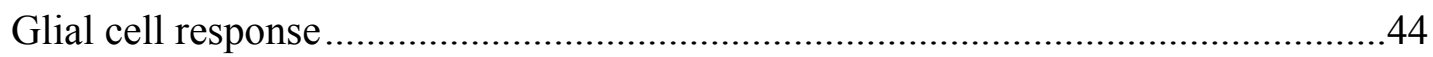

Improving Gene Transfer through rAAV Capsid Mutations......................................... 45

Establish a Therapeutic Dose Curve ............................................................................ 46

Can EPO-R76E Protect against Glaucomatous Damage Later in the Disease

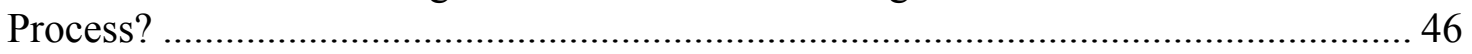

Further Reduction of EPO-R76E's Hematopoietic Properties ……………………....... 47

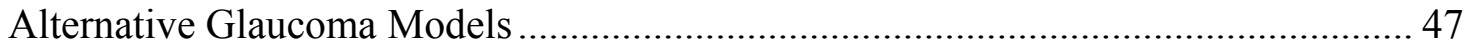

B10-Sh3pxd2b ${ }^{\text {nee }}$ hereditary mouse model of glaucoma ………………………….....4

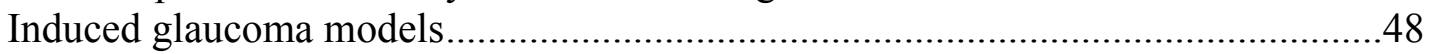

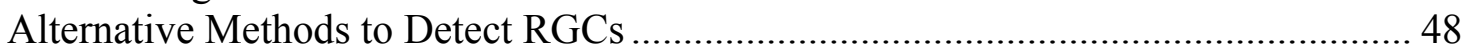

EPO's Role in Other Neurodegenerative Diseases ...................................................... 49

Treatment of Alzheimer's with EPO-R76E.............................................................. 49

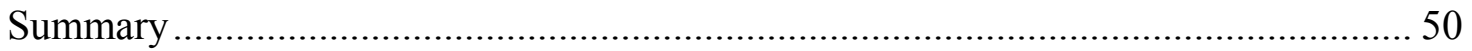

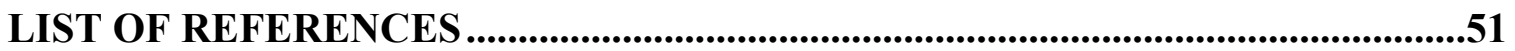


APPENDIX. TESTING AAV EPO PRODUCTION IN VITRO .............................74

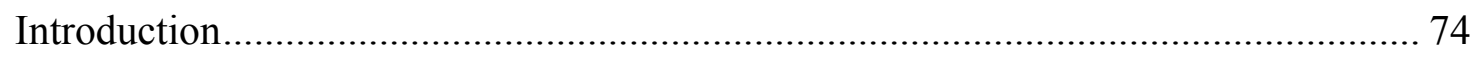

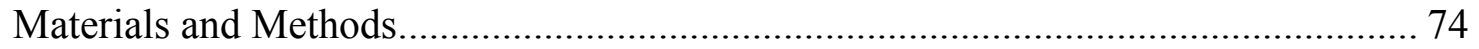

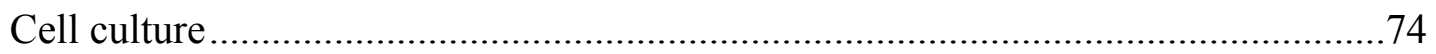

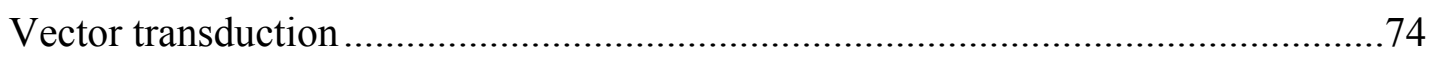

EPO enzyme-linked immuno-sorbant analysis (ELISA) ...................................75

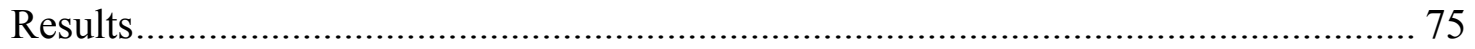

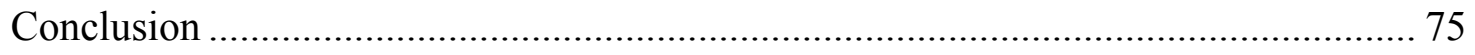

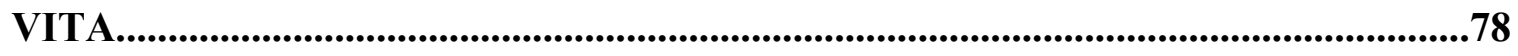




\section{LIST OF TABLES}

Table 2-1. Serum EPO and hematocrit of vector treated BALB/cByJ mice.................20

Table 3-1. Serum EPO and hematocrit of vector treated ten month old mice. ..............38

Table A-1. EPO and EPO-R76 levels in transduced HEK 293 cells. .............................76 


\section{LIST OF FIGURES}

Figure 1-1. Schematic of the mouse eye..................................................................4

Figure 1-2. Hematoxylin and esosin stained cross section of a BALB/cByJ mouse retina.

Figure 1-3. Schematic illustrating the basic morphology of a RGC...........................6

Figure 1-4. Sequence alignment for rhesus EPO and the amino acid translation. 10

Figure 2-1. Treatment with rAAV2/5.CMV.Epo or rAAV2/8.CMV.EpoR76E provides a level of protection to NeuN positive cells at the GCL layer against optic nerve crush.

Figure 2-2. Treatment with rAAV2/5.CMV.Epo or rAAV2/8.CMV.EpoR76E does not protect axons from optic nerve crush..

Figure 3-1. IOP increases in DBA/2J mice over time.

Figure 3-2. Treatment with rAAV2/5.CMV.Epo or rAAV2/5.CMV.EpoR76E protects the optic nerve of DBA/2J mice with exceedingly high IOP $(\geq$ $25 \mathrm{~mm} \mathrm{Hg}$ ) from glaucomatous neurodegeneration.

Figure 3-3. Treatment with rAAV2/5.CMV.Epo or rAAV2/5.CMV.EpoR76E protects NeuN positive cells at the GCL from glaucomatous cell death......33

Figure 3-4. rAAV2/5.CMV.Epo or rAAV2/5.CMV.EpoR76E provide functional rescue to the visual pathway of glaucomatous $\mathrm{DBA} / 2 \mathrm{~J}$ mice.

Figure 3-5. Quantitative analysis of rAAV2/5.CMV.Epo or rAAV2/5.CMV.EpoR76E treatment on flash-visual evoked potential in glaucomatous DBA/2J mice. 


\section{LIST OF ABBREVIATIONS}

$\begin{array}{ll}\text { AAV } & \text { Adeno-Associated Virus } \\ \text { AGEs } & \text { Advanced Glycation End Products } \\ \text { ALS } & \text { Amyotrophic Lateral Sclerosis } \\ \text { AQP4 } & \text { Aquaporin 4 } \\ \text { Bax } & \text { BCL2-Associated X } \\ \text { CNS } & \text { Central Nervous System } \\ \text { CSF } & \text { Cerebrospinal Fluid } \\ \text { EAE } & \text { Experimental Autoimmune Encephalomyelitis } \\ \text { ECM } & \text { Extra Cellular Matrix } \\ \text { ELISA } & \text { Enzyme-Linked Immuno-Sorbant Analysis } \\ \text { EPO } & \text { Erythropoietin } \\ \text { F-VEP } & \text { Flash Visual-Evoked Potential } \\ \text { GCL } & \text { Ganglion Cell Layer } \\ \text { GFAP } & \text { Glial Fibrillary Acidic Protein } \\ \text { GPx } & \text { Glutathion Peroxidase } \\ \text { IM } & \text { Intramuscular } \\ \text { IOP } & \text { Intraocular Pressure } \\ \text { IP } & \text { Intraperitoneal } \\ \text { JAK } & \text { Janus Kinase } \\ \text { LGN } & \text { Lateral Geniculate Nucleus } \\ \text { mGluR } & \text { Meabotropic Glutamate Receptors } \\ \text { MMPs } & \text { Metalloproteinases } \\ \text { MS } & \text { Multiple Sclerosis } \\ \text { NeuN } & \text { Neuronal Nuclei } \\ \text { PBS } & \text { Phosphate Buffered Saline } \\ \text { PG } & \text { Pigmentary Glaucoma } \\ \text { PKC } & \text { Protein Kinase C } \\ \text { PMCC } & \text { Pearson Product-Moment Correlation Coefficient } \\ \text { PPD } & \text { Paraphenylenediamine } \\ \text { rAAV } & \text { Recombinant Adeno-Associated Virus } \\ \text { RGC } & \text { Retinal Ganglion Cell } \\ \text { SC } & \text { Superior Colliculus } \\ & \\ & \\ & \end{array}$




\section{CHAPTER 1. INTRODUCTION}

\section{Clinical Relevance}

For humans sight is arguably the most important of the five senses. Over half of our neocortex is devoted to processing visual information. Our ability to have normal visual function can be affected by a number of devastating diseases. Over 11 million Americans currently experience some type of vision loss and that number is expected to double by 2030 [1]. Glaucoma alone accounts for 4 million of these cases [2].

Therefore, there is an urgent need to develop novel treatments and treatment strategies for ocular diseases.

\section{Glaucoma}

Glaucoma refers to a group of progressive neuropathies. It is characterized by degeneration of retinal ganglion cells (RGCs) and their axons, resulting in visual field deficits [3-4]. The vision lost during the disease process cannot be regained. The mechanism of its pathology has not yet been elucidated; however there are several common risk factors including age, race, hypertension, thin cornea, myopia, steroid exposure, and diabetes [5-6]. The most predominant risk factor along with age is increased intraocular pressure (IOP) [7], though not all individuals with increased IOP develop glaucoma [8-9]. Genetic predisposition can also plays a role in glaucoma [10$11]$ and a number of susceptibility genes have been identified $[12,11]$. However, despite this progress the genetic etiology remains a mystery.

In order to maintain a healthy IOP, the aqueous humor must be drained at the same rate it is produced. Increased IOP occurs when drainage of the aqueous humor becomes obstructed or when production occurs at a faster rate than drainage [13].

Aqueous humor is a clear fluid that is produced by the ciliary body. It migrates through a narrow cleft between the lens and the iris into the anterior chamber where it is eventually drained from the eye [14]. Drainage occurs as it passes through the trabecular meshwork and into the canal of Schlemm. Small changes in aqueous humor lead to significant differences in IOP [15]. The manner in which IOP becomes elevated can be used to classify the type of glaucoma.

Glaucomas are usually considered either primary or secondary depending on their etiology and aqueous humor dynamics [16]. Primary glaucomas are either open-angle or closed angle. Open-angle glaucoma occurs when IOP increases slowly over time despite the open appearance of the drainage structures. Closed-angle glaucoma occurs when the drainage structures become obstructed resulting in a sharp increase in IOP. Secondary glaucomas result from a predisposing disease such as uveitis, trauma, or diabetes, that affect aqueous humor dynamics. These include pseudoexfoliation glaucoma and pigmentary glaucoma (PG) [16]. Some patients develop glaucoma without increased IOP [17-18], this is referred to as normal tension glaucoma. 
Combined, glaucoma affects more than 70 million people world-wide [2]. According to the World Health Organization it is the second leading cause of blindness. Since there is no cure, the available treatment options act to prevent further damage from occurring. Currently, there are only two main treatment strategies and both focus on lowering IOP; drugs that are applied via eye drops, and surgery. The eye drops function by either slowing down the production of aqueous humor (beta blockers or carbonic anhydrase inhibitors) or increasing its drainage (cholinergic or prostaglandin analogs) or both (alpha agonist). Surgeries can include implantation of drainage devices or use of lasers to create scars in the trabecular meshwork that increase drainage. These types of surgeries can be risky and have side effects such as, spike in IOP, inflammation, cornea damage, and blurry vision. Given the limited treatment strategies, side effects, nonresponding patients, and number of cases with normal tension glaucoma, novel treatments are needed that act independently of IOP.

\section{Mouse Models for RGC Death and Glaucoma}

\section{Optic nerve crush}

Optic nerve crush is a well known model for acute neurodegeneration in vivo. The procedure is routinely performed in rats and mice. Induction of an optic nerve crush causes rapid, stereotypical RGC death and the reproducibility of this model makes it ideal for testing therapies. The crush injury is carried out using an intra-orbital approach to damage the optic nerve [19]. Post-crush, RGC death starts within one week and only about half the cells remain by the second week [20-21]. Out of 15 strains tested the $\mathrm{BALB} / \mathrm{cByJ}$ mouse was the least resistant to the crush [21] and therefore selected for use in this study.

\section{DBA/2J mouse model for glaucoma}

Inbred DBA/2Jmice develop an iris disease caused by recessive mutations in two genes, glycosylated protein nmb (Gpnmb; NCBI GeneID 93695) and tyrosinase related protein 1 (Tyrp1; NCBI GeneID 22178) [22-23]. Inheritance of both genes causes severe deterioration of the iris pigment epithelium and iris stromal atrophy, resulting in ocular abnormalities that are similar to those in human PG patients [22-23,11]. The iris pathology causes pigment to accumulate in the anterior segment of the eye clogging the trabecular meshwork, leading to a reduction in outflow of aqueous humor and therefore increased IOP. However, the disease process is not uniform and IOP can vary between the two eyes as well as mice of the same age $[22,24]$.IOP begins to rise around 6 months of age and continues to increase until about 12 months. The increase in IOP causes severe damage to the optic nerve and eventually apoptotic death of the RGCs[11,25-26]. There is a clear age dependent increase in the severity of optic nerve damage following increased IOP [27-28,25]. Similar to IOP the degree of damage is not uniform between 
eyes or mice. The slow progressive rate in which these mice develop glaucoma mimics that in humans and makes them an attractive model for testing EPO-R76E.

Mice are an appropriate and useful animal model for the study of glaucoma despite some major differences between the visual system of a mouse and a human. Mice are nocturnal, and therefore are rod dominated, [29-30] with poor visual acuity [31]. Certain structural differences also exist within the retina and the optic nerve. The human retina contains a fovea that allows for increased acuity, mice lack this region altogether [32]. Further, unlike humans, the lamina region of the optic nerve in mice does not contain compressed lamellar sheets of collagen [33-34]. Despite these differences much of the basic anatomy and physiology is similar, and the mechanisms and pathologies of degenerations are often similar, allowing many human diseases to be studied in mice.

\section{The Eye}

The role the mammalian eye plays in vision can be divided into two phases. The first phase consists of capturing a clear image and projecting it onto the retina. In this regard the eye is often compared to a camera. The pupil controls the amount of light that strikes the retina. The light is passed through a lens, which focuses the image onto the retina. The second phase involves the conversion of this image into an electrical signal. Photoreceptors within the retina convert the light into electrical signals. These signals are modified as the information passes though the retina to reach the optic nerve. The optic nerve conducts the signal to the brain for further processing. Each of the components involved must act with great precision in order to maintain clear vision.

Much like the human eye, the mouse eye (Figure 1-1) can be divided into three main layers. An external layer that provides structural support and protection, a central layer that provides blood flow and nutrients and an inner layer that contains the retina. The external layer or corneoscleral coat is made up of the cornea and sclera. The cornea is transparent, allowing light to enter and acting as a window for the eye. Like other nocturnal mammals, mice have a very large cornea and lens that enables a greater amount of light to enter the eye [35]. The sclera is made up of a dense fibrous tissue, which gives the eye its shape. The central layer is made up of the ciliary body, iris, and choroid which house most of the vasculature. The size of the pupil is controlled by the iris, while the ciliary body interacts with the lens allowing light from different distances to be focused on the retina.

\section{The Retina}

The neural retina is a unique specialized sensory organ where visual perception begins. Unlike all other sensory structures that are located in the peripheral nervous system, the retina is part of the central nervous system. Like other mammalian retinas the mouse retina contains 5 classes of neurons (photoreceptor, horizontal, bipolar, amacrine, and RGCs), which are layered in a specific anatomical arrangement (Figure 1-2). These 


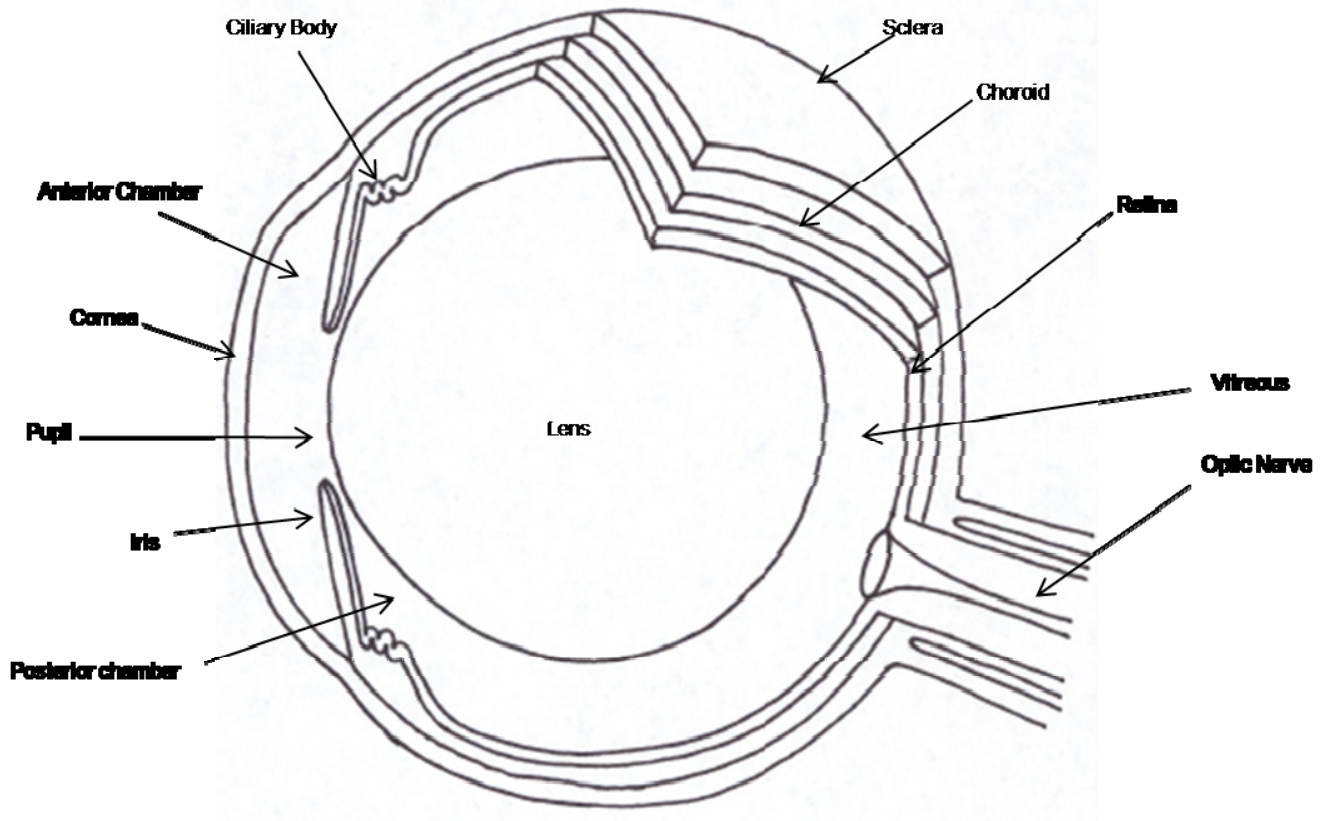

Figure 1-1. Schematic of the mouse eye.

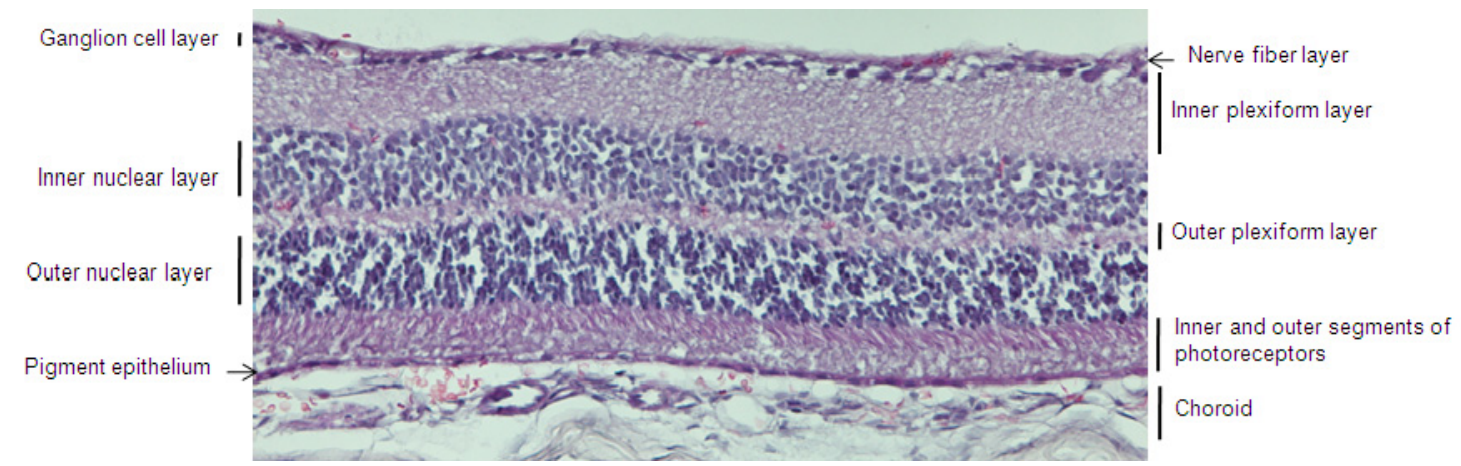

Figure 1-2. Hematoxylin and esosin stained cross section of a BALB/cByJ mouse retina. 
neurons communicate via an intricate network of connections. The photoreceptors are responsible for phototransduction; converting light into an electrical signal. There are two types of photoreceptors, the rods and the cones. The rods are highly sensitive to light and are specialized for night vision. The cones on the other hand, have lower light sensitivity and function optimally during the day. In the mouse, the majority of the photoreceptor population $(97 \%)$ is made up of rods, and there are only two classes of cone photoreceptor- short-wavelength (UV) cones, and medium wavelength cones [30]. Horizontal, bipolar, and amacrine cells modify and conduct the signal to its final destination within the retina, the RGC. The cascade of information begins at the photoreceptor cells and terminates within the visual cortex.

\section{Retinal Ganglion Cells}

RGCs are the final output neurons within the retina. To date there are over 22 types that have been discovered in humans [36] and 14 in mice [30,37]. On average RGCs are the largest neurons in the retina. The morphology of the RGC consists of branching dendrites that synapse in the inner plexiform layer, a cell body or "soma", and a single axon that is many centimeters in length (Figure 1-3). A significant amount of processing occurs at the RGC itself. Different RGC types encode various features such as size, speed, and motion and they relay this information though the optic nerve to visual centers in the brain for further processing and visual perception.

\section{Optic Nerve}

The optic nerve is a key part in the visual pathway. In mice approximately 45,000 axons bundle together forming the optic nerve, compared to 1.5 million in humans [3839]. The optic nerve itself can be divided into 4 main regions. 1) The optic nerve head: where axons collect in the center of the retina to form the optic nerve. 2) The lamina region: where the nerve fibers exit the eye passing through the choroid and sclera. 3) The unmyelinated region: a short extraocular portion of the nerve fiber that is unmyelinated. 4) The myelinated region: located posterior to the orbit, nearly all of the nerve fibers are myelinated in this region [40]. In addition to housing the axons of RGCs the optic nerve also contains a variety of glial cells. Their diversity and population vary based upon the region of the optic nerve [41-42]. Glial cells play a major role in maintaining axonal health. Through close interactions with axons they provide support and nutrition [43]. They also play a key role in maintaining a homeostatic environment for axons by controlling the levels of ions and metabolites [44].

In mice and other mammals, the optic nerve from each eye meets at the optic

chiasm. Here the majority of axons cross over and project to the contralateral side of the brain while the remaining axons project to the ipsilateral side. Mice, unlike humans, have a small binocular field and therefore only about $2-3 \%$ of the axons project ipsilaterally [45]. Upon exiting the optic chiasm, their axons project to one of three major subcortical targets: the pretectum, the superior colliculus (SC), or the lateral 


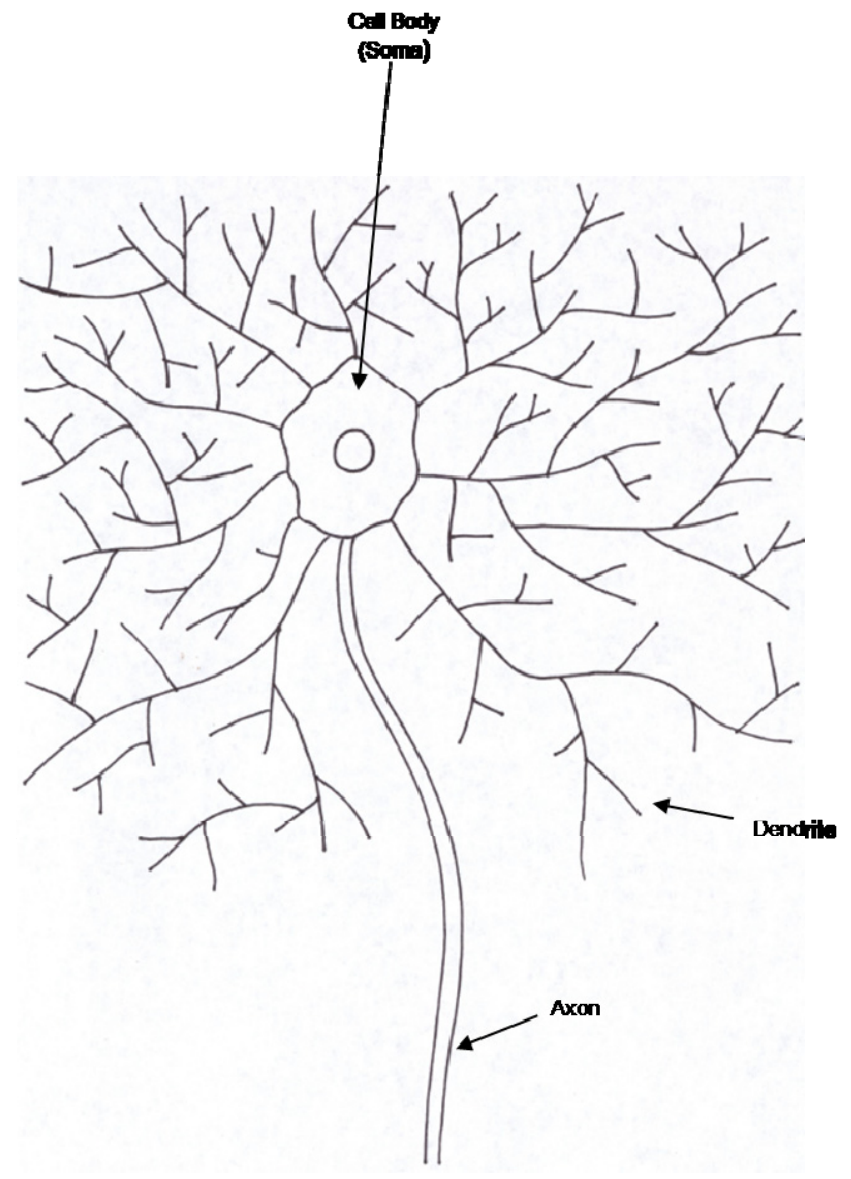

Figure 1-3. Schematic illustrating the basic morphology of a RGC. 
geniculate nucleus (LGN) [46-47]. In mice the main image forming pathway is through the SC [48], while RGCs that project to the pretectum control pupillary light reflexes. Both the SC and the LGN have cells that project to the visual cortex, the endpoint of the visual pathway.

\section{Neuroprotection}

Neuroprotection, i.e. the prevention, slowing, or reversal of neuronal cell death from the primary neuronal lesion [49] appears to be a good strategy for the treatment of glaucomas. It focuses on preventing neuronal cell death regardless of the disease process by which the death occurs. This type of treatment strategy is ideal for glaucoma for a number of reasons. First, neuronal loss is the primary pathology for all types of glaucoma, of which the mechanism is unknown. Neuroprotection would allow treatment of these neurons without the need to elucidate the mechanism that causes their death. Second, the large number of genes involved, many of which are still unidentified, makes many strategies like gene silencing or knockdown impossible. A neuroprotective strategy would be effective even though there are a large amount of factors contributing to the pathology. Over 500 agents have been investigated for neuroprotective properties in various disease states including apoptosis inhibitors, free radical scavengers, ion channel modulators, neurotrophic factors and metal ion chelators [49]. Among those that have been examined, erythropoietin (EPO) has shown to be effective in reducing cell death in glaucoma models [50].

\section{Erythropoietin}

EPO is a 165 -amino acid $(\sim 35 \mathrm{kDa})$ glycoprotein that belongs to the cytokine type I superfamily [51]. The classical role of EPO is to regulate erythropoiesis (red blood cell production). Under hypoxic conditions, hypoxia-inducible factor-1 alpha activates gene expression of Epo in the kidney [52,51]. Within the bone marrow, EPO binds to a homodimeric EPO receptor (EPOR $)_{2}$ located on the cell membrane of erythroid cells. The cytoplasmic portion of EPO receptor is physically engaged with Janus tyrosine kinase-2 (JAK), and binding of EPO results in its phosphorylation [53]. This initiates a signaling cascade that utilizes a number of downstream pathways that ultimately inhibit apoptosis of erythrocyte progenitor cells [54,53].

\section{Neuroprotective EPO}

Discovery of EPO in many other tissues that do not involve erythropoiesis, including the retina, the brain, the reproductive tract, the lung, the spleen, and the heart lead to investigations about other possible functions [55-58]. Early reports demonstrated that EPO exhibited trophic effects on cultured embryonic central cholinergic neurons, including the promotion of cell survival after serum deprivation [59] as well as the existence of a functional EPO receptor on neural-like clonal cell lines (PC12 and SN6) 
[60]. Since these early discoveries EPO has firmly established its role as a neuroprotective agent both in vivo and in vitro[59,61-64]. Some evidence, based on coimmunoprecipitation and binding assays, suggest that the neuroprotective pathway is activated through an alternative receptor that is composed of EPOR and the interleukin $\beta$ common receptor [65].

A broad range of neuroprotective effects are elicited by EPO, including antiapoptotic, anti-inflammatory, and anti-oxidative [66-67]. These effects are triggered via different signaling cascades that vary depending on the specificity of the cell type and the nature of the injury. Similar to erythropoiesis, most are initiated by phosphorylation of Jak-2 or Jak-1 [68-71]. This can lead to subsequent phosphorylation of proteins including Signal Transducers and Activator of Transcription protein, phosphatidylinositol 3 kinase, protein kinase $B$, and mitogen-activated protein kinase [69,72,71,73]. Given EPO's broad neuroprotectant effects, it comes as no surprise that it's being tested in a variety of clinical trials including amyotrophic lateral sclerosis (ALS), spinal cord injury, traumatic brain injury, cerebral palsy, Parkinson disease, and stroke [74].

Of the many neuroprotective effects of EPO, the molecular pathway by which it prevents apoptosis is probably the best described. Although the pathways somewhat differ depending on the disease or cell type, many of the same players are often involved. In many neurodegenerative diseases including diabetic retinopathy and Alzheimer's, accumulation of advanced glycation end products (AGEs) can be major pathogenic factors [75-76]. EPO has demonstrated protection of retinal neurons from AGE-induced injury in a dose dependent manner [77-78]. EPO enhanced BAD phosphorylation therefore reducing its effect as an apoptotic molecule. EPO also lead to the upregulation of Bcl-xL an anti-apoptotic protein and downregulated the pro-apoptotic protein Bax. EPO was shown to regulate these apoptotic related proteins via phosphorylation of ERK and Akt [78].

EPO appears to function in a similar fashion to protect neurons in the CA1 region of the rat hippocampus following global cerebral ischemia [79]. Both pretreatment and post-treatment EPO prevented neuronal damage. The molecular mechanism appears again to be via phosphorylation of Akt. The protective effects of EPO were also abolished through the use of phosphoinositide 3 kinase inhibitors. In addition to stimulating these anti-apoptotic pathways, EPO was also able to increase brain derived neurotrophic factor which is known to increase neuronal survival $[80,79]$.

It is clear that following transection of the optic nerve RGC cell bodies undergo apoptosis as evidenced by condensed nuclei [81], activation of caspase-3 and -9 [82-83], and downregulation PI-3K/Akt kinases [84]. EPO is able to protect RGCs in retinas where it is over-expressed. Through the use of selective inhibitors it was demonstrated that this protection functions through phosphorylation of the ERK-1-2 pathway but not the Akt pathway [85]. However, other groups report that Akt phosphorylation is involved in protection following optic nerve transection in rats [86]. Additionally, in this same study, EPO was not neuroprotective if PI-3-kinase was inhibited [86]. 


\section{Treatment of Ocular Diseases with EPO}

EPO is an excellent candidate for the treatment of ocular diseases. A single intraocular injection of EPO (200 ng or $10 \mathrm{U})$ increased retinal thickness and reduced photoreceptor cell death in an inducible rat model of diabetes [77] and an inherited mouse model of retinal degeneration [87]. In addition, gene delivery of Epo to the skeletal muscle of Lewis rats and Balb/c mice was able to protect the retina in both a light damage model as well as a genetic model of retinal degeneration [88]. One week after optic nerve transection in rats, intraperitoneal (IP) injections of EPO significantly enhanced survival of RGCs [89], demonstrating that despite severe optic nerve injury RGCs could be rescued. In a rat model, where IOP was artificially raised to induce glaucomatous pathology, intravitreal injection of EPO was able to rescue RGCs [90]. Using a spontaneous mouse model of glaucoma, repeated IP injectionof EPO promoted survival of RGCs [50]. These experiments highlight EPOs ability to protect RGCs in a glaucomatous environment, however long term treatment with EPO can be dangerous.

\section{Non-Erythropoietic EPO}

The amount of circulating EPO required to provide tissue protection is much higher than that needed for erythropoiesis [66]. Long term use of exogenous EPO causes overstimulation of the erythropoietic pathway. The effects can be deep vein, coronary, and cerebral thromboses leading to increased mortality [91-92]. Forms of nonerythropoietic EPO have been developed in an attempt to exploit its neuroprotective effects without increasing hematocrit [93]. These forms include chemical modifications, mutations, and small peptide derivatives [94-95,93,96-97]. Our lab has also developed a novel mutant that contains a single amino acid change (R76E) [98].

\section{Creation of EpoR76E}

EPO undergoes post-translational modifications that include cleavage of the first 27 amino acids in the amino terminus that result in the active-form. The Epo-R76E mutation created in our lab was generated by mutating a single amino acid from an arginine to a glutamate at the $76^{\text {th }}$ position in the active-form (the $103^{\text {rd }}$ position in the pro-form) (Figure 1-4). Originally this mutation was made in an attempt to generate a previously discovered form of EPO (EpoR103E in the active-form) that was not erythropoietic [99], but was neuroprotective [93]. Due to confusion in the nomenclature between the pro-from and the active-form, we instead generated EPO-R76E. This mutant was first tested in our lab using a mouse model of photoreceptor cell death where it demonstrated both neuroprotective effects and attenuated erythropoietic activity [98].

The R76E mutation was introduced into the cDNA of the rhesus Epo gene. There is a high degree of homology in the sequence of EPO from different mammals (human, monkey, and mouse) [100] and therefore can be used interchangeably to stimulate erythropoiesis in other mammals [101-102]. After sequencing the EpoR76E mutant, it 


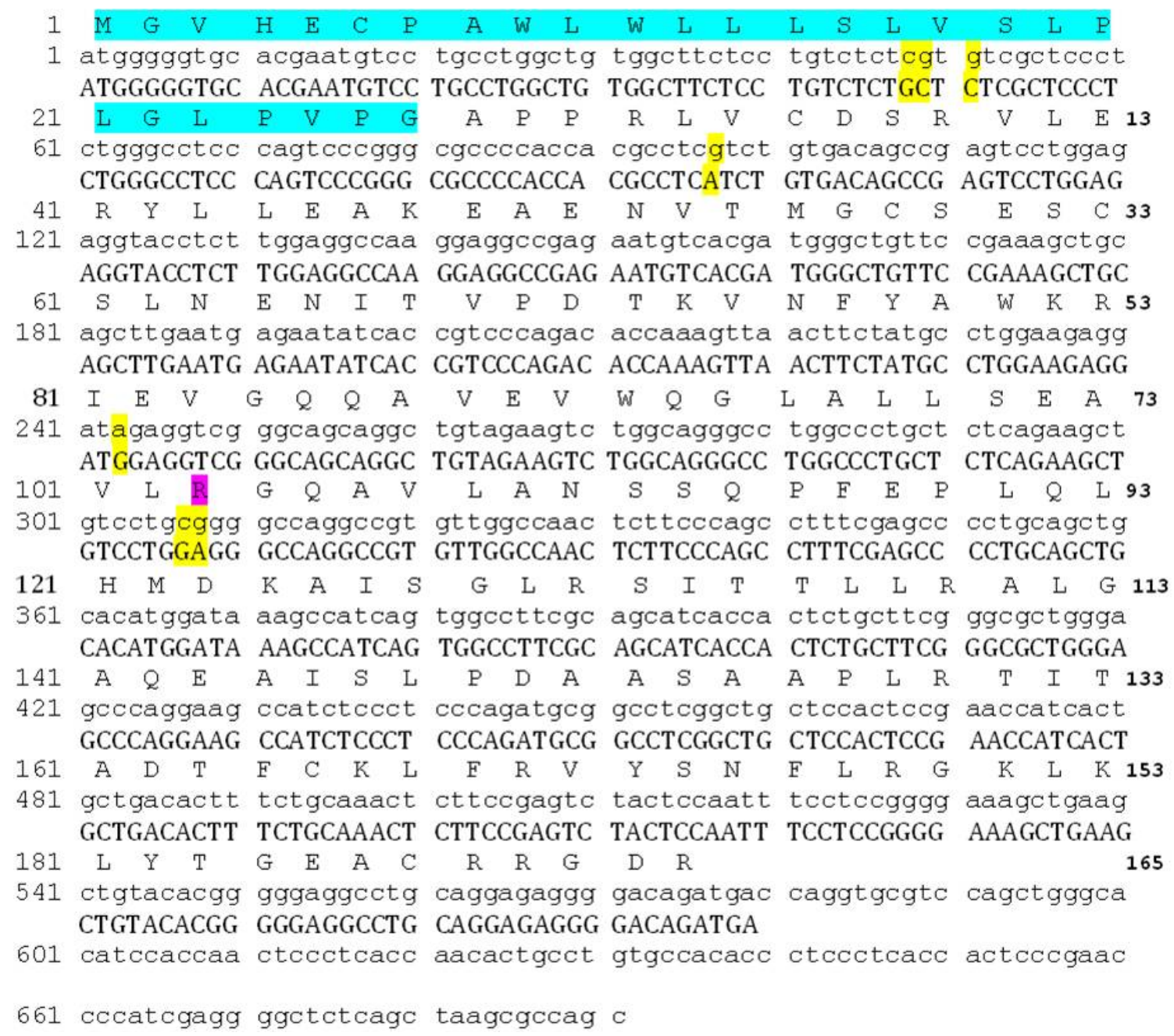

Figure 1-4. Sequence alignment for rhesus EPO and the amino acid translation.

Alignment of the NCBI (lower case) published sequence for rhesus EPO and the sequencing results obtained in our laboratory from EPO-R76E (upper case), and the amino acid translation. The first 27 amino acids (highlighted in blue) are cleaved during normal post-translational processing of EPO. The numbers to the left of the amino acid sequence indicate the numbering of the pro-protein (prior to loss of the first 27 amino acids). The numbers to the right of the amino acid sequence indicate the numbering of the active protein which is used in published literature when studying the structure/function of EPO. The amino acid change that we introduced $(\mathrm{R}$, in pink highlight) is at position 76 in the active form of the protein. There are 5 additional nucleotide differences between our sequence and the NCBI published sequence (in yellow highlight). Three of these are in the cleaved portion of the protein and have no effect on the active form. The remaining 2 mutations in our sequence are also found in other species and considered natural variations that would not be expected to affect protein function. 
was compared to the NCBI published sequence for rhesus Epo. In addition to successfully mutating the arginine 76 to a glutamate, six other nucleotide changes were also noticed. Three of these were in the cleaved portion of the protein and result in the conversion of a leucine to a valine. In all species other than monkey, there is a leucine at this location [100]. It also has no effect on the active form of the protein since it is cleaved off during normal processing. At amino acid 6 we have an isoleucine rather than a valine, however every species other than rhesus monkey also has an isoleucine at this position, so this is considered natural variation, not a mutation, and would not be expected to affect protein function [100]. At amino acid 54 (mature form), we have a methionine instead of an isoleucine. However, the human sequence also has a methionine at this position and therefore this is considered natural variation and would not be expected to affect protein function [103].

\section{Delivery of EPO-R76E}

There are a variety of delivery methods to select from when using EPO-R76E as a neuroprotectant for ocular diseases. Local delivery of EPO to the eye via subretinal injection or intravitreal injection have proven successful [90,77,87,104]. These methods are appealing because of the low dose required; in addition local delivery fails to stimulate the erythropoietic pathway. EPO is able to cross the blood brain barrier allowing physical access to both the retina and the optic nerve after systemic injection [105-106]. Therefore EPO is particularly attractive for systemic treatment of glaucoma. Systemic delivery is advantageous because it prevents any further injury to the eye caused by repeated intraocular injections. Protein therapy delivered by IP injection or intravenous injection as well as viral mediated gene therapy are all viable methods to achieve protection within the eye $[88,87,104,107]$. Gene therapy using EPO-R76E offers several advantages over other more traditional methods of delivery. First, using this approach provides more consistent levels of circulating EPO that remain within the neuroprotective range at all times, unlike the spikes or dips observed when EPO is used as a protein therapy $[108,87]$. Second, only a single intramuscular (IM) injection is required to provide long term expression [109]. This eliminates the need for repeated injections that can be costly and add increased risk of error.

\section{Adeno-Associated Virus}

Adeno-Associated virus (AAV) is a small (25-nm) nonenveloped virus that belongs to the Parvoviridae family. This nonpathogenic virus belongs to the genus Dependovirus because it requires a helper virus such as adenovirus or herpes virus for a productive infection. AAV integrates into chromosome 19, making it the only known mammalian DNA virus that has site-specific integration [110]. The genome consists of a linear, single-stranded DNA approximately $4.7 \mathrm{kB}$ in length. AAV virions package both the sense and antisense stands with equal frequency [111]. The genome carries two viral genes Rep and Cap. Through the use of multiple promoters, alternative splicing, and internal ribosome entry sites an array of proteins are produced from these two genes. The 
structural proteins are derived from the Cap gene while the enzymatic proteins for replication are derived from the Rep gene. The genome is flanked on both ends by inverted terminal repeats that contain the virus and important cis-active sequences. The inverted terminal repeat is the origin of replication and serves as a primer for second strand synthesis [112]. In addition it plays a key role in replication, site specific integration, and negative regulation under nonpermissive conditions [113-115].

\section{Recombinant AAV}

Recombinant AAV (rAAV) gene therapy vectors are produced by the removal of the two viral genes and insertion of a gene of interest between the inverted terminal repeats. Since there are no viral genes present in the rAAV prep the toxicity is minimal.rAAV vectors are a desirable tool for delivering a wide range of transgenes applicable to many disease models. In addition to being nonpathogenic they can infect and transduce a broad range of tissues including brain, retina, muscle, liver, and lungs [117-119]. Unlike many retroviral vectors, rAAV can transduce quiescent cells [120] and is produced at very high titers. Furthermore, since rAAV does not contain the Rep gene, which permits it to integrate, there is no risk of insertional mutagenesis[121].

To date there are twelve known human serotypes (AAV-1 to AAV-12) with AAV-2 being the best characterized. The serology is defined as the inability of an antibody that is reactive to the viral capsid of one serotype in neutralizing those of another serotype[115]. Pseudotyping rAAV genomes with capsids from different AAV serotypes creates novel combinations that can expand the tropism and increase expression and spread of viral transgenes [121-123]. In a recent study serotypes $2 / 1,2 / 5$, and $2 / 8$ were all able to transduce skeletal muscle at much higher levels than $2 / 2$ [124], thus making them ideal vectors for IM injections.

\section{Types of Neuronal Cell Death}

There are three main types of neuronal death; apoptosis, necrosis, and Wallerian degeneration. Apoptosis is a programmed cell death that occurs during development of the nervous system and is also involved in pathological neuronal death following nerve injury or disease [125-126]. It is characterized by loss of cell membrane asymmetry and attachment, cell shrinkage, nuclear fragmentation, chromatin condensation, and chromosomal DNA fragmentation. Extensive membrane blebbing of apoptotic cell bodies occurs. These bodies are subsequently phagocytosed by macrophages, and degraded within phagolysosomes. This entire process allows neurons to be eliminated without releasing their cellular constituents into the surrounding tissue. Furthermore, there is essentially no inflammatory response associated with this process [127].

Apoptosis can be triggered by either intrinsic or extrinsic signals. The extrinsic pathway is activated when "death receptors" at the plasma membrane are triggered [128]. This causes caspase- 8 activation eventually leading to apoptosis. The intrinsic pathway 
involves a non-receptor-mediated stimuli that produce intracellular signals that act directly on targets within the cell and are mitochondrial-initiated events. The control and regulation of these apoptotic mitochondrial events occurs through members of the Bcl-2 family of proteins [129]. It is thought that the main mechanism of action of the Bcl-2 family of proteins is the regulation of cytochrome $c$ release from the mitochondria via alteration of mitochondrial membrane permeability. Some of the anti-apoptotic proteins include Bcl-2, Bcl-x, and Bcl-XL. Some of the pro-apoptotic proteins include Bcl-10, Bax, Bid, and Bad. These proteins have can determine if the cell commits to apoptosis or aborts the process. Activation of either the intrinsic or extrinsic pathway results in cleavage of caspase- 3 and therefore it is often used as a marker for apoptosis.

The alternative to apoptotic cell death is necrosis, which is considered to be a toxic process by which the cell degrades. Necrotic cell injury can occur via two main mechanisms; interference with the energy supply of the cell and direct damage to cell membranes. Some of the major morphological changes that occur with necrosis include cell swelling, formation of cytoplasmic vacuoles, swollen or ruptured mitochondria, disaggregation and detachment of ribosomes, disrupted organelle membranes and swollen and ruptured lysosomes [130]. The loss of cell membrane integrity causes the release of cytoplasmic contents into the surrounding tissue. This results in eventual recruitment of inflammatory cells and a powerful immune response that can cause a large amount of damage to the area.

Wallerian degeneration is defined by axonal degeneration distal to the injury site [131]. The mechanism that triggers it is still unknown. After injury, the axonal cytoskeleton and the axonal membrane dismantle. Neurofilament breakdown, which depends on $\mathrm{Ca}^{2+}$ and the $\mathrm{Ca}^{2+}$ activated protease calpain, is a prominent feature of this degenerative phase and is often used as a marker for it [132]. The process is completely independent of apoptosis [133].

\section{RGC Death Following Optic Nerve Injury and Disease}

\section{Optic nerve crush}

Optic nerve crush causes death of both the RGC soma and its axon by independent events. After severe optic nerve injury the RGC somata no longer receive neurotrophic factors via retrograde transport and undergo apoptosis [134]. RGC death via apoptosis has been demonstrated in a variety of ways. Ultrastructural observations at the GCL show chromatin aggregation [135]. Caspase inhibitors are able to block RGC death after optic nerve transection. In addition, transgenic mice have been very instrumental in demonstrating the role apoptosis after optic nerve injury. Mice that overexpress Bcl-2 have 55\% more RGCs than controls 3 months after transection [136]. In addition, $\mathrm{Bax}^{-/}$mice also have a significantly higher amount of RGC somata than wildtype controls following optic nerve crush [25]. 
Since the RGC axon is no longer receiving nutrients and proteins from the soma it undergoes Wallerian degeneration [131,133]. This is supported by the lack of caspase-3 activation after transection and the fact that caspase inhibitors are unable to prevent axonal degeneration despite being able to keep the parent neurons alive [133]. Further proof comes from transgenic mice that harbor the $\mathrm{Wld}^{\mathrm{s}}$ gene. The RGC axons of these mice demonstrate a much slower rate of degeneration after optic nerve transection [137].

\section{Glaucoma}

In glaucoma the RGC somata die via apoptosis [138] although there are a limited number of publications that also implicate necrosis as well [139]. As discussed previously there are multiple types of glaucoma and RGC apoptosis occurs in both openangle glaucoma and normal tension glaucoma [140,139]. Reports also demonstrate that RGC apoptosis occurs in the DBA/2J mouse model for pigmentary glaucoma [141]. This is clearly demonstrated in DBA/2 $\mathrm{J} \mathrm{Bax}^{-/ /}$mice that develop massive axonal degeneration in response to increased IOP but still maintain a high number of RGC somata [25]. It is likely that the RGC apoptosis which results from glaucoma occurs as a result of axonal injury $[142,34]$.

Glaucomatous damage causes the axons to degenerate by Wallerian degeneration. This is demonstrated in transgenic DBA/2J mice that harbor the $\mathrm{Wld}^{\mathrm{s}}$ gene and have delayed onset of axonal degeneration [34]. The degeneration results from increased IOP that effects axonal transport and can cause mechanical damage to the axons within the optic nerve [142].

\section{Testing EPO-R76E}

The next two chapters compare wild-type EPO to EPO-R76E in regards to its erythropoietic activity and its neuroprotective effects. In addition, systemic gene delivery of EPO-R76E is examined as a viable method to protect RGCs against direct optic nerve injury and disease. Experiments were conducted using two different models for RGC death; an optic nerve crush model (Chapter 2) and the DBA/2J mouse model for glaucoma (Chapter 3).

The experiments in Chapter 2 address the hypothesis that systemic gene delivery of EpoR76E would protect the RGC somata against direct axonal injury without causing an increase in hematocrit. EPO-R76E was first examined using the injury model because of the much shorter experimental timeline. Erythropoietic activity and neuroprotection could be tested in this model within approximately 3 months; compared the 10 months it takes for the DBA/2J mice to develop RGC death. Since the optic nerve crush is a very severe injury, any neuroprotection that occurred gave a high likelihood that protection would also be achieved in the glaucoma model. 
Chapter 3 addresses the hypothesis that systemic gene delivery of EpoR76E would protect RGC somata in a mouse model of glaucoma without considerably increasing hematocrit. This chapter also examines the effects of EPO-R76E on axonal degeneration and RGC function in DBA/2J mice with an increased IOP. The value of testing neuroprotection in this model is the direct link to clinical application of EPO$\mathrm{R} 76 \mathrm{E}$ as a therapeutic for glaucoma. 


\section{CHAPTER 2. SYSTEMIC AAV-MEDIATED GENE THERAPY PROTECTS NeuN POSITIVE CELLS IN BALB/cByJ MICE AGAINST OPTIC NERVE CRUSH}

\section{Introduction}

Optic nerve crush is a common model to induce RGC death in vivo [143]. Crushing the optic nerve causes Wallerian degeneration of the axons and apoptotic loss of RGC somata over time [81]. This pattern of cell death is very similar to that observed in glaucoma where optic nerve injury causes secondary RGC death. Many of the same apoptotic pathways are activated in both instances [144,82,145,25,146]. The mechanical injury to the axons of the optic nerve due to an elevated pressure is one theory on the mechanism of cell death in glaucoma [147-148]. Optic nerve crush can simulate this mechanical injury and is a technique that that is used to study RGC injury in monkeys, rats, and mice [149]. Among other advantages, the speed at which neuronal cell death occurs after optic nerve is crush makes it an attractive technique for examining potential neuroprotectants. Unlike some spontaneous models of neurodegeneration that can take 1 year to reach peak damage levels, the majority of RGC loss occurs within just 2 weeks $[20,149]$.

EPO is a broad range neuroprotectant, in addition to providing protection to neurons in excitotoxic and ischemic settings, EPO also protects neurons in models of mechanical trauma (retinal, cerebral, and spinal cord) in vivo[80,150-151]. Intravitreal injection of EPO protects RGCs in rodent models of optic nerve crush or optic nerve lesion that would otherwise be detrimental to RGCs [86,104]. The effects of EPO in these optic nerve injury models appears to be two fold, prevention of cell death followed by regeneration of axons [104]. However, these results require repeated injections of EPO that have the potential to cause additional damage to the globe. Here we use rAAVmediated gene therapy to express either of two forms of EPO systemically, thereby eliminating the need for intraocular injections and repeated dosing.

EPO's use as a clinical neuroprotectant is hindered by its unwanted erythropoietic activity. One way to sidestep this issue is through the use of non-erythropoietic forms of EPO. In this study the neuroprotective effects of one such form (EPO-R76E) is investigated. Thus far EPO-R76E has been shown to protect photoreceptors in the retinal degeneration slow mouse model without causing a large increase in hematocrit levels [98]. EPO-R76E's ability to protect neurons in the retina and optic nerve against mechanical damage is tested using the optic nerve crush technique. Due to its genetic background, the BALB/cByJ mouse is the strain most susceptible to optic nerve crush [21] and therefore serves as an ideal model to study EPO-R76E as a neuroprotectant. 


\section{Methods}

\section{Injections}

BALB/cByJ mice were obtained from Jackson Laboratories (Bar Harbor, Maine).Either the University of Iowa or the University of Pennsylvania Vector Cores produced the vectors. A Hamilton syringe was used to deliver $10 \mu \mathrm{l}$ of $1 \times 10^{10}$ genome copies of rAAV2/5.CMV.eGFP, rAAV2/5.CMV.Epo, rAAV2/5.CMV.EpoR76E (stock 1) or $1 \mathrm{X} 10^{11}$ genome copies of rAAV2/8.CMV.EpoR76E into the quadriceps of two month old mice. The Epo transgene was derived from rhesus. All experimental procedures were conducted in accordance with the ARVO Statement for the Use of Animals in Ophthalmic and Vision Research and were approved by the Institutional Animal Care and Use Committee at the University Tennessee Health Science Center.

\section{Optic nerve crush}

Thirty days after IM vector delivery mice were anesthetizedwith ketamine/xylazine/urethane $(25 / 10 / 1000 \mu \mathrm{g} / \mathrm{g}$ body weight). A small incision was made in the lateral aspect of the conjunctiva. With a pair of small forceps the edge of the conjunctiva next to the globe was retracted slightly and rotated laterally, allowing visualization of the posterior aspect of the globe where the optic nerve could be observed. Viewed under a binocular operating microscope, the surrounding connective tissue and muscle was gently separated from the nerve. The exposed optic nerve was grasped for 10 sec with a pair of Dumont cross-clamp \#7 forceps (Roboz, cat. \#RS $=5027$, Gaithersburg, MD). This instrument was chosen because its spring action applied a moderate yet constant and consistent force to the optic nerve. The forceps were then removed and the eye was allowed to rotate back into place.

\section{Immunohistochemistry}

At 10 months of age mice were euthanized and eyes were enucleated and stored in $4 \%$ paraformaldehyde in $0.1 \mathrm{M}$ phosphate buffer, $\mathrm{pH} 7.4$ at $4^{\circ} \mathrm{C}$. Retinas were isolated and incubated in phosphate buffered saline (PBS) and blocked in 20\% normal donkey serum in PBS containing $0.1 \%$ Triton-X-100 and $0.5 \%$ BSAfor a minimum of $2 \mathrm{~h}$ at $4^{\circ}$ C. Primary antibody, anti-Neuronal Nuclei [(NeuN) mAb; Chemicon, Temecula, CA] was used at 1:500 and secondary antibody was used at 1:200 (Alexa 488, Invitrogen, Carlsbad, CA). Retinas were placed RGC side up, mounted with Vectashield containing DAPI (Vector Labs, Burlingame, CA) and viewed using a Nikon Eclipse TE2000 laser scanning confocal microscope (Nikon, Japan). 


\section{RGC imaging and counts}

Retinas were first imaged at $4 \mathrm{X}$ magnification and a grid was placed over each retina to randomly select 8 locations to be imaged at $40 \mathrm{X}$ magnification. The number of NeuN positive cells in each region was counted manually using ImageJ software (available by ftp at http://rsbweb.nih.gov/ij/ developed by Wayne Rasband, National Institutes of Health, Bethesda, MD) and Metamorph (Universal Imaging Corporation, Downingtown, PA).

\section{EPO enzyme-linked immuno-sorbant analysis (ELISA) and hematocrit}

Serum from blood samples was probed for EPO and EPO-R76E using the human Quantikine IVD EPO ELISA Kit according to manufacturer's protocol (R\&D Systems, Minneapolis, MN). It should be noted that the ELISA kit is calibrated against human EPO and has been shown to be 4-fold less sensitive for rhesus versus human EPO [152], and this was taken into account for calculations within the manuscript. The absorbance at $450 \mathrm{~nm}$ with $600 \mathrm{~nm}$ reference was detected on a BioTek - $\mu$ Quant plate reader (Winooski, VT). In some mice the serum samples were pooled in order to obtain sufficient material for the ELISA. Hematocrit was measured by capillary centrifugation.

\section{Optic nerve damage}

Optic nerves were isolated and placed in $4 \%$ paraformaldehyde in $0.1 \mathrm{M}$ phosphate buffer, $\mathrm{pH} 7.4$ for one week at $4{ }^{\circ} \mathrm{C}$. Next, samples were post-fixed in $1 \%$ osmium tetroxide in $0.1 \mathrm{M}$ cacodylate buffer, dehydrated in graded ethanols, further dehydrated in propylene oxide and embedded in Embed-812 resin(EMS, Hatfield PA), cut into $1 \mu \mathrm{m}$ sections (Reichert-Jung Ultracut E, Austria) and stained with 1\% paraphenylenediamine (PPD) in 50\% methanol (Sigma-Aldrich, St Louis, MO). Sections were viewed by light microscopy using an Olympus BX51 microscope (Olympus Ameirca inc, PA). Prior to beginning axon counts, the optic nerve was traced at $20 \mathrm{X}$ magnification and cross- sectional area automatically calculated using ImageJ software. The entire length from top to bottom of same cross section was then imaged using a $120 \mathrm{X}$ oil immersion. Approximately the same region of $0.010 \mathrm{~mm}^{2}$ was selected from each 120X image; both live and dead axons were manually counted using ImageJ software. Measurements of the cross-sectional area of the optic nerve were used with axon density to estimate the total number of axons.

\section{Statistical analysis}

A one-way ANOVA followed by a pair-wise Bonferroni post hoc comparison test was used to determine statistical significance when comparing NeuN counts, axon counts, and serum EPO levels. Statistical analysis was performed with Prism 4.0 software (GraphPad, San Diego, CA). 


\section{Results}

\section{Systemic treatment of EPO or EPO-R76E provides a moderate level of protection to NeuN positive cells at the ganglion cell layer against optic nerve crush}

EPO and EPO-R76E were expressed systemically to investigate their neuroprotective effects at the ganglion cell layer (GCL) after optic nerve crush. $\mathrm{BALB} / \mathrm{cByJ}$ mice were injected with rAAV vector carrying eGFP (control), Epo, or EpoR76E. The mutant (EPO-R76E) was delivered at two different doses (low and high) (Table 2-1). Retinal flatmounts were probed with anti-NeuN, a marker for RGCs and some displaced amacrine cells [153-154,50,155] (Figure 2-1A). As expected, a drastic loss of NeuN positive cells occurred at the GCL layer in control mice that received the optic nerve crush. Of those that received the optic nerve crush, mice treated with rAAV2/5.CMV.Epo or rAAV2/8.CMV.EpoR76E appeared to have less cell death compared to controls and mice receiving rAAV2/5.CMV.EpoR76E (low dose). To confirm these observations, NeuN positive cells at the GCL layer were manually counted (Figure 2-1B). The average cell density of control mice after optic nerve crush was $175 / \mathrm{mm}^{2}$, a $57 \%$ reduction from a healthy uncrushed retina $\left(410 / \mathrm{mm}^{2}\right)$. There was no difference in cell survival in mice that received rAAV2/5.CMV.EpoR76E (low dose). However, treatment with rAAV2/5.CMV.Epo $\left(208 / \mathrm{mm}^{2}\right)$ or rAAV2/8.CMV.EpoR76E (high dose) $\left(253 / \mathrm{mm}^{2)}\right.$ was able to provide protection against optic nerve crush compared to controls $(\mathrm{P} \leq 0.001)$. The protection was dose dependent, as the high dose of the mutant resulted in $44 \%$ more cell survival than crushed controls and $22 \%$ more than mice treated with wild-type EPO $(\mathrm{P} \leq 0.01)$.

\section{EPO and EPO-R76E are unable to protect axons against optic nerve crush}

To determine the effect that EPO had on axons subjected to optic nerve crush, PPD stained cross sections of the nerves were examined (Figure 2-2A). Cross sections from uncrushed nerves contained an average of 34,562 healthy myelinated axons with few if any dead axons. Following optic nerve crush this number decreased dramatically to 1,877 axons per nerve in controls mice. The majority of the cross sections contained mainly dead axons and a significant amount of gliosis. Treatment with rAAV2/5.CMV.Epo (1452 axons/nerve), rAAV2/5.CMV.EpoR76E (1808 axons/nerve) or rAAV2/8.CMV.EpoR76E (1545 axons/nerve) had no effect on the preservation of axons (Figure 2-2B). There was no significant difference between any of the treatment groups after optic nerve crush $(\mathrm{P} \geq 0.05)$.

\section{Effects of systemically expressed EPO and EPO-R76E on hematocrit and serum EPO levels in BALB/cByJ mice}

The amount of circulating EPO produced by each vector and the effect it had on hematocrit levels in BALB/cByJ mice was examined (Table 2-1). Control mice that 
Table 2-1. Serum EPO and hematocrit of vector treated BALB/cByJ mice.

\begin{tabular}{lccc}
\hline \multicolumn{1}{c}{ Vector Treatment } & Hematocrit & EPO $(\mathbf{m U} / \mathbf{m l})$ & $\mathbf{N}$ \\
\hline rAAV2/5.CMV.eGFP & $45.8 \% \pm 1.7$ & $0 \pm$ & 10 \\
rAAV2/5.CMV.Epo & $83.8 \% \pm 4.5$ & $84 \pm 18.2$ & 9 \\
rAAV2/5.CMV.EpoR76E & $51.0 \% \pm 4.0$ & $23 \pm 4.3$ & 12 \\
rAAV2/8.CMV.EpoR76E & $66.3 \% \pm 7.8$ & $236 \pm 15.0$ & 11 \\
\hline
\end{tabular}


A.
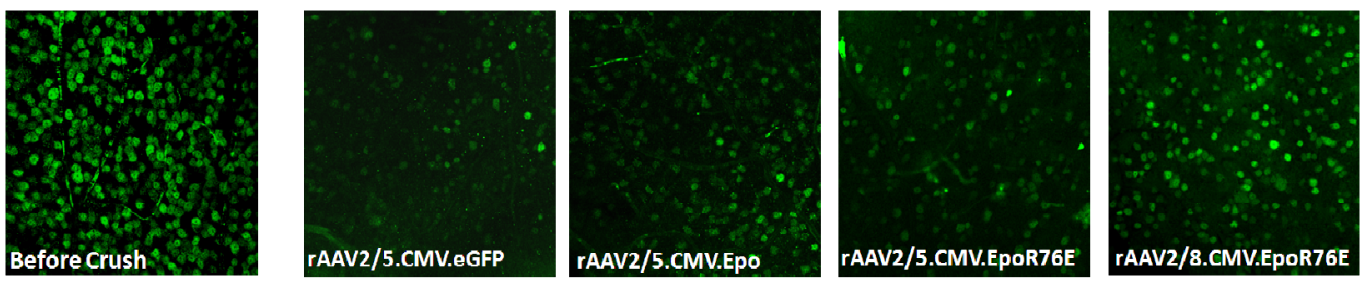

30 Days Post Crush

B.

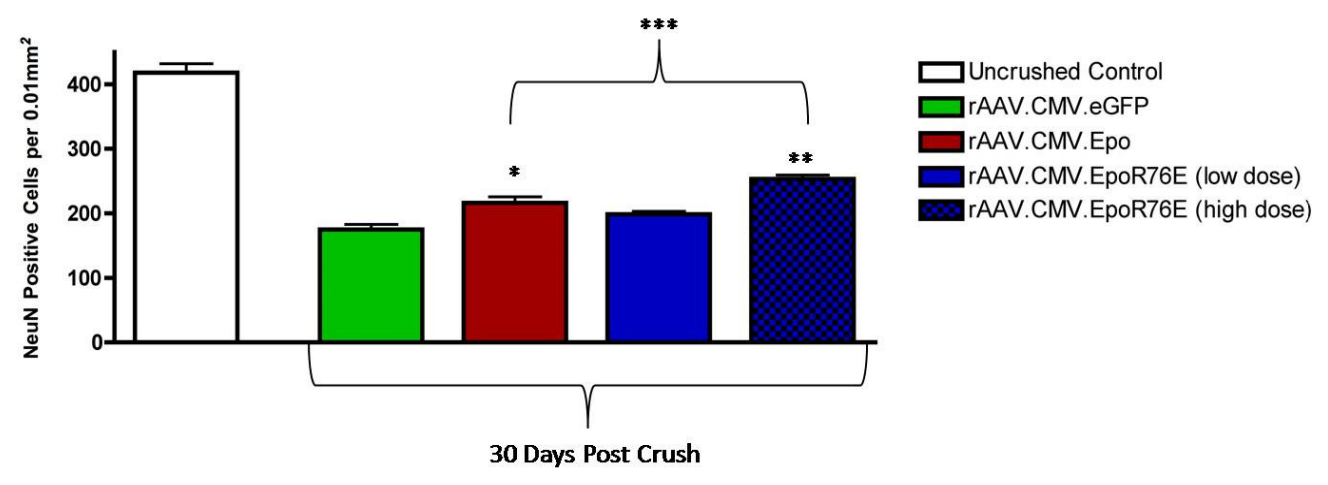

Figure 2-1. Treatment with rAAV2/5.CMV.Epo or rAAV2/8.CMV.EpoR76E provides a level of protection to NeuN positive cells at the GCL layer against optic nerve crush.

A) Confocal micrographs (40X magnification) of retinal flat mounts labeled with anti NeuN. Images are at the retinal ganglion cell layer of the retina. B) Bar graph showing the average density of NeuN positive cells. Data are means \pm S.E.M., and statistical analysis was done by one-way ANOVA with pair-wise Bonferroni post hoc test. There was no statistically significant difference between the rAAV2/5.CMV.eGFP, and rAAV2/5.CMV.EpoR76E (low dose) groups.

* $\quad \mathrm{P} \leq 0.01$ vs. rAAV2/5.CMV.eGFP

$* * \quad \mathrm{P} \leq 0.001$ vs. rAAV2/5.CMV.eGFP

$* * * \mathrm{P} \leq 0.01$ vs. rAAV2/5.CMV.Epo 
A.
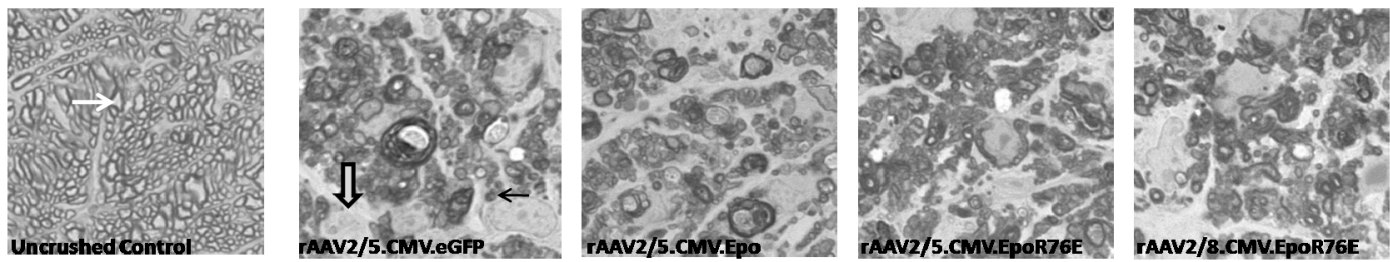

1

TAAV2/5,CMV.EPOR76E

TAAV2/8.CMV.EPOR76E

30 Days Post Crush

B.

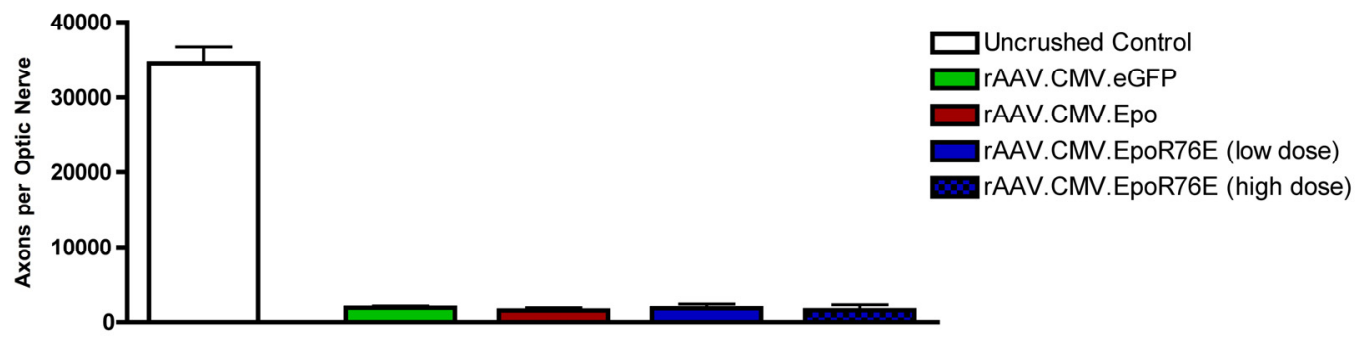

Figure 2-2. Treatment with rAAV2/5.CMV.Epo or rAAV2/8.CMV.EpoR76E does not protect axons from optic nerve crush.

A) Light microscopy of optic nerve cross sections (120X magnification) stained with PPD. Nerves from uncrushed controls have a high density of healthy axons (white arrow). Nerves subjected to crush had profound neurodegeneration marked the loss of healthy axons, increased sick/dying axons $(\rightarrow)$, and gliosis $(\vec{\longrightarrow})$. B) Bar graph of average number of axons per optic nerve. There was no statistically significant difference between groups that received vector treatment. Data are means \pm S.E.M., and statistical analysis was performed by one-way ANOVA with pair-wise Bonferroni post hoc test. 
received rAAV2/5.CMV.eGFP had an average hematocrit of 46\%. The amount of endogenous circulating EPO in these mice was undetectable with the methods used in this study. Mice that received rAAV2/5.CMV.Epo had $84 \mathrm{mU} / \mathrm{ml}$ of EPO in their serum. As expected, this caused an immense increase in the percent hematocrit (84\%). Treatment with rAAV2/5.CMV.EpoR76E resulted in a lower level of circulating EPO $(23 \mathrm{mU} / \mathrm{mL})$ and only slightly increased the hematocrit level (51\%). Delivering a higher dose of the mutant form (rAAV2/8.CMV.EpoR76E) resulted in an extremely high level of circulating EPO (263 mU/ml). Even though the level of circulating EPO was nearly 3 fold higher than wild-type (rAAV2/5.CMV.Epo) the hematocrit level was raised only moderately $(66 \%)$.

\section{Discussion}

Optic nerve injury caused by mechanical stress is an excellent method to study neuroprotection within the central nervous system (CNS). Two independent pathways of cell death [133,156-157], Wallerian degeneration of axons and apoptotic death of the RGC somata[34,158], can be examined simultaneously.In addition, the axons and somata are located in separate anatomical compartments. This study demonstrates that rAAVmediated gene therapy using Epo or EpoR76E protects cells at the GCL layer but not the axons within the optic nerve thirty days after optic nerve crush. Furthermore, neuroprotection by EPO-R76E is achieved without stimulating erythropoiesis to the same extent as its wild type counterpart. The level of protection is dose dependent and shows a statistically significant increase as the level of circulating EPO is increased.

The mouse GCL is composed of nearly $60 \%$ displaced amacrine cells and $40 \%$ RGCs[30]. In addition to labeling RGCs, NeuN also labels a small population of displaced amacrine cells (5-15\%) at the GCL mice [155]. Therefore, it is possible that the population of neurons being protected by EPO is composed of either RGCs, displaced amacrine cells, or both. In rat, displaced amacrine cells are not affected one month after optic nerve lesion [159], suggesting that EPO and EPO-R76E are protecting mainly RGCs in the current study and very few if any displaced amacrine cells.

EPO is well known for its anti-apoptotic effects on neurons [160]. Following transection of the optic nerve RGC cell bodies undergo apoptosis as evidenced by condensed nuclei [81], activation of caspase-3 and -9 [82-83], and downregulation PI$3 \mathrm{~K} /$ Akt kinases [84]. Previous reports demonstrate that directly injecting EPO into the vitreous prevents RGC apoptosis after optic nerve injury by preventing activation of caspase-3 [86]. EPO and EPO-R76E are most likely acting in a similar fashion in the current study to prevent apoptotic death of RGCs.

The signaling pathways that regulate axonal degeneration are different from those that mediate most neuronal apoptosis. Injury to the optic nerve causes RGC death via apoptosis [161-162], however the axons undergo Wallerian degeneration [163,34,158] a process that is independent of the apoptotic pathway [156-157]. EPO protects RGCs in rat models of optic nerve crush and optic nerve transection[86,104], in addition it also 
stimulates axonal regeneration in retinal explants [151]. Furthermore, recent studies demonstrate that intraocular injection of EPO protects a significant number of axons from degenerating after optic nerve crush $[164,104]$. However, in the current study we did not detect any axonal preservation. Three explanations could address these conflicting results. The first involves the region of the optic nerve being analyzed. King et al., 2007 imaged the optic nerve in longitudinal sections and reported axonal regrowth at two regions of the optic nerve, both are proximal to the transection site. Here we only examined a $5 \mu \mathrm{m}$ cross section of the optic nerve and the spatial relationship to the injury site was unknown. Therefore it is possible that neuroprotection may be provided in other regions of the optic nerve. A more careful examination would need to be carried out to completely rule out the absence of any neuroprotection within the optic nerve. A second aspect that should be considered is the amount of EPO used to prevent Wallerian degeneration. Wang et al., 2009 injected $250 \mathrm{mU}$ to $50 \mathrm{U}$ of EPO per eye to reduce the amount of axonal degeneration. The highest amount detected in serum of treated mice in this study was $263.2 \mathrm{mU} / \mathrm{ml}$. EPO crosses the BBB at a rate of $0.5-1 \%$ [165-167] therefore approximately $2.6 \mathrm{mU} / \mathrm{ml}$ likely reached the CNS. Using published mouse eye dimensions [35] this translates to approximately $0.026 \mathrm{mU}$ per mouse eye, over 1000 fold lower than that observed by Wang et al., 2009. Therefore, the lack of axonal protection may have been because an appropriate therapeutic dose was not achieved. Third, the difference in axonal protection could be explained by time. Wang et al., 2009 examined the optic nerve two weeks post crush while this study examined the damage four weeks post crush. It is possible that treatment with EPO provides temporary protection that is lost by four weeks post-crush.

Obtaining the optimal therapeutic dose is an important aspect in drug delivery. To be used as a neuroprotectant, others have reported that EPO must be administered at much higher levels than is necessary for erythropoiesis [66]. Despite a multitude of research highlighting EPO as a broad range neuroprotectant, only a limited number of investigations have attempted to identify an optimal dose [86,50]. In doing such, EPO's neuroprotective activity was shown to function in a bell shaped dose curve [86]. The current study has begun to identify the lower limit of circulating EPO required for neuroprotection of cells at the GCL layer. These results indicate that the peak levels of protection observed thus far by EPO-R76E (44\%), might be improved by increasing the amount serum EPO levels. The neuroprotective properties EPO-R76E, combined with its weakened ability to stimulate erythropoiesis, warrant its examination as a potential treatment for neurodegenerative diseases.

When used at the high dose, rAAV2/5.CMV.EpoR76E moderately increased the hematocrit (66\%). The normal range for a laboratory mouse is between 40-60\% [168]. Slight increases above the normal level appear to be beneficial. When hematocrit levels between are between 58-68\%, mice actually perform better on exhaustion tests due to increased $0_{2}$ uptake [169]. Mice appear to tolerate very high hematocrit levels much better than humans. Rather unexpectedly, transgenic mice chronically expressing Epo had no evidence of thrombembolic complications or embolization despite hematocrit levels at $80 \%$. In addition, the blood pressure, heart rate, and cardiac output were normal as well [170]. However, when hematocrit levels are this high, mice perform poorly on 
exhaustion tests and the average survival time was reduced by 3 months [171]. In humans the normal hematocrit for females and males is below $48 \%$ and $52 \%$ respectively. Patients that exceed these levels would be considered to have polycythemia [172]. In both Chapters 2 and 3, treatment with rAAV2/5.CMV.EpoR76E raised hematocrit levels to above $55 \%$ in mice. If this same increase was observed in patients they would need to undergo regular phlebotomy [173].

The optic nerve crush causes severe injury to the axons within the nerve. Given the neuroprotection demonstrated by EPO in this model it was likely protection would also occur in models of optic nerve disease. This theory is examined in Chapter 3 using the DBA/2J mouse model for pigmentary glaucoma in which there is severe axonal degeneration and apoptotic death of the RGC somata. Based on the experiments in Chapter 2, we hypothesized that systemic gene delivery of EPOR76E would protect the RGC somata in the DBA/2J mouse without considerably increasing the hematocrit. 


\title{
CHAPTER 3. SYSTEMIC AAV-MEDIATED GENE THERAPY PRESERVES RETINAL GANGLION CELLS AND VISUAL FUNCTION IN DBA/2J GLAUCOMATOUS MICE
}

\begin{abstract}
Introduction
Many neurodegenerative diseases such as Alzheimer's, amyotrophic lateral sclerosis (ALS), multiple sclerosis (MS), Parkinson's, and glaucoma are characterized by the slow progressive loss of neurons. The neuronal death is caused by a variety of factors that in most cases are disease specific. Autoimmunity plays a key role in MS causing severe axonal damage, as well as in ALS where it leads to loss of motor neurons. Alzheimer's is often associated with plaques and tangles in the brain and in glaucoma it appears that an increase in IOP causes axonal damage and RGC death. While many laboratories are working to develop disease-specific interventions, we hope to develop general neuroprotective treatments such as EPO that may ameliorate neurodegenerative diseases regardless of their initiating factors. We have chosen to use glaucoma as a model system to study the treatment for a progressive loss of neurons. This is an ideal model system for examining progressive neuronal degeneration because neuronal cell death and axonal degeneration occur in separate anatomical compartments. The RGC somata are located in the most proximal layer of the retina, while the RGC axons are bundled in the optic nerve. Further, tests of visual function exist (F-VEP) that require communication from the RGC soma, through the axon, to the visual cortex.
\end{abstract}

We selected a well characterized murine model of pigmentary glaucoma, the DBA/2J mouse [22]. The initial neuronal injury occurs at the optic nerve head $[34,155]$. Here, anterograde Wallerian degeneration is responsible for death of the ganglion cell axons projecting to the brain. This results in a loss of vision. The axonal injury also leads to programmed cell death of the RGC somata within the retina [34,158]. The pathology of this pigmentary glaucoma can be predicted despite the asynchronous nature of the disease from eye to eye.IOP increases between 6-12 months of age which is followed by optic nerve damage beginning at 8 months of age [11]. Using this model we studied both the morphological neuroprotection and function of RGCs and their axons by treatment with rAAV carrying EpoR76E.

A number of different approaches are being taken to achieve neuroprotection $[174,87]$. Previously, our laboratory focused on delivery of a mutated form of EPO to rescue photoreceptor cells in a mouse model of retinal degeneration [175]. This mutant form of EPO, was able to provide high levels of protection without significantly increasing hematocrit. The success of EPO in protecting photoreceptors compelled us to test this approach as a treatment for the slow progressive loss of neurons that occurs in many neurodegenerative diseases. EPO has firmly established its role as a neuroprotective agent both in vivo and in vitro proving capable of protecting multiple neuronal cell types from various injuries [59,61-64]. EPO and EPO-R76E can cross the blood brain barrier [105-106] allowing for direct access to vulnerable neurons. The 
present study used gene therapy and systemic delivery of EPO-R76E to rescue neurons in the DBA/2J model of glaucoma.

\section{Methods}

\section{Injections}

DBA/2J mice were obtained from Jackson Laboratories (Bar Harbor, Maine). Vectors were produced by the University of Iowa Vector Core. A Hamilton syringe was used to deliver $10 \mu \mathrm{l}$ of $1 \mathrm{X} 10^{10}$ genome copies of rAAV2/5.CMV.eGFP, rAAV2/5.CMV.Epo, or rAAV2/5.CMV.EpoR76E (stock 1) into the quadriceps of 1 month old mice. The Epo gene was derived from rhesus. All experimental procedures were conducted in accordance with the ARVO Statement for the Use of Animals in Ophthalmic and Vision Research and were approved by the Institutional Animal Care and Use Committee at the University Tennessee Health Science Center.

\section{Intraocular pressure}

Mice were anesthetized with ketamine/xylazine/urethane $(25 / 10 / 1000 \mu \mathrm{g} / \mathrm{g}$ body weight). IOP was measured monthly from 5-8 months of age using a TonoLab tonometer (Colonial Medical Supply Co; Franconia, NH). The TonoLab rebound tonometer was used because it is noninvasive, accurate, and reproducible in the DBA/2Js as well as other mouse strains [176-177]. Mice that developed an IOP of $13 \mathrm{~mm} \mathrm{Hg}$ or greater were used in the analysis.

\section{Retinal flatmounts and NeuN counts}

Retinal flatmounts were prepared as previously described in Chapter 2. NeuN positive cells at the GCL layer were counted as previously described in Chapter 2.

\section{Optic nerve cross sections and total axon counts}

Optic nerve cross sections were prepared as previously described in Chapter 2. Axon counts were performed as previously described in Chapter 2 with one exception. Light microscopy images of the optic nerves were taken at $60 \mathrm{X}$ oil immersion.

\section{EPO enzyme-linked immuno-sorbant analysis (ELISA) and hematocrit}

Serum EPO levels and percent hematocrit was determined as previously described in Chapter 2. 


\section{F-VEP}

After overnight dark adaptation, mice were anesthetized with an intraperitoneal injection of ketamine/xylazine/urethane $(25 / 10 / 1000 \mu \mathrm{g} / \mathrm{g}$ body weight $)$. Body temperature was maintained at $37^{\circ} \mathrm{C}$ with a heading pad. Pupils were dilated with $1 \%$ Atropine. Platinum needle electrodes (Grass Technologies, West Warwick, RI) were placed approximately $3 \mathrm{~mm}$ lateral to lambda over the left and right cortex. Flashes of white light at an intensity of $1.0 \mathrm{~cd} . \mathrm{s} / \mathrm{m}^{2}$ were presented in a Ganzfeld dome (Diagnosys, Lowell, MA). Flash frequency was $1 \mathrm{~Hz}$ with an inner sweep delay of $500 \mathrm{~ms}$. Each result was an average of 200 sweeps.

\section{Statistical analysis}

A one-way ANOVA followed by a pair-wise Bonferroni post hoc comparison test with a $P$ value $\leq 0.01$ considered statistically significant was used to compare NeuN counts, axon counts, N1 amplitude, P1 amplitude, and serum EPO levels. Statistical analysis was performed with Prism 4.0 software (GraphPad, San Diego, CA). A Pearson product-moment correlation coefficient was used to compare EPO's effect on IOP.

\section{Results}

\section{IOP as marker for glaucoma in DBA/2J mice}

The DBA/2J mouse strain has a variable response in the elevation of IOP; however, when IOP is high neuronal loss results. To define the animals with elevated IOP and, therefore, the potential for developing glaucoma, we measured the IOP between the ages of 3 to 8 months (Figure 3-1). The baseline IOP was measured at 3 months of age $(12.5 \mathrm{~mm} \mathrm{Hg})$ and was in agreement with previous reports $[22,178]$. Once the baseline data were collected we aged a cohort of 47 mice. At 8 months of age 73 of the 94 eyes had an IOP that exceeded the baseline. All of the eyes with an elevated IOP of greater than $13 \mathrm{~mm} \mathrm{Hg}$ were included in the study to test the effects of EPO and EPOR76E.

\section{Both rAAV2/5.CMV.Epo and rAAV2/5.CMV.EpoR76E protect RGC axons}

The neuroprotective effects of EPO were tested in a model of glaucoma, the $\mathrm{DBA} / 2 \mathrm{~J}$ mouse. We examined the optic nerves of four groups of mice: 3 month old mice (before the onset of glaucoma), 10 month old mice receiving either rAAV2/5.CMV.eGFP (control vector), rAAV2/5.CMV.Epo (Epo vector), or rAAV2/5.CMV.EpoR76E (mutant Epo vector). An obvious difference was observed when examining the cross sections of the optic nerves (Figure 3-2A). As expected $[11,155]$ there was little degeneration in the 


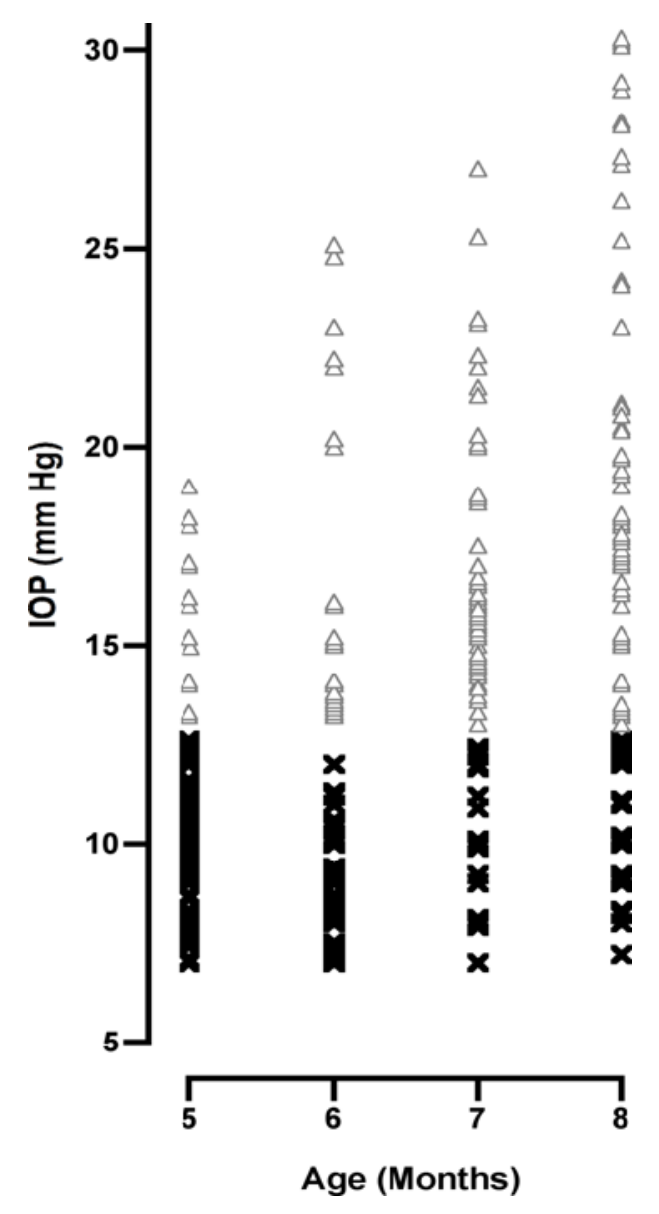

Figure 3-1. IOP increases in DBA/2J mice over time.

The IOP was increased in 73/94 DBA/2J mouse eyes by 8 months of age. The scatter plot shows IOP measured monthly by rebound tonometry from DBA/2J mice. Only mice that exhibited an increased IOP above $13 \mathrm{~mm} \mathrm{Hg}(\triangle)$ were considered glaucomatous and entered into the study for further analysis. Mice that exhibited an IOP below $13 \mathrm{~mm} \mathrm{Hg}$ (X) were not likely to have appreciable RGC loss and were not included within this study. 
Figure 3-2. Treatment with rAAV2/5.CMV.Epo or rAAV2/5.CMV.EpoR76E protects the optic nerve of DBA/2J mice with exceedingly high IOP $(\geq 25 \mathrm{~mm} \mathrm{Hg})$ from glaucomatous neurodegeneration.

A) Brightfield micrographs of optic nerve cross sections (60X magnification) stained with PPD. Nerves from preglaucomatous mice ( 3 months old) have a high density of healthy axons (white arrow). At 10 months of age optic nerves from control mice (rAAV2/5.CMV.eGFP) had profound axonal degeneration, marked the loss of healthy axons, increased sick/dying axons $(\rightarrow)$, and gliosis $(\vec{b})$. The majority of optic nerves from mice that were treated with either EPO vector had little or no axonal degeneration. B) Bar graph of the number of healthy axons per optic nerve. Data are means \pm S.E.M., and statistical analysis was performed by one-way ANOVA with pair-wise Bonferroni post hoc test. There was no statistically significant difference between the preglaucomatous, rAAV2/5.CMV.Epo, and rAAV2/5.CMV.EpoR76E groups. $* * \mathrm{P} \leq 0.001$ vs. rAAV2/5.CMV.eGFP 
A.
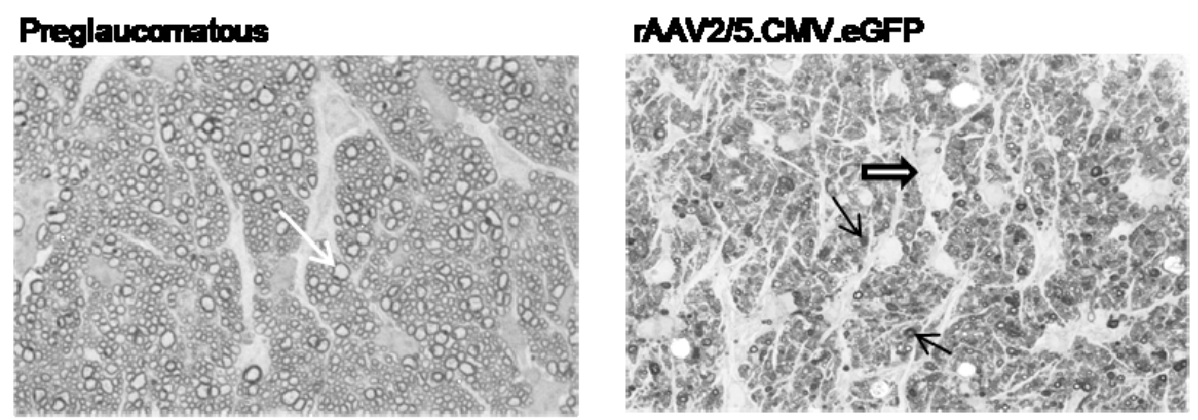

\section{IAAV25.CMN.Epo}

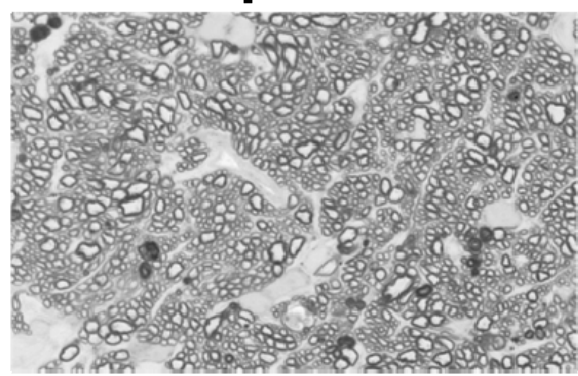

\section{rAV2/5.CWN_EpoR76E}

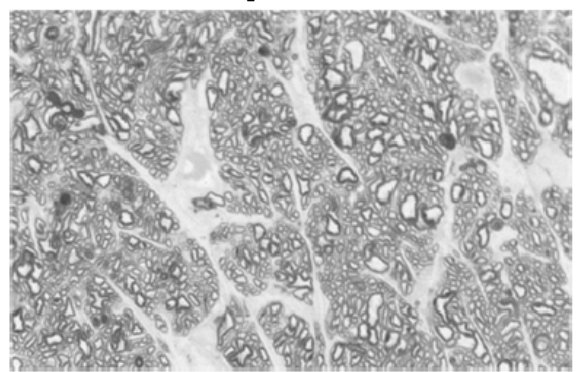

B.

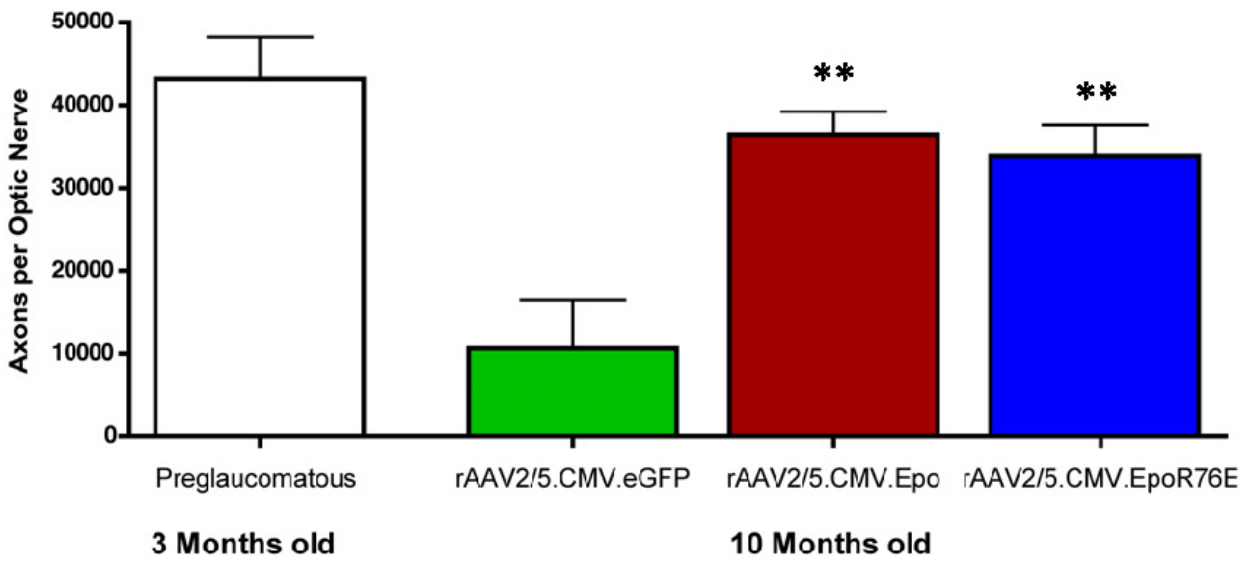


optic nerves from young untreated mice and a significant amount of degeneration in the nerves from the older control mice that received vector at 1 month of age. The effects of both the normal EPO and the mutant EPO were apparent even at low magnification. The mice treated with either Epo vector had optic nerves that resembled the young mice and not the aged matched control mice. To confirm these observations, axons in the optic nerve were counted (Figure 3-2B). This quantification confirmed our initial observation with 3 fold more surviving axons $(\mathrm{P} \leq 0.001)$ in mice treated with the Epo vector $(36,366$ axons/nerve) and with the mutant Epo vector (33,841 axons/nerve), than in age-matched control mice (10,648 axons/nerve). There was no significant difference in the number of surviving axons in between the Epo treated optic nerves as compared to the young controls.

\section{Treatment with rAAV2/5.CMV.Epo or RAAV2/5.CMV.EpoR76E protects NeuN positive cells}

The preservation of the optic nerve naturally led us to examine the RGC soma, and we found that the protective effect of both EPO vectors did extend to the RGC bodies. Retinal flat mounts from all four groups were probed with anti-NeuN (Figure 3-3A), a marker for RGCs $[153-154,50,155]$ and some displaced amacrine cells. Young mice had a high NeuN positive cell density throughout the entire retina whereas older control mice had some areas that were completely devoid of cells. The ganglion cell layer (GCL) of mice treated with either Epo vector closely resembled that of younger mice having a dense population of cells throughout. To directly assess the effects of our treatment, the NeuN positive cells in the GCL were counted (Figure 3-3B). The average cell density in young mice ( 406 cells per $0.1 \mathrm{~mm}^{2}$ ) was almost two fold greater than the density in older control mice ( $243 \mathrm{NeuN}+$ cells per $\left.0.1 \mathrm{~mm}^{2}\right)$. Treatment with the Epo vector (384 cells per $0.1 \mathrm{~mm}^{2}$ ) or the mutant Epo vector $\left(344\right.$ cells per $0.1 \mathrm{~mm}^{2}$ ) provided a significant level of protection to the RGC soma $(\mathrm{P} \leq 0.001)$. In addition, there was no significant difference in the number of NeuN positive cells in the Epo treated groups as compared to the young controls.

\section{Functional preservation of the visual pathway in DBA/2J mice treated with rAAV2/5.CMV.Epo and rAAV2/5.CMV.EpoR76E}

Gene therapy using either Epo vector preserved visual function in DBA/2J mice. The anatomical sparing of both the axon and soma should result in the maintenance of visual function.DBA/2J mice from all 4 groups were subjected to flash-visually evoked potentials (F-VEP). For a signal to reach the visual cortex both the RGC soma and axon must be intact. The classical N1 and P1 peaks were observed in the averaged waveforms of each treatment group (Figure 3-4A and B). Young DBA/2J mice produced a robust and reproducible signal. By 10 months of age the signal had severely diminished, particularly the N1 peak and a number of these mice had no detectable signal at all. Ten month old mice that received treatment with either the Epo or the mutant Epo vector had visually evoked responses that resembled their younger counterparts. The average 
A.
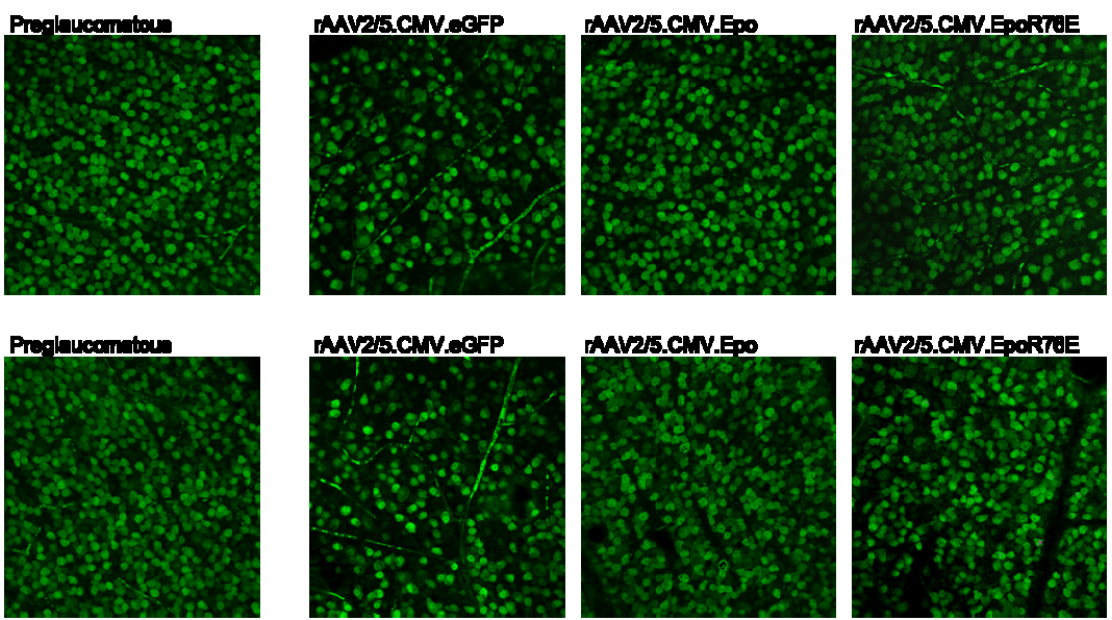

B.

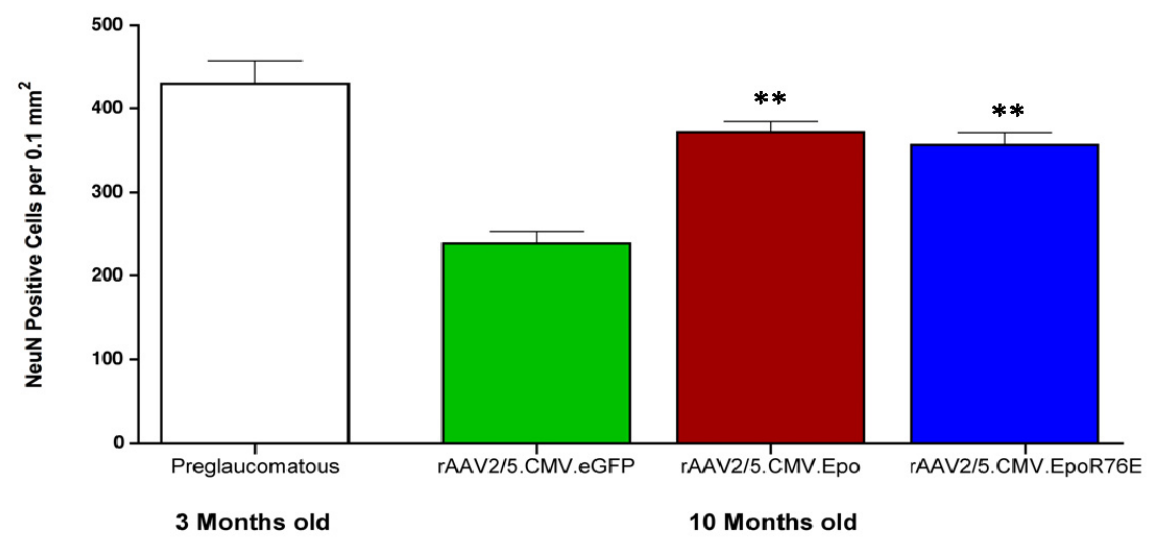

Figure 3-3. Treatment with rAAV2/5.CMV.Epo or rAAV2/5.CMV.EpoR76E protects NeuN positive cells at the GCL from glaucomatous cell death.

A) Confocal micrographs (40X magnification) of retinal flat mounts from DBA/2J mice labeled with anti-NeuN. The first column contains representative images from preglaucomatous mice 3 months of age. Columns 2-4 are images from 10 month old DBA/2J mice treated with rAAV2/5.CMV.eGFP, rAAV2/5.CMV.Epo, or rAAV2/5.CMV.EpoR76E respectively.All images come from independent eyes. B) Bar graph showing average density of NeuN positive cells. Data are means \pm S.E.M., and statistical analysis was done by one-way ANOVA with pair-wise Bonferroni post hoc test. There was no statistically significant difference between the preglaucomatous,rAAV2/5.CMV.Epo, and rAAV2/5.CMV.EpoR76E groups. $* * \mathrm{P} \leq 0.001$ vs. rAAV2/5.CMV.eGFP 
A.

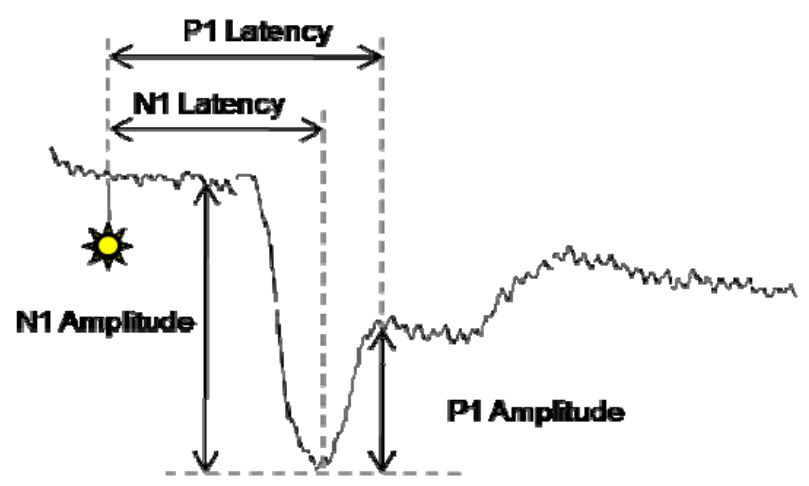

B.

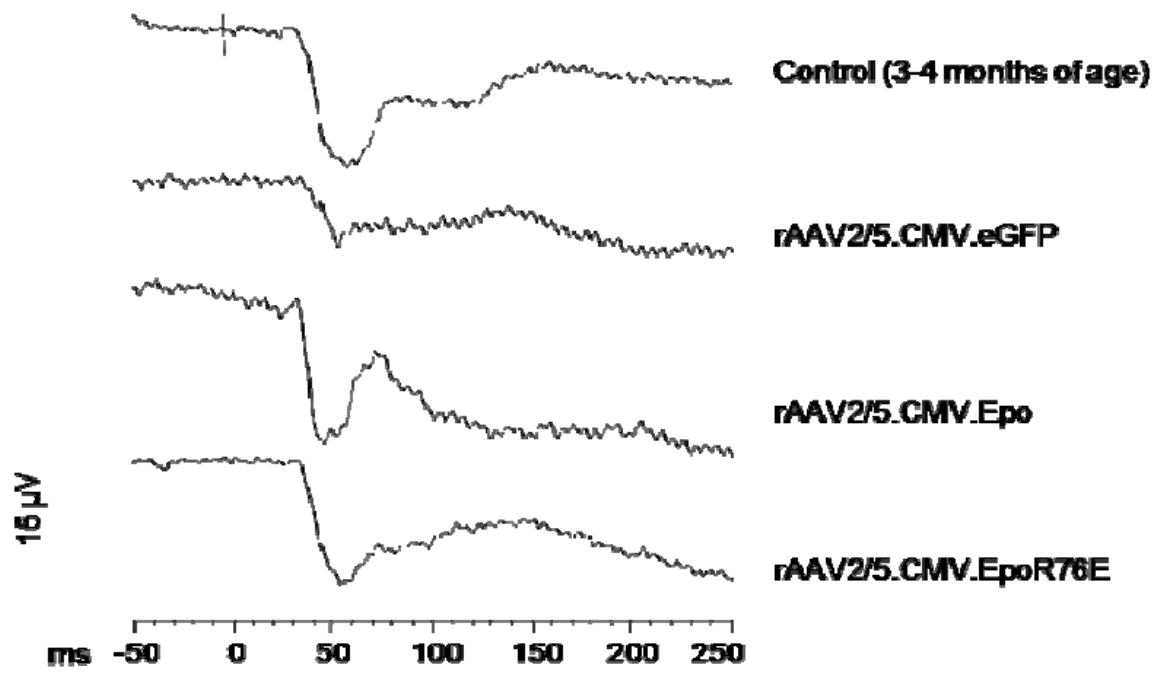

Figure 3-4. rAAV2/5.CMV.Epo or rAAV2/5.CMV.EpoR76E provide functional rescue to the visual pathway of glaucomatous $\mathrm{DBA} / 2 \mathrm{~J}$ mice.

A) Representative image of recording response from flash-visual evoked potential. Arrows and dotted lines indicate how the peak amplitude and latency were determined from each recording. The represents when the flash of light was delivered. B) Recordings from flash-visual evoked potential. The recordings from each treatment group were averaged together and aligned vertically to allow for visual comparison. Young control mice display large N1 and P1 peaks that result from a fully intact and functional visual pathway. These peaks are nearly lost in 10 month old mice glaucomatous mice treated with eGFP vector. Treatment with either the Epo or mutant Epo vector rescues the peaks, restoring the visual pathway. $\mu \mathrm{V}=$ micro volts; $\mathrm{ms}=$ milliseconds. 
amplitude and the latency of the $\mathrm{N} 1$ and $\mathrm{P} 1$ peaks were quantified (Figure 3-5). Young mice had normal $\mathrm{N} 1(15.7 \mu \mathrm{V})$ and $\mathrm{P} 1(11.3 \mu \mathrm{V})$ peak amplitudes. There was a considerable attenuation of the peaks in older mice $(\mathrm{N} 1=7.3 \mu \mathrm{V}, \mathrm{P} 1=4.2 \mu \mathrm{V})$. When animals received either Epo vector there was a preservation of the evoked potential. Ten month old mice that received the Epo vector had a N1 peak of $16 \mu \mathrm{V}$ and a P1 peak of 14 $\mu \mathrm{V}$. These evoked potentials were significantly better than that observed in age matched controls $(\mathrm{P} \leq 0.001)$. Similarly treatment with the mutant Epo vector also rescued both peaks $(\mathrm{N} 1=14 \mu \mathrm{V}, \mathrm{P} 1=8 \mu \mathrm{V}, \mathrm{P} \leq 0.001$ and $\mathrm{P} \leq 0.05$ respectively). There was no statistically significant difference in the peak latency of the N1 and P1 waves between any of the treatment groups and young control mice.rAAV-mediated gene transfer effects on hematocrit, serum EPO levels, and IOP in DBA/2J mice.

Gene therapy using the EpoR76E mutant produced similar amounts of circulating EPO without causing a large increase in the hematocrit. Long term treatment with wild type EPO leads to dangerously high hematocrit levels, therefore the amount of circulating EPO and its effect on hematocrit levels was examined in all three treatment groups (Table 3-1). In control DBA/2J mice the low levels of EPO within the serum are undetectable by the method used and therefore the hematocrit levels remained at baseline (46\%). Treatment with either the Epo vector or the mutant Epo vector greatly increased serum Epo levels, $92 \mathrm{mU} / \mathrm{mL}$ or $67 \mathrm{mU} / \mathrm{mL}$ respectively. Despite similar levels of protein production $(\mathrm{P} \geq 0.05)$ by both vectors the physiological response in animals was quite different. Treatment with the Epo vector resulted in average hematocrit levels above $90 \%$ and required regular phlebotomy while the same level of mutant EPO caused only a slight increase in hematocrit (55\% without phlebotomy), still within the healthy range for a DBA/2J mouse. Treatment with either EPO vector had no statistically significant affect on the IOP (PMCC -.026).

\section{Discussion}

Glaucoma is the second leading cause of blindness worldwide, affecting nearly 70 million people[2]. Currently, there are no neuroprotective agents clinically available for preventing RGC death or reducing visual field loss in patients with primary open angle glaucoma [119]. Here we show for the first time that systemic gene delivery of Epo or EpoR76E is capable of protecting both the axons and the RGC somata from glaucomatous damage in $\mathrm{DBA} / 2 \mathrm{~J}$ mice and that this morphological protection translates into functional rescue of the visual pathway against glaucomatous damage. In addition, the expression of the mutant EPO-R76E provided this protection while maintaining the hematocrit within healthy limits.

With the experimental design it was important that the majority of eyes used for this study developed glaucoma. Since IOP is major risk factor for the development of glaucoma in these mice it was used as a positive marker for glaucoma. We used the TonoLab rebound tonometer because it is noninvasive, accurate, and reproducible in the DBA/2Js as well as other mouse strains [176-177]. Both the temporal increase in IOP and the increase in the number of eyes with high IOP, correlates well with previously 
Figure 3-5. Quantitative analysis of rAAV2/5.CMV.Epo or rAAV2/5.CMV.EpoR76E treatment on flash-visual evoked potential in glaucomatous DBA/2J mice.

Treatment with wild type or mutant EPO significantly increased both the N1 and P1 amplitude while not affecting the latency of flash-visual evoked potential. A) N1 peak amplitude and B) P1 peak treated with either Epo vector return to preglaucomatous levels. There is no statistically significant difference of the C) N1 latency or the D) P1 latency between young preglaucomatous mice and 10 month old glaucomatous mice. Treatment with any of the three vectors did not have a positive or negative effect on the latency.Data are means \pm S.E.M., and statistical analysis was done by one-way ANOVA with pair-wise Bonferroni post hoc test.

$* \mathrm{P} \leq 0.01 ; * * \mathrm{P} \leq 0.001$ vs. rAAV2/5.CMV.eGFP 
A.

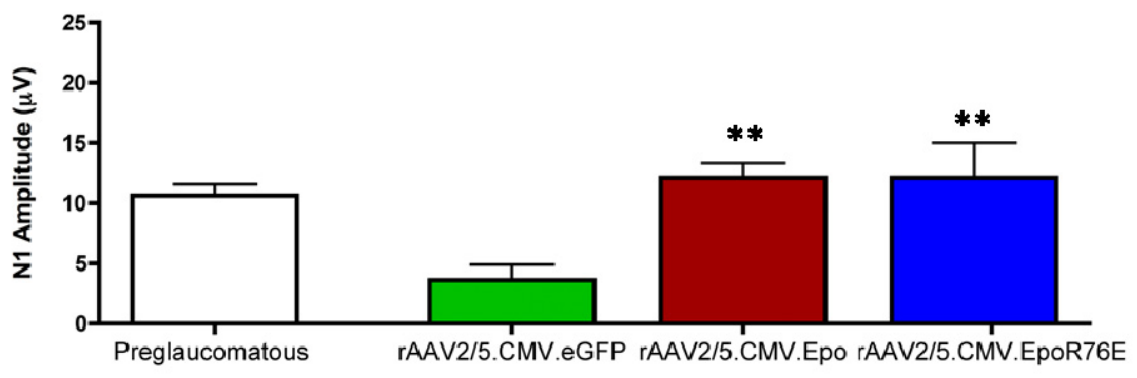

B.

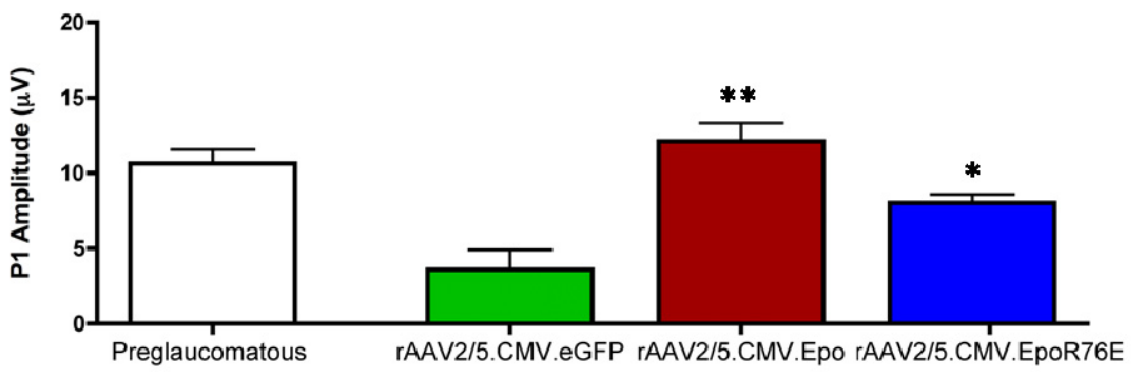

C.

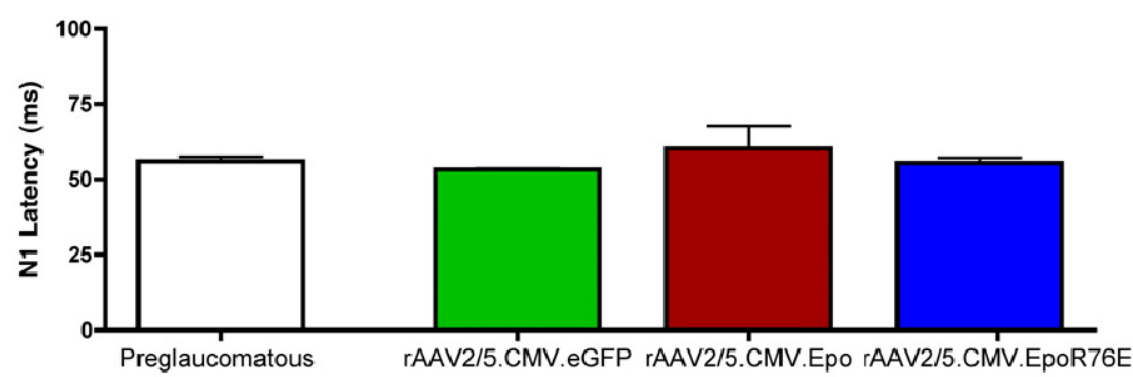

D.

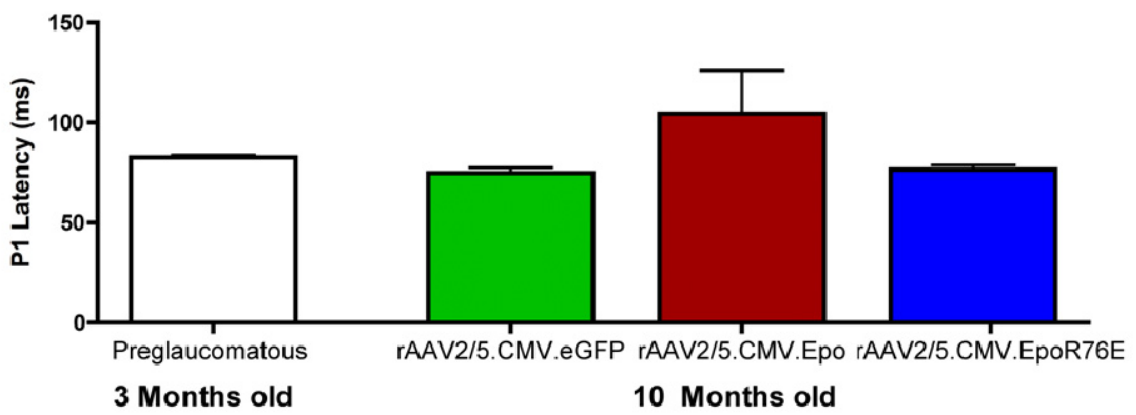


Table 3-1. Serum EPO and hematocrit of vector treated ten month old mice.

\begin{tabular}{lcccc}
\hline Vector Treatment & \multicolumn{2}{c}{ EPO $(\mathbf{m U} / \mathbf{m l})$} & \multicolumn{2}{c}{ Hematocrit } \\
\hline rAAV2/5.CMV.eGFP & 0 & $(\mathrm{n}=6)$ & $46 \% \pm 2.5(\mathrm{n}=17)$ \\
rAAV2/5.CMV.Epo & $92 \pm 37$ & $(\mathrm{n}=8)$ & $81 \%{ }^{1} \pm 10.1(\mathrm{n}=9)$ \\
rAAV2/5.CMV.EpoR76E & $67 \pm 89.4(\mathrm{n}=18)$ & $55 \% \pm 11.3(\mathrm{n}=23)$ \\
\hline
\end{tabular}

${ }^{1}$ Mice treated with rAAV2/5.CMV.Epo were phlebotomized routinely to keep hematocrit levels from exceeding 90\%; no other treatment groups required this. Data are means \pm STDEV. 
published data [22,11]. At the time the experiments were performed the accuracy of the rebound tonometer had not been tested on older $\mathrm{DBA} / 2 \mathrm{~J}$ mice that often develop a robust corneal calcification by 9-12 months of age [11]. Therefore we did not continue to measure IOP into the $9^{\text {th }}$ and $10^{\text {th }}$ month of the experiment. Since this time however, Pease et al., 2010 has tested the TonoLab tonometer in older glaucomatous DBA/2Js. Their findings prove it to be accurate in this glaucoma model as well as in the bead induced model [179]. Measuring IOP in the $9^{\text {th }}$ and $10^{\text {th }}$ month would not have changed the outcome of the experiments performed but would have perhaps added more mice to the study given the two extra months to develop an IOP above the baseline.

The VEP, which detects bioelectrical signals from the visual system, is an appropriate electrophysiological test when studying optic nerve diseases [180]. The FVEP is used to detect the functional integrity of RGCs and the optic nerve. If either the RGC soma or axon are compromised the signal cannot reach the visual cortex and therefore won't be detected by F-VEP [181-183]. The markers for functional assessment when using the F-VEP are the latency and peak amplitude of the N1 and P1 wave. The amplitude is associated with the number of cells present to relay the signal such that the smaller the signal the greater the cell death. The latency of the N1 and P1 waves are coupled with the synaptic connections and related to the health of existing cells. At 2 years of age nearly all untreated DBA/2J mice have advanced glaucoma very few RGCs and almost no detectable cortical activity by F-VEP [181]. In the current study we found that as early as 10 months of age the majority of control mice also had minimal cortical response due to glaucomatous damage. Untreated glaucomatous mice had low, but detectable N1 and P1 amplitudes and normal latencies indicating extensive cell death, but normal synaptic connectivity in the remaining cells. Treatment with either rAAV2/5.CMV.Epo or rAAV2/5.CMV.EpoR76E preserved the F-VEP waveform similar to that observed in young mice. On average, mice receiving these vectors showed complete rescue of the $\mathrm{N} 1$ and $\mathrm{P} 1$ amplitude demonstrating functional protection of the RGC soma and axon.

Axonal degeneration usually precedes neuron cell body death in many neurodegenerative diseases and is often causal of disease symptoms $[184,156]$. The same is true in glaucoma where progressive axon degeneration is the key pathogenic event causing vision loss and eventual death of the RGC soma [34,185,158]. In the DBA/2J model the primary insult to the optic nerve occurs in the glial lamina as a result of increased IOP [34]. Although the mechanism of the pathogenesis is unknown several candidates exist including mechanical stress, glutamate excitotoxicity, neurotrophin deprivation, oxidative stress, glial cell modulation, and inflammation [186-187]. Here we report that EPO functions independently of IOP. Therefore, three hypotheses exist that could explain the observed protection. 1) Direct interaction with the RGCs. EPO could interact directly with the RGC somata or axons allowing them to maintain metabolic activity and function despite increased pressure. This hypothesis is supported by the fact that EPO and its receptor are expressed in the RGC layer of both human and mouse and that EPO treatment of the retina activates the expected signal transduction cascades $[188,160,189]$. Also, in vitro evidence suggests that EPO acts as a paracrine factor [190] and protects neurons from excitotoxic conditions including exposure to $\mathrm{N}$-methyl-D- 
aspartic acid [191] or nitric oxide [192]. 2) Interactions with surrounding cells. EPO may act on the surrounding tissue to provide indirect protection to the optic nerve. Increased glial reactivity within astrocytes and Müller cells in the retina [193] as well as astrocytes and microglia within the optic nerve head are associated with the glaucomatous state in the DBA/2J model [194-195]. We have shown that treatment with EPO can decrease Müller cell hypertrophy [87]. In astrocytes, glutamate activation of aquaporin 4 increases water permeability and causes edema. EPO prevents this aquaporin mediated swelling in astrocytes by blocking the activation of group 1 metabotropic glutamate receptors [196]. In addition, reactive astrocytes in the optic nerve head produce nitric oxide synthase in response to increased IOP [197-198]. Nitric oxide has been shown to be an "axonal injury factor" that stimulates production of endogenous EPO as a protective factor to reduce axonal degeneration in an acrylamide induced neuropathy model [199]. 3) Indirect effects on blood flow and cerebrospinal fluid (CSF) pressure. Some patients suffer from normal-tensive glaucoma, in which IOP is normal but visual field loss from optic nerve damage still occurs. In a retrospective study of patients with normal-tensive glaucoma, many had lower cerebral spinal fluid pressure, that resulted in a trans-pressure gradient across the optic nerve (the IOP was comparatively higher than CSF pressure [200]). This trans-pressure difference may be responsible for optic nerve damage in normal-tensive glaucoma patients [201-202]. EPO may alter this trans-pressure by altering blood flow [203-204] and, in our model, it might indirectly raise CSF pressure resulting in a restored balance of pressure on the optic nerve and hence neuroprotection.

In summary, studies by our group and others have demonstrated that systemic therapy with EPO provides protection in various neurodegenerative models including photoreceptor degeneration [88,98], optic nerve crush [104], acrylamide induced neuropathy [199], chronic constriction injury model [205] and sciatic nerve transection [206]. Results of the current study have expanded these findings by establishing intramuscular delivery of rAAV2/5.CMV.EpoR76E as an improved therapy without large hemotopoietic side effects and with potential to treat glaucoma as well as a broad range of neurodegenerative diseases both in the peripheral nervous system and central nervous system. Since systemic EPO is already FDA approved and currently the choice protein therapy for anemic patients [207], EPO-R76E is a promising candidate to move quickly from bench to bedside. 


\section{CHAPTER 4. DISCUSSION}

\section{EPO-R76E Protects RGC Somata and Axons Independently}

Systemic gene delivery of EpoR76E protects RGCs in a spontaneous mouse model for glaucoma (Chapter 3) and an induced model of neurodegeneration (Chapter 2). Together these results demonstrate that EPO-R76E protects the RGC soma and its axon independently. In the DBA/2J mouse model of glaucoma, protection of the axon as well as its parent neuron is observed. The preservation of the RGC somata most likely occurs because severe axonal injury never takes place. Thus far, the initial site of injury in the DBA/2J mouse appears to occur first within the optic nerve and not the RGC somata [34]. Deterioration of the optic nerve deprives RGCs of nutrients and other factors leading to eventual apoptotic death. Evidence to support this hypothesis comes from experiments carried out in transgenic DBA/2J mouse that over-express the $\mathrm{Wld}^{\mathrm{s}}$ allele. The Wld ${ }^{\mathrm{s}}$ protein product protects axons from Wallerian degeneration induced by axonal trauma [208-209,137]. It is well established that the $\mathrm{Wld}^{\mathrm{s}}$ gene product selectively protects the axons and not the RGC somata [210-214]. DBA/2J mice that harbored this gene had average axon counts that matched young preglaucomatous mice. In cases where the axons were spared the RGC somata were as well. Further proof demonstrating that RGC somata death is secondary to axonal injury comes from DBA/2J: $\mathrm{Bax}^{-/ 2}$ mice. Bax or BCL2-associated X protein play a major role in neuronal apoptotic cell death [215-216]. Despite preservation of the RGC somata in glaucomatous DBA/2J:Bax ${ }^{-/}$ mice, severe axonal degeneration still occurs [25].

\section{Potential Mechanism of Neuroprotection}

Increased IOP is a major risk factor for glaucoma. However, the neuroprotective effects of EPO demonstrated in this study are independent of IOP. Despite extremely high IOP, RGCs are able to function normally. The mechanism of protection provided by EPO is not completely understood, but it could affect any of the following proposed underlying causes of RGC death in glaucoma: mechanical stress [217], glutamate excitotoxicity [218], ischemia [219-220], glial cell modulation [43,221].

\section{Mechanical injury}

In humans the lamina region near the optic nerve head is composed of bundles of axons that pass through pores in the lamina. Structural support is provided to the axon bundles as they pass through the lamina by extra cellular matrix plates. Compared to the surrounding tissue (sclera), this porous region of the optic nerve is much weaker. IOP must be in relative equilibrium with extra ocular pressure for the nerve head to maintain its position [148,222,202]. In glaucoma, when IOP is increased the optic nerve head begins to bow out (cup). The result is compression of the structural plates that contain the axon bundles. It is hypothesized that this compression causes physical damage to the 
axonal bundles resulting in RGC death [217]. This hypothesis is supported by the sectoral pattern of RGC death observed in glaucoma [223]. In addition, the increased IOP also causes mechanical damage to the axons by physically pressing them or pinching them at the optic nerve head. This pinching obstructs retrograde transport and anterograde transport [224-226,142].

Recent evidence suggests that the mechanism of RGC death in mice may differ somewhat from that in humans. DBA/2J mice lack the collagenous plates in the lamina, yet still develop glaucoma [34]. Therefore the mechanical damage caused by the laminar plates in humans does not appear to occur in mice. Similar to humans, axonal transport is blocked in DBA/2J mice as a result of increased IOP [155,227]. Based on the results in Chapter 3 and other studies described above [224-226,142,34,155,227], mechanical pinching of the nerves at the optic nerve head is a likely mechanism for RGC death in mice. The optic nerve crush technique attempts to mimic this mechanical injury to the optic nerve that occurs in glaucoma. In Chapter 2, protection of the axons by EPO was not observed following optic nerve crush. However, EPO protected the RGC somata and axons from glaucomatous injury the DBA/2J mouse model (Chapter 3). It should be noted that the amount of damage caused by the optic nerve crush procedure far greatly exceeds that which occurs in glaucoma, and this could also explain the lack of axonal protection in that model. However, there are also many additional theories on why increased IOP could cause RGC cell death and they are discussed below.

\section{Glutamate excitotoxicity}

Glutamate is a neurotransmitter found normally in the retina and optic nerve. Excitotoxicity is a process by that neuronal cells undergo cell death in response to higher than normal glutamate levels [228]. Specifically, a low but chronic dose of glutamate is able to cause RGC apoptosis [229]. Glutamate toxicity has been implicated in glaucoma and was once a very prominent theory [230]. However much of this data was based on work that has been difficult to replicate [231] and therefore this hypothesis has been somewhat abandoned. In vitro experiments demonstrate that EPO can prevent RGC death in the presence of excess glutamate [203]. However, the controversial results surrounding the glutamate hypothesis and the failure of memantine [232], a glutamate receptor analogue, to treat glaucoma in clinical trials, emphasis will be placed on other theories.

\section{Ischemia}

In a healthy eye, constant blood flow is required to meet the high metabolic needs of the retina and the optic nerve head. The choroid is responsible for $85 \%$ of the blood flow to the eye while the central retinal artery makes up the remainder [219]. It has been demonstrated in both animal models and clinical studies in humans that ischemia causes RGC death and optic nerve head atrophy [233-234]. Patients with glaucoma have reduced blood flow to the retina and optic nerve [219]. The reduction in flow can 
essentially starve the surrounding tissue from essential nutrients as well as create a high level of oxidative stress. In glaucoma increased IOP causes compression on the microvasculature of the retina therefore reducing the perfusion pressure [219-220].

The neuroprotection observed in this study could be a result of EPO's ability to affect blood flow. EPO has demonstrated tissue protective effects in stoke and cerebral ischemia models [235-236]. In addition, these results are also achieved by using nonhematopoietic forms of EPO [237], which could explain why EPO-R76E is neuroprotective in the current study. EPO could be improving blood flow by promoting the growth of new vessels. It has demonstrated angiogenic effects in a variety of different models [238-240].

There are a variety of techniques to measure blood flow in the eye. The Heidelberg Retina Flowmeter technique combines laser Doppler flowmetry with Confocal scanning laser tomography. This would allow visualization of the vasculature in the retina and optic nerve head as well as provide a way to measure quantify perfusion. If EPO is acting in an angiogenic fashion there could be a clear difference in the amount and size of vessels present in EPO treated mice vs. controls, therefore increasing blood flow.

Ischemic conditions can also lead to oxidative stress [220]. EPO may reduce tissue damage by decreasing oxidative stress. EPO has been reported to activate antioxidants such as glutathion peroxidase (GPx) [241]. Immunohistochemistry using an antibody to GPx could be used to examine changes in GPx levels at the optic nerve head. Additionally, changes in GPx activity could be measured in retinal and optic nerve lysate. It is possible that EPO also affects expression of other oxidative stress proteins known to be elevated during glaucoma. Oxidative stress leads to the upregulation of metalloproteinases (MMPs) in the eye [242]. In patients with glaucoma both MMP-2 and MMP-9 are upregulated in the optic nerve head. Immunohistochemistry could be used to compare the levels of MMP-2 and MMP-9 at the optic nerve head of DBA/2J mice. If EPO is acting as an antioxidant the level of these two proteins may be reduced in EPO treated mice.

Oxidative stress causes damage to proteins. When proteins are damaged they are marked by ubiquitn and sent to proteosomes for degradation. During oxidative stress the activity of proteosomes is increased and can therefore act as a marker. In glaucoma the $20 \mathrm{~S}$ proteosome alpha subunit is upregulated, adding further support to the hypothesis that oxidative stress plays a role [243]. Western blot analysis could be used on retinal lysates from glaucomatous DBA/2J mice to compare the levels of the $20 \mathrm{~S}$ alpha subunit. It would be expected if EPO were acting as an anti-oxidant, the level of $20 \mathrm{~S}$ alpha subunit could be indirectly decreased in treated mice. 


\section{Glial cell response}

Alteration in glial cell function is another hypothesis for the mechanism underlying axonal degeneration and cell death in glaucoma. When an injury occurs in the CNS, the neurons do not participate in the repair process, instead glial cells help limit the damage [43]. In response to injury "glial activation" occurs, causing a change in their cell morphology and protein expression. These changes can have both positive and negative effects on the injury site [244]. Glial cells are found in the retina as well as the optic nerve. Glaucoma likely affects the optic nerve first [217,34], therefore the remainder of the discussion will focus on glia in the optic nerve. Of the glial cells in the optic nerve three types are activated in glaucoma; astrocytes, microglia, and oligodendrocytes $[245,194,246]$. Of these three, astrocytes appear to be the most likely candidate for the following reasons: astrocyte reactivity occurs early in the disease process in at least two animal models of glaucoma, the DBA/2J mouse and a rat ocular hypertension model [194]; and oligodendrocytes and microglia are not affected until later in the disease process [194].

Under normal conditions astrocytes maintain the homeostasis of extracellular ions, glucose, water, $\mathrm{pH}$, and neurotransmitters such as glutamate [43,244,44]. In response to injury astrocytes proliferate and become reactive. Reactivity is characterized by hypertrophy, hyperplasia, and increased glial fibrillary acidic protein (GFAP) expression [196]. After the axons degenerate the debris is phagocytosed and replaced by a GFAP-positive astrocytic scar [247] that does not support axonal regrowth [248]. This process attempts to limit further damage. However, reactive astrocytes have also been thought to contribute to the pathogenesis in of many neurodegenerative diseases including glaucoma[249-250].

Increased IOP is a major risk factor in glaucoma and also causes astrocyte proliferation. In cell culture, hydrostatic pressure causes a five-fold increase in the number of astrocytes [43]. In vivo, artificially increasing the IOP in a mouse models, including the DBA/2J mouse, causes astrocytes to increase at the optic nerve head $[251,221]$. The proliferation and reactivity that occurs in response to increased IOP could contribute to the pathogenesis of glaucoma in several different ways. First, nitric oxide produced by astrocytes might be toxic to the axons. Increased IOP causes reactive astrocytes in the optic nerve head to produce nitric oxide synthase [197-198]. This enzyme produces large amounts of nitric oxide that can be toxic to the axons of RGCs [198]. EPO has been shown to prevent neuronal cell death in vitro caused by nitric oxide toxicity, therefore EPO could be acting in a similar fashion in vivo to limit RGC death during glaucoma. Increased levels of nitric oxide have been reported in both human glaucoma and rat models of glaucoma [198,252]. However, other studies in human glaucoma have not been able to confirm these results and nitric oxide inhibitors have been unable to provide neuroprotection [253-255]. Second, EPO may prevent astrocytes within the optic nerve from becoming hypertrophic and therefore limiting or preventing the glaucomatous damage that would normally ensue. Astrocytes express EPO receptor and therefore could interact directly with EPO. EPO is capable of acting as an antiinflammatory and does so in the CNS by reducing pro-inflammatory cytokines such as 
TNF- $\alpha$, IL-6, IL-1 $\beta$, and IL-1Ra [256-257]. In addition EPO has also reduced pathogenesis in other neurodegenerative disease by acting as an anti-inflammatory agent [256].

Aquaporin 4 (AQP4) is a water channel expressed by astrocytes that helps regulate water homeostasis [258]. During CNS injury astrocyte hypertrophy occurs via AQP4 [259-260]. In the absence of AQP4 these effects are reduced [259]. Several lines of evidence suggest that EPO could prevent astrocyte hypertrophy during glaucoma via AQP4. First, AQP4 is highly expressed at the optic nerve head and elevated IOP in rats causes increased expression of AQP4 [261]. Second, the neurotransmitter glutamate, which is increased during glaucoma [262], activates permeability of AQP4 through activation of group I metabotropic glutamate receptors (mGluRs) [260] and EPO is able to prevent this activation [263]. Third, activation of protein kinase $\mathrm{C}$ (PKC) rapidly decreases AQP4 permeability [264], eventually causing its internalization [265], and EPO activates PKC in tissue protective scenarios [266]. Fourth, AQP4 is upregulated in other edema related neurodegenerative diseases such as autoimmune encephalomyelitis(EAE) [267] where EPO has also decreased disease pathogenesis [256].

To investigate AQP4's role in glaucoma, experiments using AQP4 knockout mice should be carried out [268]. IOP could be artificially induced by injecting polystyrene beads into the anterior chamber of these mice [269]. IOP could be monitored noninvasively using rebound tonometry [270]. The level of damage between knockout mice and wild type mice could be examined both in the retina and the optic nerve using the same methods discussed in Chapter 3. Alternatively these experiments could also be examined in the context of the DBA/2J mouse; however, the experimental time line would be much longer.

In order to investigate the hypothesis that EPO protects RGCs by preventing astrocyte swelling via AQP4 several experiments should be carried out. In two rat models of induced IOP, AQP4 is upregulated at the optic nerve head [261]. Therefore, immunohistochemistry (antiAQP4) should be used to probe both retinal flatmounts and axonal cross sections of the optic nerves from 10 month old DBA/2J control mice and rAAV2/5.CMV.Epo treated mice. If EPO is involved, one would expect a downregulation of AQP4 in treated mice. This downregulation would most likely occur though EPO's activation of PKC which could be investigated by examining the phosphorlyation states of remaining AQP4. PKC phosphorlyates the Ser ${ }^{180}$ in AQP4 to decrease water permeability [265].

\section{Improving Gene Transfer through rAAV Capsid Mutations}

Gene therapy vectors are constantly evolving and rAAV vectors are no different. There are several steps including viral trafficking and second strand synthesis that can affect rAAV transduction efficiency [271-272]. Several technologies have improved efficiency as well as increased genome size. The genome capacity was increased by creating vectors that exploit trans-splicing [273] allowing therapeutic genes of up to $9 \mathrm{~kb}$ 
to be expressed [274]. Self-complementary vectors have been successful in bypassing the rate limiting aspects of second-strand synthesis [275]. Self-complementary AAV anneals to itself forming a transcriptionally competent double stranded DNA, however, this reduces genome size by $50 \%$.

The rAAV viral capsid is the main determinant of tropism and transduction efficiency therefore many labs have exploited either naturally occurring [276] or artificially modified [277] capsids. Epidermal growth factor receptor protein tyrosine kinase signaling negatively affects AAV vector transduction by phosphorylating tyrosine residues on the capsid therefore priming it for ubiquitination and proteasomal degradation [278-279]. Mutating these surface-exposed tyrosines lead to the creation of rAAV vectors that express over 8 fold higher in muscle tissue than controls [280-281]. Similar mutations could be introduced to the rAAV2/5.CMV.EpoR76E vectors to improve transduction efficiency. The benefits would be 2 -fold. First, the amount of vector needed to reach therapeutic levels would be decreased, therefore reducing the costs of vector production. Second and more importantly, reducing the amount of vector delivered would improve the safety profile.

\section{Establish a Therapeutic Dose Curve}

As a neuroprotectant, EPO functions in a bell shaped dose curve both in vitro (neurotrophic factor deprivation) and in vivo (optic nerve lesion) [86]. The results from Chapter 2 suggest that increasing the amount of systemic EpoR76E expression would provide a greater level of neuroprotection. Future experiments should establish a therapeutic dose curve that characterizes the minimal and maximal amount of EpoR76E expression required for neuroprotection.

Ideally these experiments should be carried out in a mouse model of glaucoma to increase the relevance. Using the DBA/2J spontaneous mouse model would be appropriate since protection has already been demonstrated within this study. However, alternative mouse models of glaucoma (both discussed below) would provide a much shorter experimental time line. The caveat being that protection with EPO has not been demonstrated in these models.

\section{Can EPO-R76E Protect against Glaucomatous Damage Later in the Disease Process?}

Chapter 3 firmly establishes that rAAV mediated gene therapy using EpoR76E preserves visual function in 10 month old DBA/2J mice. These mice begin to develop optic nerve damage beginning around 9 months which leads to apoptotic death of the RGC soma [22,28]. Glaucoma is a slow progressive neurodegenerative disease and continues to destroy RGCs, further impairing vision as the mice age. Treatment using rAAV2/5.CMV.EpoR76E should be tested at later time points (12-14 months) further in

the disease process. This would examine EPO-R76E's ability to sustain long term 
neuroprotection. Based on the results in Chapter 3, mice should be treated with the same dose of vector since complete rescue of visual function with minimal hematocrit increase was observed. Testing visual functional in these mice could be done using the F-VEP methods discussed in Chapter 3. Alternatively, pattern electroretinogram could also be used to test visual function. This technique has been used as a tool for detection and monitoring the onset and progression of RGC dysfunction in DBA/2J mice $[34,185,282$ 283]. Demonstrating long term neuroprotection throughout the entire disease process, in a slow progressive disease like glaucoma, with EPO-R76E would be a great step towards its clinical relevance.

\section{Further Reduction of EPO-R76E's Hematopoietic Properties}

Based on the results in this study the R76E mutation reduces the amount of hematopoietic activity but maintains a similar level of neuroprotective capability. The neuroprotective activity of EPO functions in a dose curve manner [86]. As indicated in the optic nerve crush portion of this study, the amount of EPO expressed in mice treated with the EpoR76E vector may be below the level needed for maximum protection. However, when rAAV2/5.CMV.EpoR76E is delivered at high doses it increases the hematocrit to unsafe levels. There are a variety of other EPO mutations, truncations, and analogs that achieve similar results [94-95,93,96-97]. The R76E mutation could also be combined with other known mutations to further decrease the remaining hematopoietic activity without decreasing the level of neuroprotection [93,284]. Potentially this mutant could be used at higher protein concentrations to investigate the maximal level of neuroprotection in the ONC model.

\section{Alternative Glaucoma Models}

\section{B10-Sh3pxd2b ${ }^{\text {nee }}$ hereditary mouse model of glaucoma}

Although the DBA2/J mouse is an excellent model for studying glaucomatous neurodegeneration, and the best characterized and most utilized model [22,28,34], a recently discovered strain, the $\mathrm{B} 10-\mathrm{Sh} 3 \mathrm{pxd} 2 \mathrm{~b}^{\text {nee }}$ mouse, offers some unique advantages [285]. First, the onset of disease is a great deal faster in the B10-Sh3pxd2 $b^{\text {nee }}$ mouse, occurring at 3-4 months vs. 10-12 months in the DBA/2J mouse. Therefore experimental time frames, equipment and reagent costs, and animal housing costs can all be reduced. Second, the large variability in penetrance and asymmetry of the disease progression in the DBA/2J mouse are not observed in the B10-Sh3pxd2 $b^{\text {nee }}$ mouse. This large amount of variability in the DBA/2J mouse model can lead to experimental challenges and often requires a larger amount of animals be tested [28]. Testing the neuroprotective effect of rAAV2/5.CMV.EpoR76E in this model would eliminate certain challenges, expedite histological and functional assessment times, and demonstrate protection in an additional mouse model of glaucoma. 
This model is not without its flaws as well. B10-Sh3pxd2 ${ }^{\text {nee }}$ mice also develop corneal opacity and cataracts, making non-invasive IOP measurements impossible and in vivo imaging difficult [285]. In addition, unlike the slow increase in IOP observed in the DBA/2J mouse, which more closely reflects that observed in patients, the B10$\mathrm{Sh} 3 \mathrm{pxd} 2 \mathrm{~b}^{\text {nee }}$ mouse develops a much higher IOP over a shorter period of time. This causes an aggressive glaucoma and testing the neuroprotective effects of EPO-R76E in this model would be very intriguing. If a significant amount of protection could be demonstrated in this type of environment, EPO-R76E would prove to be an extremely powerful neuroprotectant for the treatment of glaucoma.

\section{Induced glaucoma models}

A variety of methods exist to induce glaucoma in rodents. IOP can be artificially increased using traditional techniques such as photocoagulation of the trabecular meshwork [286], hyperosmotic saline microinjection into the episcleral veins (increases outflow resistance) [287-288], and cauterization of the episcleral veins [289-290]. These methods induce glaucoma but lack reproducible damage profiles and cause harm other cell types. Recently several groups have injected polystyrene beads into the anterior chamber mimicking pigment dispersion [269,291]. This technique yields a fairly consistent increase in IOP, does not cause harm to other retinal neurons, and lacks detrimental effects to the cornea and sclera [269]. However, in vivo imaging of the retina can be hindered due to the presence of the beads. By testing EPO-R76E in this induced model results from a variety of strains could be obtained within a few months.

\section{Alternative Methods to Detect RGCs}

A variety of useful techniques including, immunohistochemistry [155], retrograde labeling [292], reporter genes [293], and in situ hybridization [294] are available to label RGCs. Retrograde labeling is a well-established method and has been the gold standard in the field for quite some time. However, because this method labels RGCs via their axons it cannot be used when the optic nerve is compromised as in optic nerve crush, for example. The current study utilizes immunohistochemistry, using the antibody NeuN. NeuN is a monoclonal antibody that reacts with an uncharacterized neuron-specific nuclear protein. Despite reacting with a broad range of neurons, NeuN can be used to examine RGCs by imaging at the RGC layer within the retina. Imaging at this layer encompasses only displaced amacrine cells and RGCs. NeuN also labels a small amount the displaced amacrine cells (10-15\%) [155]. The small percentage of amacrine cells labeled, combined with the RGC specific death observed in glaucoma, makes NeuN an appropriate marker to use. However, there are alternative techniques that are reported to be more specific than NeuN and their use should be considered in future experiments [294].

In situ hybridization using Sncg (also known as Persyn) mRNA was shown to label the majority if not all of the RGCs in adult mice [294]. The mRNA is expressed 
highly and specifically in the RGCs of adult mice. It is found only in the ganglion cell layer (GCL) and a very small number of cells in the inner nuclear layer, consistent with the known small number of displaced RGCs in the mouse retina [295]. Experiments using probes for Sncg and the GABA synthetic enzyme glutamic acid decarboxylase (a gene expressed in a fraction of amacrine cells found in the GCL [296]), demonstrated that none of the GABA positive amacrine cells were Sncg positive. Furthermore the fraction of GCL cells expressing Sncg (45\%) also matches previous estimates of the number of RGCs found within the mouse GCL (41-44\%) [30].

\section{EPO's Role in Other Neurodegenerative Diseases}

In addition to glaucoma, EPO is therapeutic in models of other neurodegenerative diseases, and as in glaucoma, the exact mechanism of EPOs protective effects are unknown, but are most likely a combination of anti-inflammatory and anti-apoptotic processes. In a rat model of experimental autoimmune encephalomyelitis (EAE), EPO has a protective effect that is marked by a reduction in glial cell activation/proliferation and a decrease in inflammatory cytokines such as TNF and IL-6 [256]. EPO improves locomotor activities in a mouse model of Parkinson's disease by increasing nitric oxide levels and glutathione peroxidase activity in both the substantianigra and striatum [297,241]. Lastly, it delays symptom onset, prolong lifespan, and preserves motor neurons by attenuating inflammatory signals (COX-2, CD11b and PGE2) and enhancing survival signals (PI3-K and pAkt)in a mouse model of ALS [298]. Elucidation of EPO's mechanism or mechanisms of action in one disease will likely apply to other neurodegenerative diseases.

\section{Treatment of Alzheimer's with EPO-R76E}

EPO-R76E should be tested on other neurodegenerative diseases such as Alzheimer's. Neurodegenerative diseases including Alzheimer's, glaucoma, Parkinson's, and ALS often have many commonalities [299,138,300]. Neurodegenerative diseases often activate the same chemical pathways and share similar mechanisms of apoptotic cell death [300]. The results from this study and others [297,256,241,298] demonstrate EPO's neuroprotective ability in glaucoma, Parkinson's, ALS, and autoimmune encephalomyelitis. Despite the therapeutic effects EPO has in many other neurodegenerative diseases, very little work has been done to examine EPO's function in Alzheimer's disease.

Like glaucoma, Alzheimer's disease is a slow progressive neurodegenerative disease characterized by neurofibrillary tangles and abnormal accumulation of amyloid beta peptide in the hippocampus [301-302]. The hyperphosphorylation of tau disrupts its normal function in regulating axonal transport and leads to the accumulation of neurofibrillary tangles[303]. Recent data demonstrates EPO prevents tau hyperphosphorylation in SH-SY5Y cells exposed to the $\beta$-amyloid peptide[304]. In 
addition, pretreatment with EPO protected PC12 cells against amyloid-beta induced cell death [305].

rAAV.2/5.CMV.EpoR76E treatment should be examined in mouse models of Alzheimer's disease such as the B6;129-Psen $1 \mathrm{tm} 1 \mathrm{Mpm} \operatorname{Tg}(\mathrm{APPS} w e, t a u P 301 \mathrm{~L}) 1 \mathrm{Lfa} / \mathrm{J}$ strain [306]. These mice express both amyloid beta precursor protein and microtubuleassociated protein. They exhibit plaque and tangle pathology associated with synaptic dysfunction, similar to that observed in Alzheimer's disease patients. These mice should be treated with the vector around 1 month of age as amyloid beta peptide deposits are detected as early as three months[307]. A variety of different approaches could be used to examine EPO-R76Es therapeutic potential within this model such as immunohistochemistry examining hippocampal sections for amyloid beta deposits or western blot analysis to examine the level of tau phosphorylation in hippocampus lysate. Furthermore, tests such as the Barnes maze could be used to examine EPO-R76E's effect on memory in these mice [308].

\section{Summary}

Glaucoma is a complex disease that currently has no cure. The vision lost during the disease process cannot be recovered. All available treatment options function by lowering IOP. This study identifies EPO-R76E as a potential therapeutic candidate that acts independently of IOP. This novel mutant maintains the neuroprotective effects of EPO without stimulating erythropoiesis to the same extent. Using gene therapy to express EPO-R76E systemically bypasses the need for local delivery or repeated treatments, and provides long term protection. To the best of my knowledge this is the first example of a neuroprotective agent that preserves the full morphology and function of RGCs in glaucoma. In addition, EPO's broad neuroprotective effects suggest that these results could apply to other neurodegenerative diseases. 


\section{LIST OF REFERENCES}

1. Carden, S.M. Analysis of the national health and nutrition examination survey. Comment on "Prevalence of visual impairment in the United States." Surv Ophthalmol 51, 525-526 (2006).

2. Quigley, H.A., et al. The number of people with glaucoma worldwide in 2010 and 2020. Br J Ophthalmol 90, 262-267 (2006).

3. Hitchings, R.A. Glaucoma-fundamentals of clinical ophthalmology (BMJ Publishing Group, London 2000).

4. Quigley, H.A. Glaucoma: Macrocosm to microcosm the Friedenwald lecture. Invest Ophthalmol Vis Sci 46, 2662-2670 (2005).

5. Leske, M.C., et al. Risk factors for open-angle glaucoma. The Barbados eye study. Arch Ophthalmol 113, 918-924 (1995).

6. Weinreb, R.N., et al. Primary open-angle glaucoma. Lancet 363, 1711-1720 (2004).

7. Rotimi, C.N., et al. Genomewide scan and fine mapping of quantitative trait loci for intraocular pressure on $5 \mathrm{q}$ and $14 \mathrm{q}$ in West Africans. Invest Ophthalmol Vis Sci 47, 3262-3267 (2006).

8. Leske, M.C. The epidemiology of open-angle glaucoma: A review. Am J Epidemiol 118, 166-191 (1983).

9. Kass, M.A., et al. The ocular hypertension treatment study: A randomized trial determines that topical ocular hypotensive medication delays or prevents the onset of primary open-angle glaucoma. Arch Ophthalmol 120, 701-713; discussion 829830 (2002).

10. Netland, P.A., et al. Inheritance of glaucoma and genetic counseling of glaucoma patients. Int Ophthalmol Clin 33, 101-120 (1993).

11. Libby, R.T., et al. Complex genetics of glaucoma susceptibility. Annu Rev Genomics Hum Genet 6, 15-44 (2005).

12. Gould, D.B., et al. Anterior segment dysgenesis and the developmental glaucomas are complex traits. Hum Mol Genet 11, 1185-1193 (2002).

13. Grieshaber, M.C., et al. Clinical evaluation of the aqueous outflow system in primary open-angle glaucoma for canaloplasty. Invest Ophthalmol Vis Sci 51, 1498-1504 (2010). 
14. Seidel, E.U.D. Abfluss des kammerwassers aus der vorderen augenkammer. Graefes Arch Ophthalmologhy 102, 357-402 (1921).

15. Goel, M., et al. Aqueous humor dynamics: A review. Open Ophthalmol J 4, 5259 (2010).

16. Sheilds, M. Sheilds' textbook of glaucoma (Lippincott Williams and Wilkins publishers, New York, 2005).

17. Collaborative Normal-Tension Glaucoma Study Group. Comparison of glaucomatous progression between untreated patients with normal-tension glaucoma and patients with therapeutically reduced intraocular pressures. Am J Ophthalmol 126, 487-497 (1998).

18. AGIS, I. The advanced glaucoma intervention study (AGIS): 11. Risk factors for failure of trabeculectomy and argon laser trabeculoplasty. Am J Ophthalmol 134, 481-498 (2002).

19. Duvdevani R, Rosner M., Belkin M. Graded crush of the rat optic nerve as a brain injury model: Combining electrophysiological and behavioral outcome. $J$ Neuroscience Methods 2, 31-38 (1990).

20. Li, Y., et al. Experimental induction of retinal ganglion cell death in adult mice. Invest Ophthalmol Vis Sci 40, 1004-1008 (1999).

21. Li, Y., et al. Dominant inheritance of retinal ganglion cell resistance to optic nerve crush in mice. BMC Neurosci 8, 19 (2007).

22. John, S.W., et al. Essential iris atrophy, pigment dispersion, and glaucoma in DBA/2J mice. Invest Ophthalmol Vis Sci 39, 951-962 (1998).

23. Anderson, M.G., et al. Mutations in genes encoding melanosomal proteins cause pigmentary glaucoma in DBA/2J mice. Nat Genet 30, 81-85 (2002).

24. Zhou, X., et al. Involvement of inflammation, degradation, and apoptosis in a mouse model of glaucoma. J Biol Chem 280, 31240-31248 (2005).

25. Libby, R.T., et al. Susceptibility to neurodegeneration in a glaucoma is modified by BAX gene dosage. PLoS Genet 1, 17-26 (2005).

26. Schlamp, C.L., et al. Progressive ganglion cell loss and optic nerve degeneration in DBA/2J mice is variable and asymmetric. BMC Neurosci 7, 66 (2006).

27. Thanos, S., et al. Correlation between retinal ganglion cell death and chronically developing inherited glaucoma in a new rat mutant. Exp Eye Res 79, 119-129 (2004). 
28. Libby, R.T., et al. Inherited glaucoma in DBA/2J mice: Pertinent disease features for studying the neurodegeneration. Vis Neurosci 22, 637-648 (2005).

29. Carter-Dawson, L.D., et al. Rods and cones in the mouse retina. I. Structural analysis using light and electron microscopy. J Comp Neurol 188, 245-262 (1979).

30. Jeon, C.J., et al. The major cell populations of the mouse retina. $J$ Neurosci $\mathbf{1 8}$, 8936-8946 (1998).

31. Prusky, G.T., et al. Rapid quantification of adult and developing mouse spatial vision using a virtual optomotor system. Invest Ophthalmol Vis Sci 45, 4611-4616 (2004).

32. Rowe, M.H., et al. Functional morphology of beta cells in the area centralis of the cat's retina: A model for the evolution of central retinal specializations. Brain Behav Evol 21, 1-23 (1982).

33. May, C.A., et al. Morphology of the murine optic nerve. Invest Ophthalmol Vis Sci 43, 2206-2212 (2002).

34. Howell, G.R., et al. Axons of retinal ganglion cells are insulted in the optic nerve early in DBA/2J glaucoma. J Cell Biol 179, 1523-1537 (2007).

35. Remtulla, S., et al. A schematic eye for the mouse, and comparisons with the rat. Vision Res 25, 21-31 (1985).

36. Volgyi, B., et al. Tracer coupling patterns of the ganglion cell subtypes in the mouse retina. J Comp Neurol 512, 664-687 (2009).

37. Coombs, J., et al. Morphological properties of mouse retinal ganglion cells. Neuroscience 140, 123-136 (2006).

38. Williams, R.W., et al. Three-dimensional counting: An accurate and direct method to estimate numbers of cells in sectioned material. J Comp Neurol 278, 344-352 (1988).

39. Ahmad, A., et al. Effects of aging on the size, density, and number of rhesus monkey lateral geniculate neurons. J Comp Neurol 334, 631-643 (1993).

40. Honjin, R., et al. Electron microscopy of the mouse optic nerve: A quantitative study of the total optic nerve fibers. Arch Histol Jpn 40, 321-332 (1977).

41. Wong, S.L., et al. Comparative ultrastructural study of the optic nerves and visual cortices of young (2.5 months) and old (17 months) mice. Acta Anat (Basel) 105, 426-430 (1979). 
42. Lawson, L.J., et al. Quantification of the mononuclear phagocyte response to Wallerian degeneration of the optic nerve. J Neurocytol 23, 729-744 (1994).

43. Hernandez, M.R. The optic nerve head in glaucoma: Role of astrocytes in tissue remodeling. Prog Retin Eye Res 19, 297-321 (2000).

44. Sofroniew, M.V., et al. Astrocytes: Biology and pathology. Acta Neuropathol 119, 7-35 (2010).

45. Antonini, A., et al. Anatomical correlates of functional plasticity in mouse visual cortex. J Neurosci 19, 4388-4406 (1999).

46. Drager, U.C. Autoradiography of tritiated proline and fucose transported transneuronally from the eye to the visual cortex in pigmented and albino mice. Brain Res 82, 284-292 (1974).

47. Provencio, I., et al. Melanopsin: An opsin in melanophores, brain, and eye. Proc Natl Acad Sci U S A 95, 340-345 (1998).

48. Drager, U.C., et al. Physiology of visual cells in mouse superior colliculus and correlation with somatosensory and auditory input. Nature 253, 203-204 (1975).

49. Barkana, Y., et al. Neuroprotection in ophthalmology: A review. Brain Res Bull 62, 447-453 (2004).

50. Zhong, L., et al. Erythropoietin promotes survival of retinal ganglion cells in DBA/2J glaucoma mice. Invest Ophthalmol Vis Sci 48, 1212-1218 (2007).

51. Jelkmann, W. Erythropoietin after a century of research: Younger than ever. Eur J Haematol 78, 183-205 (2007).

52. Semenza, G.L., et al. Hypoxia-inducible nuclear factors bind to an enhancer element located 3' to the human erythropoietin gene. Proc Natl Acad Sci U S A 88, 5680-5684 (1991).

53. Jelkmann, W., et al. Biology of erythropoietin. Adv Exp Med Biol 502, 169-187 (2001).

54. Jelkmann, W. Biology of erythropoietin. Clin Investig 72, S3-10 (1994).

55. Fandrey, J., et al. In vivo and in vitro regulation of erythropoietin mRNA: Measurement by competitive polymerase chain reaction. Blood 81, 617-623 (1993).

56. Marti, H.H., et al. Erythropoietin gene expression in human, monkey and murine brain. Eur J Neurosci 8, 666-676 (1996). 
57. Juul, S.E., et al. Tissue distribution of erythropoietin and erythropoietin receptor in the developing human fetus. Early Hum Dev 52, 235-249 (1998).

58. Masuda, S., et al. The oviduct produces erythropoietin in an estrogen- and oxygen-dependent manner. Am J Physiol Endocrinol Metab 278, E1038-1044 (2000).

59. Konishi, Y., et al. Trophic effect of erythropoietin and other hematopoietic factors on central cholinergic neurons in vitro and in vivo. Brain Res 609, 29-35 (1993).

60. Masuda, S., et al. Functional erythropoietin receptor of the cells with neural characteristics. Comparison with receptor properties of erythroid cells. J Biol Chem 268, 11208-11216 (1993).

61. Sakanaka, M., et al. In vivo evidence that erythropoietin protects neurons from ischemic damage. Proc Natl Acad Sci U S A 95, 4635-4640 (1998).

62. Grimm, C., et al. HIF-1-induced erythropoietin in the hypoxic retina protects against light-induced retinal degeneration. Nat Med 8, 718-724 (2002).

63. Grimm, C., et al. Constitutive overexpression of human erythropoietin protects the mouse retina against induced but not inherited retinal degeneration. $J$ Neurosci 24, 5651-5658 (2004).

64. van der Kooij, M.A., et al. Neuroprotective properties and mechanisms of erythropoietin in in vitro and in vivo experimental models for hypoxia/ischemia. Brain Res Rev 59, 22-33 (2008).

65. Brines, M., et al. Erythropoietin mediates tissue protection through an erythropoietin and common beta-subunit heteroreceptor. Proc Natl Acad Sci US A 101, 14907-14912 (2004).

66. Brines, M., et al. Erythropoietin-mediated tissue protection: Reducing collateral damage from the primary injury response. J Intern Med 264, 405-432 (2008).

67. Rabie, T., et al. Brain protection by erythropoietin: A manifold task. Physiology (Bethesda) 23, 263-274 (2008).

68. Kawakami, M., et al. Erythropoietin receptor-mediated inhibition of exocytotic glutamate release confers neuroprotection during chemical ischemia. $J$ Biol Chem 276, 39469-39475 (2001).

69. Siren, A.L., et al. Erythropoietin and erythropoietin receptor in human ischemic/hypoxic brain. Acta Neuropathol 101, 271-276 (2001).

70. Digicaylioglu, M., et al. Acute neuroprotective synergy of erythropoietin and insulin-like growth factor 1. Proc Natl Acad Sci U S A 101, 9855-9860 (2004). 
71. Sharples, E.J., et al. Erythropoietin protects the kidney against the injury and dysfunction caused by ischemia-reperfusion. J Am Soc Nephrol 15, 2115-2124 (2004).

72. Parsa, C.J., et al. A novel protective effect of erythropoietin in the infarcted heart. J Clin Invest 112, 999-1007 (2003).

73. Um, M., et al. Antiapoptotic effects of erythropoietin in differentiated neuroblastoma SH-SY5Y cells require activation of both the STAT5 and AKT signaling pathways. J Biol Chem 281, 5648-5656 (2006).

74. NIH. Clinical trials Http://clinicaltrials.Gov/ct2/home. (accessed February 25, 2011).

75. Munch, G., et al. Alzheimer's disease--synergistic effects of glucose deficit, oxidative stress and advanced glycation endproducts. J Neural Transm 105, 439461 (1998).

76. Yamagishi, S., et al. Role of advanced glycation end products (ages) and oxidative stress in diabetic retinopathy. Curr Pharm Des 14, 962-968 (2008).

77. Zhang, J., et al. Intravitreal injection of erythropoietin protects both retinal vascular and neuronal cells in early diabetes. Invest Ophthalmol Vis Sci 49, 732742 (2008).

78. Shen, J., et al. Erk- and akt-dependent neuroprotection by erythropoietin (EPO) against glyoxal-AGEs via modulation of BCL-xL, BAX, and BAD. Invest Ophthalmol Vis Sci 51, 35-46 (2010).

79. Zhang, F., et al. Erythropoietin protects ca1 neurons against global cerebral ischemia in rat: Potential signaling mechanisms. J Neurosci Res 83, 1241-1251 (2006).

80. Siren, A.L., et al. Erythropoietin prevents neuronal apoptosis after cerebral ischemia and metabolic stress. Proc Natl Acad Sci U S A 98, 4044-4049 (2001).

81. Bien, A., et al. Apoptotic versus necrotic characteristics of retinal ganglion cell death after partial optic nerve injury. J Neurotrauma 16, 153-163 (1999).

82. Kermer, P., et al. Inhibition of CPP32-like proteases rescues axotomized retinal ganglion cells from secondary cell death in vivo. J Neurosci 18, 4656-4662 (1998).

83. Kermer, P., et al. Caspase-9: Involvement in secondary death of axotomized rat retinal ganglion cells in vivo. Brain Res Mol Brain Res 85, 144-150 (2000). 
84. Klocker, N., et al. Brain-derived neurotrophic factor-mediated neuroprotection of adult rat retinal ganglion cells in vivo does not exclusively depend on phosphatidyl-inositol-3'-kinase/protein kinase b signaling. J Neurosci 20, 6962$6967(2000)$.

85. Kilic, U., et al. Erythropoietin protects from axotomy-induced degeneration of retinal ganglion cells by activating ERK-1/-2. FASEB J 19, 249-251 (2005).

86. Weishaupt, J.H., et al. Effect of erythropoietin axotomy-induced apoptosis in rat retinal ganglion cells. Invest Ophthalmol Vis Sci 45, 1514-1522 (2004).

87. Rex, T.S., et al. Neuroprotection of photoreceptors by direct delivery of erythropoietin to the retina of the retinal degeneration slow mouse. Exp Eye Res 89, 735-740 (2009).

88. Rex, T.S., et al. Systemic but not intraocular EPO gene transfer protects the retina from light-and genetic-induced degeneration. Mol Ther 10, 855-861 (2004).

89. $\mathrm{Fu}, \mathrm{Q} . \mathrm{L}$. , et al. Up-regulated endogenous erythropoietin/erythropoietin receptor system and exogenous erythropoietin rescue retinal ganglion cells after chronic ocular hypertension. Cell Mol Neurobiol 28, 317-329 (2008).

90. Tsai, J.C., et al. Intravitreal administration of erythropoietin and preservation of retinal ganglion cells in an experimental rat model of glaucoma. Curr Eye Res 30, 1025-1031 (2005).

91. Fisher, J.W. Erythropoietin: Physiology and pharmacology update. Exp Biol Med (Maywood) 228, 1-14 (2003).

92. Bennett, C.L., et al. Venous thromboembolism and mortality associated with recombinant erythropoietin and darbepoetin administration for the treatment of cancer-associated anemia. JAMA 299, 914-924 (2008).

93. Leist, M., et al. Derivatives of erythropoietin that are tissue protective but not erythropoietic. Science 305, 239-242 (2004).

94. Campana, W.M., et al. Identification of a neurotrophic sequence in erythropoietin. Int J Mol Med 1, 235-241 (1998).

95. Egrie, J.C., et al. Darbepoetin alfa has a longer circulating half-life and greater in vivo potency than recombinant human erythropoietin. Exp Hematol 31, 290-299 (2003).

96. Arcasoy, M.O. The non-haematopoietic biological effects of erythropoietin. $B r J$ Haematol 141, 14-31 (2008). 
97. Brines, M., et al. Nonerythropoietic, tissue-protective peptides derived from the tertiary structure of erythropoietin. Proc Natl Acad Sci U S A 105, 10925-10930 (2008).

98. Sullivan, T., et al. Systemic gene delivery protects the photoreceptors in the retinal degeneration slow mouse. Neurochem Res 36, 613-618 (2011).

99. Grodberg, J., et al. Functional and structural role of arginine 103 in human erythropoietin. Arch Biochem Biophys 333, 427-431 (1996).

100. Wen, D., et al. Erythropoietin structure-function relationships: High degree of sequence homology among mammals. Blood 82, 1507-1516 (1993).

101. Zanjani, E.D., et al. The renal erythropoietic factor (REF). X. The question of species and class specificity. Proc Soc Exp Biol Med 131, 1095-1098 (1969).

102. Jelkmann, W. Erythropoietin: Structure, control of production, and function. Physiol Rev 72, 449-489 (1992).

103. Wen, D., et al. Erythropoietin structure-function relationships. Identification of functionally important domains. J Biol Chem 269, 22839-22846 (1994).

104. Wang, H., et al. Neuroprotective effect of recombinant human erythropoietin on optic nerve injury in rats. Chin Med J (Engl) 122, 2008-2012 (2009).

105. Brines, M.L., et al. Erythropoietin crosses the blood-brain barrier to protect against experimental brain injury. Proc Natl Acad Sci U S A 97, 10526-10531 (2000).

106. Ehrenreich, H., et al. Erythropoietin: A candidate compound for neuroprotection in schizophrenia. Mol Psychiatry 9, $42-54$ (2004).

107. Khalil Ghasemi Falavarjani, M.M. Erythropoietin: a novel neuroprotective agent for ocular disorders. JOVR 6, 75-77 (2011).

108. Veng-Pedersen, P., et al. Kinetic evaluation of nonlinear drug elimination by a disposition decomposition analysis. Application to the analysis of the nonlinear elimination kinetics of erythropoietin in adult humans. J Pharm Sci 84, 760-767 (1995).

109. Osborne, W.R., et al. Gene therapy for long-term expression of erythropoietin in rats. Proc Natl Acad Sci US A 92, 8055-8058 (1995).

110. Laughlin, C.A., et al. Latent infection of kb cells with adeno-associated virus type 2. J Virol 60, 515-524 (1986).

111. Srivastava, A., et al. Nucleotide sequence and organization of the adenoassociated virus 2 genome. J Virol 45, 555-564 (1983). 
112. During, M.J., et al. In vivo expression of therapeutic human genes for dopamine production in the caudates of MPTP-treated monkeys using an AAV vector. Gene Ther 5, 820-827 (1998).

113. Song, S., et al. Sustained secretion of human alpha-1-antitrypsin from murine muscle transduced with adeno-associated virus vectors. Proc Natl Acad Sci U S A 95, 14384-14388 (1998).

114. Acland, G.M., et al. Gene therapy restores vision in a canine model of childhood blindness. Nat Genet 28, 92-95 (2001).

115. Lewis, P.F., et al. Passage through mitosis is required for oncoretroviruses but not for the human immunodeficiency virus. J Virol 68, 510-516 (1994).

116. Berns, K.I., et al. The cryptic life style of adeno-associated virus. Bioessays 17, 237-245 (1995).

117. Choi, V.W., et al. AAV hybrid serotypes: Improved vectors for gene delivery. Curr Gene Ther 5, 299-310 (2005).

118. Burger, C., et al. Recombinant AAV viral vectors pseudotyped with viral capsids from serotypes 1,2, and 5 display differential efficiency and cell tropism after delivery to different regions of the central nervous system. Mol Ther 10, 302-317 (2004).

119. Broekman, M.L., et al. Adeno-associated virus vectors serotyped with AAV8 capsid are more efficient than AAV-1 or -2 serotypes for widespread gene delivery to the neonatal mouse brain. Neuroscience 138, 501-510 (2006).

120. Taymans, J.M., et al. Comparative analysis of adeno-associated viral vector serotypes 1, 2, 5, 7, and 8 in mouse brain. Hum Gene Ther 18, 195-206 (2007).

121. Louboutin, J.P., et al. Gene transfer into skeletal muscle using novel AAV serotypes. J Gene Med 7, 442-451 (2005).

122. Bohenzky, R.A., et al. Sequence and symmetry requirements within the internal palindromic sequences of the adeno-associated virus terminal repeat. Virology 166, 316-327 (1988).

123. Weitzman, M.D., et al. Adeno-associated virus (AAV) rep proteins mediate complex formation between AAV DNA and its integration site in human DNA. Proc Natl Acad Sci U S A 91, 5808-5812 (1994).

124. Wang, X.S., et al. Rescue and replication signals of the adeno-associated virus 2 genome. J Mol Biol 250, 573-580 (1995).

125. Berkelaar, M., et al. Axotomy results in delayed death and apoptosis of retinal ganglion cells in adult rats. J Neurosci 14, 4368-4374 (1994). 
126. Thompson, C.B. Apoptosis in the pathogenesis and treatment of disease. Science 267, 1456-1462 (1995).

127. Savill, J., et al. Corpse clearance defines the meaning of cell death. Nature 407, 784-788 (2000).

128. Locksley, R.M., et al. The TNF and TNF receptor superfamilies: Integrating mammalian biology. Cell 104, 487-501 (2001).

129. Cory, S., et al. The bcl2 family: Regulators of the cellular life-or-death switch. Nat Rev Cancer 2, 647-656 (2002).

130. Majno, G., et al. Apoptosis, oncosis, and necrosis. An overview of cell death. Am J Pathol 146, 3-15 (1995).

131. Waller, A. Experiments on the section of glossopharyngeal and hypoglossal nerves of the frog and observations of the alternatives produced thereby in the structure of their primitive fibers. Philos Trans $R$ Soc Lond B Biol Sci 140 (1850).

132. George, E.B., et al. Axotomy-induced axonal degeneration is mediated by calcium influx through ion-specific channels. J Neurosci 15, 6445-6452 (1995).

133. Finn, J.T., et al. Evidence that Wallerian degeneration and localized axon degeneration induced by local neurotrophin deprivation do not involve caspases. $J$ Neurosci 20, 1333-1341 (2000).

134. Chaudhary, P., et al. Caspase inhibitors block the retinal ganglion cell death following optic nerve transection. Brain Res Mol Brain Res 67, 36-45 (1999).

135. Barron, K.D., et al. Qualitative and quantitative ultrastructural observations on retinal ganglion cell layer of rat after intraorbital optic nerve crush. J Neurocytol 15, 345-362 (1986).

136. Cenni, M.C., et al. Long-term survival of retinal ganglion cells following optic nerve section in adult bcl-2 transgenic mice. Eur J Neurosci 8, 1735-1745 (1996).

137. Perry, V.H., et al. Very slow retrograde and Wallerian degeneration in the CNS of C57Bl/Ola mice. Eur J Neurosci 3, 102-105 (1991).

138. Quigley, H.A., et al. Retinal ganglion cell death in experimental glaucoma and after axotomy occurs by apoptosis. Invest Ophthalmol Vis Sci 36, 774-786 (1995).

139. Schuettauf, F., et al. Retinal neurodegeneration in the DBA/2J mouse--a model for ocular hypertension. Acta Neuropathol 107, 352-358 (2004).

140. Garcia-Valenzuela, E., et al. Programmed cell death of retinal ganglion cells during experimental glaucoma. Exp Eye Res 61, 33-44 (1995). 
141. Reichstein, D., et al. Apoptotic retinal ganglion cell death in the DBA/2 mouse model of glaucoma. Exp Eye Res 84, 13-21 (2007).

142. Quigley, H.A. Neuronal death in glaucoma. Prog Retin Eye Res 18, 39-57 (1999).

143. Levkovitch-Verbin, H. Animal models of optic nerve diseases. Eye (Lond) 18, 1066-1074 (2004).

144. Isenmann, S., et al. Up-regulation of BAX protein in degenerating retinal ganglion cells precedes apoptotic cell death after optic nerve lesion in the rat. Eur J Neurosci 9, 1763-1772 (1997).

145. Li, Y., et al. BAX-dependent and independent pathways of retinal ganglion cell death induced by different damaging stimuli. Exp Eye Res 71, 209-213 (2000).

146. Zalewska, R., et al. The expressions of fas and caspase-3 in human glaucomatous optic nerve axons. Med Sci Monit 14, BR274-278 (2008).

147. Quigley, H.A., et al. Regional differences in the structure of the lamina cribrosa and their relation to glaucomatous optic nerve damage. Arch Ophthalmol 99, 137143 (1981).

148. Quigley, H.A., et al. Optic nerve damage in human glaucoma. II. The site of injury and susceptibility to damage. Arch Ophthalmol 99, 635-649 (1981).

149. Levkovitch-Verbin, H., et al. Rgc death in mice after optic nerve crush injury: Oxidative stress and neuroprotection. Invest Ophthalmol Vis Sci 41, 4169-4174 (2000).

150. Celik, M., et al. Erythropoietin prevents motor neuron apoptosis and neurologic disability in experimental spinal cord ischemic injury. Proc Natl Acad Sci US A 99, 2258-2263 (2002).

151. Kretz, A., et al. Erythropoietin promotes regeneration of adult CNS neurons via JAK2/STAT3 andPI3K/AKT pathway activation. Mol Cell Neurosci 29, 569-579 (2005).

152. Rivera, V.M., et al. Long-term pharmacologically regulated expression of erythropoietin in primates following AAV-mediated gene transfer. Blood 105, 1424-1430 (2005).

153. Canola, K., et al. Retinal stem cells transplanted into models of late stages of retinitis pigmentosa preferentially adopt a glial or a retinal ganglion cell fate. Invest Ophthalmol Vis Sci 48, 446-454 (2007).

154. Dijk, F., et al. Gap-43 expression is upregulated in retinal ganglion cells after ischemia/reperfusion-induced damage. Exp Eye Res 84, 858-867 (2007). 
155. Buckingham, B.P., et al. Progressive ganglion cell degeneration precedes neuronal loss in a mouse model of glaucoma. J Neurosci 28, 2735-2744 (2008).

156. Raff, M.C., et al. Axonal self-destruction and neurodegeneration. Science 296, 868-871 (2002).

157. Ehlers, M.D. Deconstructing the axon: Wallerian degeneration and the ubiquitinproteasome system. Trends Neurosci 27, 3-6 (2004).

158. Beirowski, B., et al. The WldS gene delays axonal but not somatic degeneration in a rat glaucoma model. Eur J Neurosci 28, 1166-1179 (2008).

159. Kielczewski, J.L., et al. The effect of experimental glaucoma and optic nerve transection on amacrine cells in the rat retina. Invest Ophthalmol Vis Sci 46, 31883196 (2005).

160. Junk, A.K., et al. Erythropoietin administration protects retinal neurons from acute ischemia-reperfusion injury. Proc Natl Acad Sci U S A 99, 10659-10664 (2002).

161. Kerrigan, L.A., et al. Tunel-positive ganglion cells in human primary open-angle glaucoma. Arch Ophthalmol 115, 1031-1035 (1997).

162. McKinnon, S.J., et al. Baculoviral iap repeat-containing-4 protects optic nerve axons in a rat glaucoma model. Mol Ther 5, 780-787 (2002).

163. Wang, A.L., et al. Degeneration of neuronal cell bodies following axonal injury in Wld(s) mice. J Neurosci Res 84, 1799-1807 (2006).

164. King, C.E., et al. Erythropoietin is both neuroprotective and neuroregenerative following optic nerve transection. Exp Neurol 205, 48-55 (2007).

165. Banks, W.A., et al. Passage of erythropoietic agents across the blood-brain barrier: A comparison of human and murine erythropoietin and the analog darbepoetin alfa. Eur J Pharmacol 505, 93-101 (2004).

166. Steuer, H., et al. Functional characterization and comparison of the outer bloodretina barrier and the blood-brain barrier. Invest Ophthalmol Vis Sci 46, 10471053 (2005).

167. Xenocostas, A., et al. The pharmacokinetics of erythropoietin in the cerebrospinal fluid after intravenous administration of recombinant human erythropoietin. Eur $J$ Clin Pharmacol 61, 189-195 (2005).

168. Hedrich, H., ed. The laboratory mouse (Elsevier, San Diego, California 2004). 
169. Schuler, B., et al. Optimal hematocrit for maximal exercise performance in acute and chronic erythropoietin-treated mice. Proc Natl Acad Sci U S A 107, 419-423 (2010).

170. Shibata, J., et al. Hemostasis and coagulation at a hematocrit level of 0.85: Functional consequences of erythrocytosis. Blood 101, 4416-4422 (2003).

171. Wagner, K.F., et al. Chronic inborn erythrocytosis leads to cardiac dysfunction and premature death in mice overexpressing erythropoietin. Blood 97, 536-542 (2001).

172. Johansson, P.L., et al. An elevated venous haemoglobin concentration cannot be used as a surrogate marker for absolute erythrocytosis: A study of patients with polycythaemia vera and apparent polycythaemia. Br J Haematol 129, 701-705 (2005).

173. Wiedemann, H.P., et al. Cor pulmonale in chronic obstructive pulmonary disease. Circulatory pathophysiology and management. Clin Chest Med 11, 523-545 (1990).

174. Vasudevan, S.K., et al. Neuroprotection in glaucoma. Indian J Ophthalmol 59, S102-113 (2011).

175. Sullivan, T., et al. Systemic gene delivery protects the photoreceptors in the retinal degeneration slow mouse. Neurochem Res 36, 613-618 (2011).

176. Wang, W.H., et al. Noninvasive measurement of rodent intraocular pressure with a rebound tonometer. Invest Ophthalmol Vis Sci 46, 4617-4621 (2005).

177. Filippopoulos, T., et al. Predictability and limitations of non-invasive murine tonometry: Comparison of two devices. Exp Eye Res 83, 194-201 (2006).

178. Savinova, O.V., et al. Intraocular pressure in genetically distinct mice: An update and strain survey. BMC Genet 2, 12 (2001).

179. Pease, M.E., et al. Calibration of the tonolab tonometer in mice with spontaneous or experimental glaucoma. Invest Ophthalmol Vis Sci 52, 858-64 (2011).

180. Holder, G.E. Electrophysiological assessment of optic nerve disease. Eye (Lond) 18, 1133-1143 (2004).

181. Heiduschka, P., et al. Loss of retinal function in aged DBA/2J mice--new insights into retinal neurodegeneration. Exp Eye Res 91, 779-783 (2011).

182. Sabel, B.A., et al. Functional recovery and morphological changes after injury to the optic nerve. Neuropsychobiology 28, 62-65 (1993). 
183. Heiduschka, P., et al. Recovery of visual evoked potentials after regeneration of cut retinal ganglion cell axons within the ascending visual pathway in adult rats. Restor Neurol Neurosci 23, 303-312 (2005).

184. Coleman, M.P., et al. Axon pathology in neurological disease: A neglected therapeutic target. Trends Neurosci 25, 532-537 (2002).

185. Nagaraju, M., et al. Iop-dependent retinal ganglion cell dysfunction in glaucomatous DBA/2J mice. Invest Ophthalmol Vis Sci 48, 4573-4579 (2007).

186. Baltmr, A., et al. Neuroprotection in glaucoma--is there a future role? Exp Eye Res 91, 554-566 (2010).

187. Qu, J., et al. Mechanisms of retinal ganglion cell injury and defense in glaucoma. Exp Eye Res 91, 48-53 (2010).

188. Scheerer, N., et al. The anemia of the newborn induces erythropoietin expression in the developing mouse retina. Am J Physiol Regul Integr Comp Physiol 299, R111-118 (2011).

189. Shah, S.S., et al. Erythropoetin receptor expression in the human diabetic retina. BMC Res Notes 2, 234 (2009).

190. Ruscher, K., et al. Erythropoietin is a paracrine mediator of ischemic tolerance in the brain: Evidence from an in vitro model. J Neurosci 22, 10291-10301 (2002).

191. Digicaylioglu, M., et al. Erythropoietin-mediated neuroprotection involves crosstalk between JAK2 and NF-KappaB signalling cascades. Nature 412, 641-647 (2001).

192. Yamamoto, M., et al. Effect of erythropoietin on nitric oxide production in the rat hippocampus using in vivo brain microdialysis. Neuroscience 128, 163-168 (2004).

193. Inman, D.M., et al. Reactive nonproliferative gliosis predominates in a chronic mouse model of glaucoma. Glia 55, 942-953 (2007).

194. Son, J.L., et al. Glaucomatous optic nerve injury involves early astrocyte reactivity and late oligodendrocyte loss. Glia 58, 780-789 (2011).

195. Hernandez, M.R., et al. Astrocytes in glaucomatous optic neuropathy. Prog Brain Res 173, 353-373 (2008).

196. Gunnarson, E., et al. Erythropoietin modulation of astrocyte water permeability as a component of neuroprotection. Proc Natl Acad Sci U S A 106, 1602-1607 (2009). 
197. Neufeld, A.H., et al. Nitric oxide synthase in the human glaucomatous optic nerve head. Arch Ophthalmol 115, 497-503 (1997).

198. Neufeld, A.H., et al. Inhibition of nitric-oxide synthase 2 by aminoguanidine provides neuroprotection of retinal ganglion cells in a rat model of chronic glaucoma. Proc Natl Acad Sci U S A 96, 9944-9948 (1999).

199. Keswani, S.C., et al. A novel endogenous erythropoietin mediated pathway prevents axonal degeneration. Ann Neurol 56, 815-826 (2004).

200. Berdahl, J.P., et al. Cerebrospinal fluid pressure is decreased in primary openangle glaucoma. Ophthalmology 115, 763-768 (2008).

201. Yang, Y., et al. Role of cerebrospinal fluid in glaucoma: Pressure and beyond. Med Hypotheses 74, 31-34.

202. Berdahl, J.P., et al. Cerebrospinal fluid pressure and glaucomatous optic disc cupping. Graefes Arch Clin Exp Ophthalmol 247, 1289-1290 (2009).

203. Yamasaki, M., et al. Neuroprotective effects of erythropoietin on glutamate and nitric oxide toxicity in primary cultured retinal ganglion cells. Brain Res $\mathbf{1 0 5 0}$, $15-26$ (2005).

204. Lin, X., et al. Sustained-release erythropoietin ameliorates cardiac function in infarcted rat-heart without inducing polycythemia. Circ J 71, 132-137 (2007).

205. Campana, W.M., et al. Erythropoietin reduces Schwann cell TNF-alpha, Wallerian degeneration and pain-related behaviors after peripheral nerve injury. Eur J Neurosci 23, 617-626 (2006).

206. Yin, Z.S., et al. Erythropoietin promotes functional recovery and enhances nerve regeneration after peripheral nerve injury in rats. Am J Neuroradiol 31, 509-515 (2010).

207. Leal, C.T., et al. Surgical approach and clinical outcome of a deforming brown tumor at the maxilla in a patient with secondary hyperparathyroidism due to chronic renal failure. Arq Bras Endocrinol Metabol 50, 963-967 (2006).

208. Lunn, E.R., et al. Absence of Wallerian degeneration does not hinder regeneration in peripheral nerve. Eur J Neurosci 1, 27-33 (1989).

209. Perry, V.H., et al. Evidence that very slow Wallerian degeneration in C57BL/Ola mice is an intrinsic property of the peripheral nerve. Eur J Neurosci 2, 802-808 (1990).

210. Glass, J.D., et al. Prolonged survival of transected nerve fibres in C57BL/Ola mice is an intrinsic characteristic of the axon. $J$ Neurocytol 22, 311-321 (1993). 
211. Deckwerth, T.L., et al. Neurites can remain viable after destruction of the neuronal soma by programmed cell death (apoptosis). Dev Biol 165, 63-72 (1994).

212. Deckwerth, T.L., et al. Placement of the bcl2 family member BAX in the death pathway of sympathetic neurons activated by trophic factor deprivation. Exp Neurol 152, 150-162 (1998).

213. Ikegami, K., et al. Non-apoptotic neurite degeneration in apoptotic neuronal death: Pivotal role of mitochondrial function in neurites. Neuroscience 122, $617-$ $626(2003)$.

214. Adalbert, R., et al. A rat model of slow Wallerian degeneration (WldS) with improved preservation of neuromuscular synapses. Eur J Neurosci 21, 271-277 (2005).

215. Deckwerth, T.L., et al. BAX is required for neuronal death after trophic factor deprivation and during development. Neuron 17, 401-411 (1996).

216. Mosinger Ogilvie, J., et al. Suppression of developmental retinal cell death but not of photoreceptor degeneration in BAX-deficient mice. Invest Ophthalmol Vis Sci 39, 1713-1720 (1998).

217. Quigley, H.A. Experimental glaucoma damage mechanism. Arch Ophthalmol 101, 1301-1302 (1983).

218. Dreyer, E.B. A proposed role for excitotoxicity in glaucoma. J Glaucoma 7, 6267 (1998).

219. Flammer, J., et al. The impact of ocular blood flow in glaucoma. Prog Retin Eye Res 21, 359-393 (2002).

220. Mozaffarieh, M., et al. Oxygen and blood flow: Players in the pathogenesis of glaucoma. Mol Vis 14, 224-233 (2008).

221. Son, J.L., et al. Glaucomatous optic nerve injury involves early astrocyte reactivity and late oligodendrocyte loss. Glia 58, 780-789 (2010).

222. Quigley, H.A., et al. Morphologic changes in the lamina cribrosa correlated with neural loss in open-angle glaucoma. Am J Ophthalmol 95, 673-691 (1983).

223. Jakobs, T.C., et al. Retinal ganglion cell degeneration is topological but not cell type specific in DBA/2J mice. J Cell Biol 171, 313-325 (2005).

224. Minckler, D.S., et al. Orthograde and retrograde axoplasmic transport during acute ocular hypertension in the monkey. Invest Ophthalmol Vis Sci 16, 426-441 (1977). 
225. Dandona, L., et al. Selective effects of experimental glaucoma on axonal transport by retinal ganglion cells to the dorsal lateral geniculate nucleus. Invest Ophthalmol Vis Sci 32, 1593-1599 (1991).

226. Osborne, N.N., et al. Ganglion cell death in glaucoma: What do we really know? Br J Ophthalmol 83, 980-986 (1999).

227. Baltan, S., et al. Metabolic vulnerability disposes retinal ganglion cell axons to dysfunction in a model of glaucomatous degeneration. J Neurosci 30, 5644-5652 (2010).

228. Choi, D.W. Excitotoxic cell death. J Neurobiol 23, 1261-1276 (1992).

229. Vorwerk, C.K., et al. Chronic low-dose glutamate is toxic to retinal ganglion cells. Toxicity blocked by memantine. Invest Ophthalmol Vis Sci 37, 1618-1624 (1996).

230. Vorwerk, C.K., et al. An experimental basis for implicating excitotoxicity in glaucomatous optic neuropathy. Surv Ophthalmol 43 Suppl 1, S142-150 (1999).

231. Dalton, R. Private investigations. Nature 411, 129-130 (2001).

232. Osborne, N.N. Recent clinical findings with memantine should not mean that the idea of neuroprotection in glaucoma is abandoned. Acta Ophthalmol 87, 450-454 (2009).

233. Cioffi, G.A., et al. The effect of chronic ischemia on the primate optic nerve. Eur J Ophthalmol 9 Suppl 1, S34-36 (1999).

234. Katai, N., et al. Apoptotic retinal neuronal death by ischemia-reperfusion is executed by two distinct caspase family proteases. Invest Ophthalmol Vis Sci 40, 2697-2705 (1999).

235. Sadamoto, Y., et al. Erythropoietin prevents place navigation disability and cortical infarction in rats with permanent occlusion of the middle cerebral artery. Biochem Biophys Res Commun 253, 26-32 (1998).

236. Bernaudin, M., et al. A potential role for erythropoietin in focal permanent cerebral ischemia in mice. J Cereb Blood Flow Metab 19, 643-651 (1999).

237. Siren, A.L., et al. Therapeutic potential of erythropoietin and its structural or functional variants in the nervous system. Neurotherapeutics 6, 108-127 (2009).

238. Carlini, R.G., et al. Recombinant human erythropoietin stimulates angiogenesis in vitro. Kidney Int 47, 740-745 (1995).

239. Yasuda, Y., et al. Estrogen-dependent production of erythropoietin in uterus and its implication in uterine angiogenesis. J Biol Chem 273, 25381-25387 (1998). 
240. Ribatti, D., et al. Human erythropoietin induces a pro-angiogenic phenotype in cultured endothelial cells and stimulates neovascularization in vivo. Blood 93, 2627-2636 (1999).

241. Genc, S., et al. Erythropoietin restores glutathione peroxidase activity in 1methyl-4-phenyl-1,2,5,6-tetrahydropyridine-induced neurotoxicity in C57BL mice and stimulates murine astroglial glutathione peroxidase production in vitro. Neurosci Lett 321, 73-76 (2002).

242. Alge-Priglinger, C.S., et al. Oxidative stress-mediated induction of MMP-1 and MM-3 in human RPE cells. Invest Ophthalmol Vis Sci 50, 5495-5503 (2009).

243. Wunderlich, K., et al. Increased plasma levels of 20s proteasome alpha-subunit in glaucoma patients: An observational pilot study. Mol Vis 8, 431-435 (2002).

244. Johnson, E.C., et al. Friend or foe? Resolving the impact of glial responses in glaucoma. J Glaucoma 18, 341-353 (2009).

245. Bosco, A., et al. Early microglia activation in a mouse model of chronic glaucoma. J Comp Neurol 519, 599-620 (2011).

246. Nakazawa, T., et al. Tumor necrosis factor-alpha mediates oligodendrocyte death and delayed retinal ganglion cell loss in a mouse model of glaucoma. J Neurosci 26, 12633-12641 (2006).

247. Johnson, E.C., et al. Chronology of optic nerve head and retinal responses to elevated intraocular pressure. Invest Ophthalmol Vis Sci 41, $431-442$ (2000).

248. Ridet, J.L., et al. Reactive astrocytes: Cellular and molecular cues to biological function. Trends Neurosci 20, 570-577 (1997).

249. Tomimoto, H., et al. Regressive changes of astroglia in white matter lesions in cerebrovascular disease and Alzheimer's disease patients. Acta Neuropathol 94, 146-152 (1997).

250. Sofroniew, M.V. Molecular dissection of reactive astrogliosis and glial scar formation. Trends Neurosci 32, 638-647 (2009).

251. Mabuchi, F., et al. Optic nerve damage in experimental mouse ocular hypertension. Invest Ophthalmol Vis Sci 44, 4321-4330 (2003).

252. Liu, B., et al. Expression of nitric oxide synthase-2 (NOS-2) in reactive astrocytes of the human glaucomatous optic nerve head. Glia 30, 178-186 (2000).

253. Kasmala, L.T., et al. Oral administration of SC-51, a nitric oxide synthase inhibitor, does not protect optic nerve axons in a hypertensive rat model of gluacoma. Inves Opthalmol and Visual Science E-Abstract 904 (2004). 
254. Pang, I.H., et al. Evaluation of inducible nitric oxide synthase in glaucomatous optic neuropathy and pressure-induced optic nerve damage. Invest Ophthalmol Vis Sci 46, 1313-1321 (2005).

255. Libby, R.T., et al. Inducible nitric oxide synthase, NOS2, does not mediate optic neuropathy and retinopathy in the DBA/2J glaucoma model. BMC Neurosci $\mathbf{8}$, 108 (2007).

256. Agnello, D., et al. Erythropoietin exerts an anti-inflammatory effect on the CNS in a model of experimental autoimmune encephalomyelitis. Brain Res 952, 128134 (2002).

257. Savino, C., et al. Delayed administration of erythropoietin and its nonerythropoietic derivatives ameliorates chronic murine autoimmune encephalomyelitis. J Neuroimmunol 172, 27-37 (2006).

258. Nielsen, S., et al. Specialized membrane domains for water transport in glial cells: High-resolution immunogold cytochemistry of aquaporin-4 in rat brain. $J$ Neurosci 17, 171-180 (1997).

259. Manley, G.T., et al. Aquaporin-4 deletion in mice reduces brain edema after acute water intoxication and ischemic stroke. Nat Med 6, 159-163 (2000).

260. Gunnarson, E., et al. Identification of a molecular target for glutamate regulation of astrocyte water permeability. Glia 56, 587-596 (2008).

261. Dibas, A., et al. Changes in ocular aquaporin-4 (aqp4) expression following retinal injury. Mol Vis 14, 1770-1783 (2008).

262. Schuettauf, F., et al. Alterations of amino acids and glutamate transport in the DBA/2J mouse retina: Possible clues to degeneration. Graefes Arch Clin Exp Ophthalmol 245, 1157-1168 (2007).

263. Gunnarson, E., et al. Lead induces increased water permeability in astrocytes expressing aquaporin 4 . Neuroscience 136, 105-114 (2005).

264. Zelenina, M., et al. Water permeability of aquaporin-4 is decreased by protein kinase c and dopamine. Am J Physiol Renal Physiol 283, F309-318 (2002).

265. Han, Z., et al. Regulation of aquaporin-4 water channels by phorbol esterdependent protein phosphorylation. J Biol Chem 273, 6001-6004 (1998).

266. Joyeux-Faure, M., et al. Early pharmacological preconditioning by erythropoietin mediated by inducible NOS and mitochondrial ATP-dependent potassium channels in the rat heart. Fundam Clin Pharmacol 20, 51-56 (2006).

267. Miyamoto, K., et al. Upregulation of water channel aquaporin-4 in experimental autoimmune encephalomyeritis. J Neurol Sci 276, 103-107 (2009). 
268. Ma, T., et al. Generation and phenotype of a transgenic knockout mouse lacking the mercurial-insensitive water channel aquaporin-4. J Clin Invest 100, 957-962 (1997).

269. Cone, F.E., et al. Differential susceptibility to experimental glaucoma among 3 mouse strains using bead and viscoelastic injection. Exp Eye Res 91, 415-424 (2010).

270. Cervino, A. Rebound tonometry: New opportunities and limitations of noninvasive determination of intraocular pressure. Br J Ophthalmol 90, 1444-1446 (2006).

271. Ferrari, F.K., et al. Second-strand synthesis is a rate-limiting step for efficient transduction by recombinant adeno-associated virus vectors. J Virol 70, 32273234 (1996).

272. Hauck, B., et al. Intracellular viral processing, not single-stranded DNA accumulation, is crucial for recombinant adeno-associated virus transduction. $J$ Virol 78, 13678-13686 (2004).

273. Yan, Z., et al. Trans-splicing vectors expand the utility of adeno-associated virus for gene therapy. Proc Natl Acad Sci U S A 97, 6716-6721 (2000).

274. Ghosh, A., et al. Viral serotype and the transgene sequence influence overlapping adeno-associated viral (AAV) vector-mediated gene transfer in skeletal muscle. $J$ Gene Med 8, 298-305 (2006).

275. McCarty, D.M., et al. Self-complementary recombinant adeno-associated virus (SCAAV) vectors promote efficient transduction independently of DNA synthesis. Gene Ther 8, 1248-1254 (2001).

276. Gao, G.P., et al. Novel adeno-associated viruses from rhesus monkeys as vectors for human gene therapy. Proc Natl Acad Sci U S A 99, 11854-11859 (2002).

277. Muzyczka, N., et al. Custom adeno-associated virus capsids: The next generation of recombinant vectors with novel tropism. Hum Gene Ther 16, 408-416 (2005).

278. Zhong, L., et al. A dual role of egfr protein tyrosine kinase signaling in ubiquitination of AAV2 capsids and viral second-strand DNA synthesis. Mol Ther 15, 1323-1330 (2007).

279. Zhong, L., et al. Tyrosine-phosphorylation of AAV2 vectors and its consequences on viral intracellular trafficking and transgene expression. Virology 381, 194-202 (2008).

280. Zhong, L., et al. Next generation of adeno-associated virus 2 vectors: Point mutations in tyrosines lead to high-efficiency transduction at lower doses. Proc Natl Acad Sci U S A 105, 7827-7832 (2008). 
281. Qiao, C., et al. Adeno-associated virus serotype 6 capsid tyrosine-tophenylalanine mutations improve gene transfer to skeletal muscle. Hum Gene Ther 21, 1343-1348 (2010).

282. Porciatti, V., et al. The pattern electroretinogram as a tool to monitor progressive retinal ganglion cell dysfunction in the $\mathrm{DBA} / 2 \mathrm{~J}$ mouse model of glaucoma. Invest Ophthalmol Vis Sci 48, 745-751 (2007).

283. Saleh, M., et al. Longitudinal evaluation of retinal ganglion cell function and iop in the DBA/2J mouse model of glaucoma. Invest Ophthalmol Vis Sci 48, 45644572 (2007).

284. Sullivan, T., et al. Systemic gene delivery protects the photoreceptors in the retinal degeneration slow mouse. Neurochem Res 36, 613-618 (2010).

285. Mao, M., et al. Anterior segment dysgenesis and early-onset glaucoma in nee mice with mutation of sh3pxd2b. Invest Ophthalmol Vis Sci (Epub 2011).

286. Levkovitch-Verbin, H., et al. Translimbal laser photocoagulation to the trabecular meshwork as a model of glaucoma in rats. Invest Ophthalmol Vis Sci 43, 402-410 (2002).

287. Johnson, E.C., et al. The effect of chronically elevated intraocular pressure on the rat optic nerve head extracellular matrix. Exp Eye Res 62, 663-674 (1996).

288. Morrison, J.C., et al. A rat model of chronic pressure-induced optic nerve damage. Exp Eye Res 64, 85-96 (1997).

289. Shareef, S.R., et al. Chronic ocular hypertension following episcleral venous occlusion in rats. Exp Eye Res 61, 379-382 (1995).

290. Sawada, A., et al. Confirmation of the rat model of chronic, moderately elevated intraocular pressure. Exp Eye Res 69, 525-531 (1999).

291. Sappington, R.M., et al. The microbead occlusion model: A paradigm for induced ocular hypertension in rats and mice. Invest Ophthalmol Vis Sci 51, 207-216 (2010).

292. Chiu, K., et al. Retrograde labeling of retinal ganglion cells by application of fluoro-gold on the surface of superior colliculus. J Vis $\operatorname{Exp} 17,819-820$ (2008).

293. Raymond, I.D., et al. A thy1-cfp DBA/2J mouse line with cyan fluorescent protein expression in retinal ganglion cells. Vis Neurosci 26, 453-465 (2009).

294. Soto, I., et al. Retinal ganglion cells downregulate gene expression and lose their axons within the optic nerve head in a mouse glaucoma model. $J$ Neurosci $\mathbf{2 8}$, 548-561 (2008). 
295. Drager, U.C., et al. Ganglion cell distribution in the retina of the mouse. Invest Ophthalmol Vis Sci 20, 285-293 (1981).

296. May, C.A., et al. Quantification and characterization of gaba-ergic amacrine cells in the retina of gad67-gfp knock-in mice. Acta Ophthalmol 86, 395-400 (2008).

297. Genc, S., et al. Erythropoietin exerts neuroprotection in 1-methyl-4-phenyl1,2,3,6-tetrahydropyridine-treated C57/BL mice via increasing nitric oxide production. Neurosci Lett 298, 139-141 (2001).

298. Koh, S.H., et al. Recombinant human erythropoietin suppresses symptom onset and progression of g93a-sod1 mouse model of ALS by preventing motor neuron death and inflammation. Eur J Neurosci 25, 1923-1930 (2007).

299. Wong, P., et al. Molecular characterization of human trpm-2/clusterin, a gene associated with sperm maturation, apoptosis and neurodegeneration. Eur $J$ Biochem 221, 917-925 (1994).

300. McKinnon, S.J. Glaucoma: Ocular Alzheimer's disease? Front Biosci 8, s1140$1156(2003)$.

301. Katzman, R. Alzheimer's disease. N Engl J Med 314, 964-973 (1986).

302. Kang, J., et al. The precursor of Alzheimer's disease amyloid a4 protein resembles a cell-surface receptor. Nature 325, 733-736 (1987).

303. Ballatore, C., et al. Tau-mediated neurodegeneration in Alzheimer's disease and related disorders. Nat Rev Neurosci 8, 663-672 (2007).

304. Sun, Z.K., et al. Protective effects of erythropoietin on tau phosphorylation induced by beta-amyloid. J Neurosci Res 86, 3018-3027 (2008).

305. Li, G., et al. Protective effect of erythropoietin on beta-amyloid-induced pc12 cell death through antioxidant mechanisms. Neurosci Lett 442, 143-147 (2008).

306. Oddo, S., et al. Triple-transgenic model of Alzheimer's disease with plaques and tangles: Intracellular abeta and synaptic dysfunction. Neuron 39, 409-421 (2003).

307. Oddo, S., et al. Temporal profile of amyloid-beta (abeta) oligomerization in an in vivo model of Alzheimer disease: A link between abeta and tau pathology. J Biol Chem 281, 1599-1604 (2006).

308. Billings, L.M., et al. Intraneuronal abeta causes the onset of early Alzheimer's disease-related cognitive deficits in transgenic mice. Neuron 45, 675-688 (2005).

309. Kaludov, N., et al. Adeno-associated virus serotype 4 (AAV4) andAAV5 both require sialic acid binding for hemagglutination and efficient transduction but differ in sialic acid linkage specificity. J Virol 75, 6884-6893 (2001). 
310. Thomas, C.E., et al. Rapid uncoating of vector genomes is the key to efficient liver transduction with pseudotyped adeno-associated virus vectors. $J$ Virol 78, 3110-3122 (2004).

311. Sabatino, D.E., et al. Identification of mouse AAV capsid-specific cd8+t cell epitopes. Mol Ther 12, 1023-1033 (2005).

312. Akache, B., et al. The 37/67-kilodalton laminin receptor is a receptor for adenoassociated virus serotypes 8, 2, 3, and 9.J Virol 80, 9831-9836 (2006).

313. Walters, R.W., et al. Binding of adeno-associated virus type 5 to 2,3-linked sialic acid is required for gene transfer. $J$ Biol Chem 276, 20610-20616 (2001).

314. Di Pasquale, G., et al. Identification of pdgfr as a receptor for AAV-5 transduction. Nat Med 9, 1306-1312 (2003).

315. Doi, M., et al. Recombinant human laminin-10 (alpha5beta1gamma1). Production, purification, and migration-promoting activity on vascular endothelial cells. J Biol Chem 277, 12741-12748 (2002). 


\section{APPENDIX. TESTING AAV EPO PRODUCTION IN VITRO}

\section{Introduction}

Previous animal experiments performed in the Rex lab were carried out using rAAV serotype 2/5 that contained either wt Epo or the mutant Epo (R76E). Eventually the stock of the $2 / 5$ mutant (stock 1 ) was depleted and replaced with a different serotype $(2 / 8)$. Serotype $2 / 8$ has a higher level of transduction in muscle tissue than the $2 / 5$ vector [121], thus theoretically increasing the Epo and Epo-R76E expression in mice receiving IM injections.

Viral titer is a quantitative method to access a virus. This can consist of either a physical titer or an infectious titer. The physical titer of a virus determines how many viral particles or viral genomes are present. However, the physical titer does not always accurately reflect how many of the viral particles are functional and are capable of infecting the target cell. The physical titer of both rAAV serotypes $(2 / 5$ and $2 / 8)$ was determined by measuring the genome copies per $\mathrm{ml}$, however the infectious titer was unknown. The appropriate amount of viral vector for neuroprotection within the retina of mice for serotype $2 / 5$ had already been worked out $[88,87,175]$. To estimate the amount of $2 / 8$ viral vector that should be used in animal work, the vectors was first tested in cell culture. The advantage to this approach is the short experimental time line. rAAV mediated EPO production can be determined in a matter of weeks in cell cultures, as opposed to months in animals.

\section{Materials and Methods}

\section{Cell culture}

Human embryonic kidney (HEK) 293cells (ATCC, Manassas, VA) were maintained in DMEM containing 10\% fetal bovine serum and 1\% penicillin/streptomycin.

\section{Vector transduction}

HEK 293 cells were seeded at approximately $65 \%$ confluence in $35-\mathrm{mm}$ dishes. Cell number was determined by using a hemocytometer. Cells were infected at various multiplicities of infections (MOI) with each of the viral vectors in a total of $1.0 \mathrm{ml}$ of media containing. After 24 and $48 \mathrm{hrs}$ the medium was replaced with $1.5 \mathrm{ml}$ of fresh medium. $48 \mathrm{hrs}$ after the final medium change the supernatant was collected and frozen at $-20{ }^{\circ} \mathrm{C}$. 


\section{EPO enzyme-linked immuno-sorbant analysis (ELISA)}

$200 \mu \mathrm{l}$ of the cellular supernatant was probed for EPO and EPO-R76E using the human Quantikine IVD EPO ELISA Kit according to manufacturer's protocol (R\&D Systems, Minneapolis, MN). The absorbance at $450 \mathrm{~nm}$ with $600 \mathrm{~nm}$ reference was detected on a BioTek- $\mu$ Quant plate reader (Winooski, VT).

\section{Results}

Transduction with the rAAV2/8 serotype produced only a fraction of the EPO that serotype $2 / 5$ produced at similar MOIs (Table A-1). At a MOI of 100 rAAV2/8.CMV.EpoR76E was unable to produce any detectable levels of EPO-R76E. However, at the same MOI, rAAV2/5.CMV.Epo and rAAV2/5.CMV.EpoR76E produced $336 \mathrm{mU} / \mathrm{ml}$ and $23 \mathrm{mU} / \mathrm{ml}$ respectively. When increased to a MOI of 1000 , rAAV2/8.CMV.EpoR76E produces $8 \mathrm{mU} / \mathrm{ml}$ of EPO-R76E, far less than the 1100 $\mathrm{mU} / \mathrm{ml}$ and $236 \mathrm{mU} / \mathrm{ml}$ produced by rAAV2/5.CMV.Epo and rAAV2/5.CMV.Epo.R76E respectively.

\section{Conclusion}

Testing rAAV vectors in cell culture is a good method to determine their relative EPO expression in HEK 293 cells. Based on the results in Table A-1 it appeared the 2/8 vector was over 1000 fold less infectious than the $2 / 5$ vectors. However, upon further investigation of the literature it appears that these two serotypes cannot be directly compared when using HEK 293 cells. Serotype $2 / 5$ and 2/8 have different capsids which are only $67 \%$ homologous [309] and therefore it is expected that their infection both in vitro as well as in vivo could vary greatly. This variation in the viral capsid can alter infection in many ways including immune response, attachment, entry, and uncoating [310-312]. The receptor used by serotype $2 / 5$ is sialic acid [309,313] and plateletderived growth factor [314], while the receptor for serotype 2/8 appears to be laminin [312]. Expression of the laminin receptor on HEK 293 has not been detected when using western blot analysis [315] thus explaining the drastic reduction in infection observed when using the $2 / 8$ vector. These results also support the hypothesis that laminin receptor expression in 293 cells is minimal. In conclusion, because of the different receptor usage between serotype $2 / 5$ and $2 / 8$ the tissue culture experiment cannot be used to determine what the relative level of infectivity is.

Since a direct comparison of the gene expression from the $2 / 5$ and $2 / 8$ vectors could not be accessed in tissue culture it was unknown how much of the $2 / 8$ vector needed to be used for the animal work carried out in Chapter 2. The information about the different receptors for each serotype was not obtained before the animal work was carried out. Therefore based on the results in Table A-1 a large amount of vector was used for the animal experiments in Chapter 2 in order to match the gene expression of the $2 / 5$ vectors. The large amount of vector $\left(1 \times 10^{12} \mathrm{gc}\right)$ is referred to in the text of Chapter 2 
Table A-1. EPO and EPO-R76 levels in transduced HEK 293 cells.

\begin{tabular}{lcc}
\hline Vector Treatment & MOI & EPO (mU/ml) \\
\hline rAAV2/5.CMV.Epo & 50 & 124 \\
& 100 & 336 \\
& 1000 & 1100 \\
rAAV2/5.CMV.EpoR76E (stock 2) & 100 & 92 \\
& 1000 & 236 \\
rAAV2/8.CMV.EpoR76E & 50 & 0 \\
& 100 & 0 \\
& 1000 & 8 \\
& 10000 & 32 \\
\hline
\end{tabular}


as rAAV2/8.CMV.EpoR76E (high dose). Additionally, for further clarification the prep of rAAV2/5.CMV.EpoR76E vector used in Chapter 2 and Chapter 3 is from stock 1

which is now depleted. The rAAV2/5.CMV.EpoR76E vector used in Table A-1 is from stock 2. 


\section{VITA}

Timothy Sullivan was born in Galax, Virginia, in 1981. In 2000 he graduated from Central High School and attended the University of South Florida. In 2004 he received a degree of Bachelor of Science, majoring in biology and was accepted into the University of Tennessee Health Science Center Integrated Program in Biomedical Sciences the same year. Timothy defended his thesis and received a Master of Science degree in December 2008. He continued his education within the program and joined the lab of Tonia S. Rex, Ph.D. for his doctoral research. Timothy expects to graduate with a Ph.D. in biomedical sciences in May 2011. 